\title{
Calcineurin Inhibitor-Induced Endothelial Cell Injury - A Role for Complement
}

\author{
by
}

\section{Chia Wei Teoh}

A thesis submitted in conformity with the requirements

for the degree of Master of Science

Institute of Medical Science

University of Toronto

(C) Copyright by Chia Wei Teoh 2017 


\title{
Calcineurin Inhibitor-Induced Endothelial Cell Injury - A Role for Complement
}

\author{
Chia Wei Teoh \\ Master of Science \\ Institute of Medical Science \\ University of Toronto
}

2017

\section{Abstract}

Calcineurin inhibitor (CNI) use significantly reduced acute rejection rates and revolutionized early allograft and patient outcomes post-transplantation. However, known nephro- and vascular toxicity preclude its use and contribute to chronic allograft injury, negatively impacting longer term outcomes. Evolving evidence suggest a role for complement dysregulation in the pathogenesis of CNI-induced endothelial injury. In an in vitro model using Blood Outgrowth Endothelial Cells (BOEC) isolated from healthy donors and a donor with a pathogenic $\mathrm{MCP} / \mathrm{CD} 46$ variant, we showed that cyclosporine resulted in a dose and time dependent increase in complement deposition, enhanced by anti-CD59 sensitization. We showed for the first time that $\mathrm{MCP} / \mathrm{CD} 46$ deficient BOECs were genetically predisposed to be more susceptible to cyclosporine-induced complement deposition (multiple-hit hypothesis). We found complement factor $\mathrm{H}$ surface dysregulation to play a key role in cyclosporine-induced complement activation on BOEC surfaces, with glycocalyx abolishment possibly being the key mechanism leading to alternative pathway dysregulation. 


\section{Acknowledgments}

I would like to extend my sincerest appreciation and heartfelt gratitude to Dr Christoph Licht who has been my research supervisor and career, as well as personal mentor. I am indebted to you for your unrelenting support. It will be an absolute honor to be your colleague at the Hospital for Sick Children and I look forward to working with you as my colleague, research collaborator and mentor.

I wish to thank Dr Lisa Robinson who has been my research co-supervisor and career mentor. Your support and constructive feedback have helped me hone my critical thinking skills, and you are an excellent role model for my development as an academic clinician.

I would like to thank Dr Magdalena Riedl. Your scientific acumen and insight, technical assistance, imaging skills and general knowledge in the field of complement biology have been a tremendous help and guidance over the past few years. You were also there to share the ups and downs as my friend, without which my time at the laboratory would have been unbearable.

I wish to extend my gratitude to all the members of my Progress Advisory Committee, Dr. Philip Marsden, Dr James Scholey and Dr Markus Selzner for taking interest in my research work and for asking the tough, probing questions that have only strengthened this work.

Sincere thanks is also extended to all the members of my Clinical Fellowship/Research Oversight Committee at the Hospital for Sick Children, Dr Norman Rosenblum, Dr Rulan Parekh, Dr Mathieu Lemaire, Dr Damien Noone and Dr Binita Kamath for all their invaluable advice, mentorship and career guidance.

To all the members and students of the Licht Laboratory - Dr Valentina Bruno and Jun Li for your help and technical support along the way; and to Dr Wouter Feitz for your support - thank you and good luck in your future careers.

To all the members and students of the Robinson Laboratory - special thanks to Dr Vikrant Bhosle for your insight, technical assistance and general knowledge in cell biology. 
Many people within the Cell Biology department have been extremely helpful and generous with their time, particularly Dr. Jing Wu and Lisa Richardson. Thank you for your technical assistance and support.

I owe my deepest gratitude to my parents and family. Thank you for your unconditional love, unrelenting support and encouragement, and endless sacrifice - without which my journey through my life with a medical career, two fellowships and a Master of Science degree would have been meaningless.

I dedicate this thesis to my patients - for they are the inspiration and motivation behind my work.

I would like to extend a special gratitude to the pharmacy at The Hospital for Sick Children for providing cyclosporine (Sandimmune ${ }^{\circledR} \mathrm{IV}$, Novartis, $50 \mathrm{mg} / \mathrm{ml}$ ) that was used throughout this research study.

I would like to acknowledge the following funding sources: Restracomp and The Transplant \& Regenerative Medicine Centre at The Hospital for Sick Children. 


\section{Contributions}

Chia Wei Teoh (author) solely prepared this thesis. All aspects of this body of work, including the planning, execution, analysis, and writing of all original research and publications was performed in whole or in part by the author.

The following contributions by other individuals are formally and inclusively acknowledged:

Dr. Christoph Licht (Primary Supervisor and Progress Advisory Committee Member) mentorship; laboratory resources; guidance and assistance in planning, execution, and analysis of experiments as well as thesis preparation

Dr. Lisa Robinson (Co-Supervisor and Progress Advisory Committee Member) - mentorship; laboratory resources; guidance and assistance in planning, execution, and analysis of experiments as well as thesis preparation

Dr. Magdalena Riedl - guidance and assistance in planning, execution, and analysis of experiments

Dr. Valentina Bruno - assistance in execution and analysis of Western blots for CFH cofactor assays

Jun $\mathrm{Li}$ - assistance in execution of Western blots of cell lysates for complement regulators 


\section{Table of Contents}

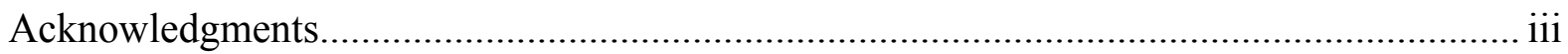

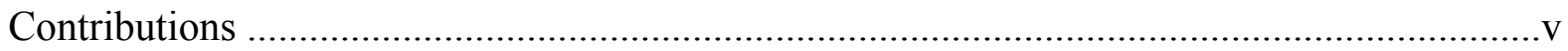

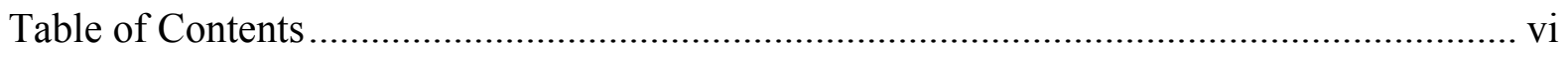

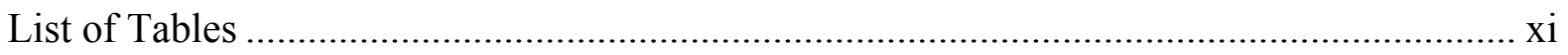

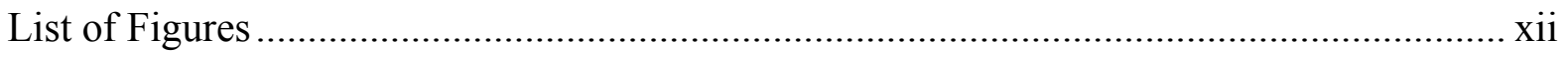

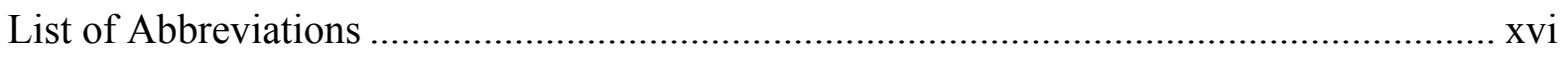

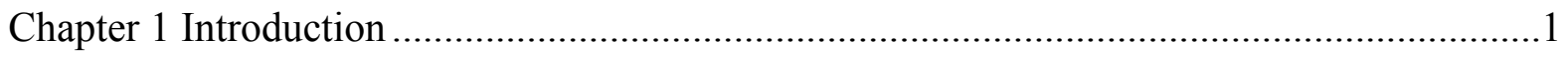

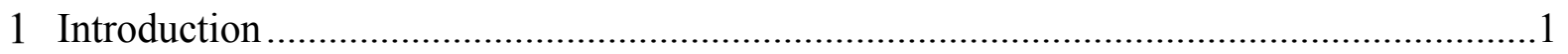

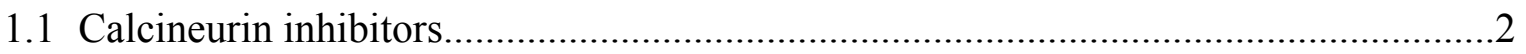

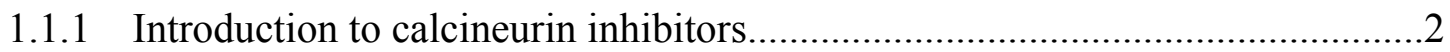

1.1.2 Mechanism of action of calcineurin inhibitors - inhibition of a family of transcription factors, the nuclear factor of activated T cells (NFAT) ................. 3

1.1.3 Calcineurin inhibitors revolutionized transplantation medicine .........................5

1.1.4 Chronic allograft injury - a major challenge in transplantation ........................

1.1.5 Calcineurin inhibitor toxicity impacts on long-term allograft survival ...........11

1.1.6 Calcineurin inhibitors lead to endothelial cell injury .......................................16

1.1.7 Calcineurin inhibitor use associated with thrombotic microangiopathy..........21

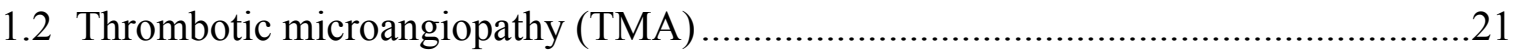

1.2.1 Introduction to thrombotic microangiopathy ……………..............................21

1.2.2 Thrombotic microangiopathy - a spectrum of complement-mediated

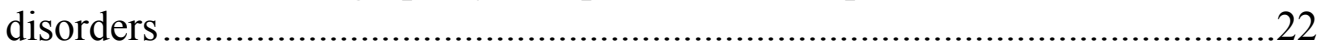

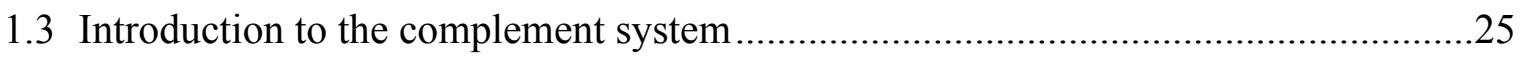

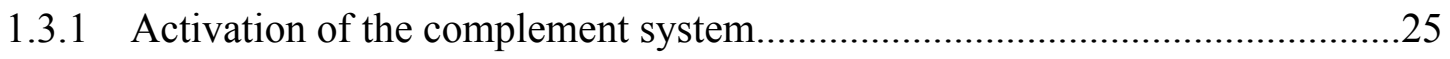

1.3.2 Regulation of the alternative pathway of the complement system ...................28

1.3.3 Functional dynamics of complement factor $\mathrm{H}$ binding and regulation.............30

1.3.4 Complement dysregulation is central to thrombotic microangiopathies ..........33 
1.3.5 Genetic susceptibility predispose to manifestation with thrombotic microangiopathy

1.3.6 Implications for a role for complement in calcineurin inhibitor toxicity..........37

1.4 Blood outgrowth endothelial cells (BOEC) ………….................................................

1.4.1 Introduction to blood outgrowth endothelial cells ............................................38

1.4.2 The utility of blood outgrowth endothelial cells to study endothelial disease.40

1.4.3 Blood outgrowth endothelial cells - a relevant model to study thrombotic

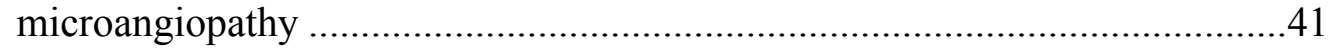

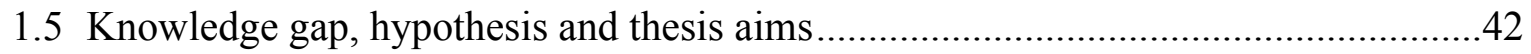

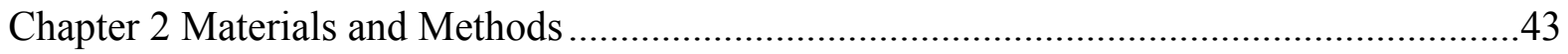

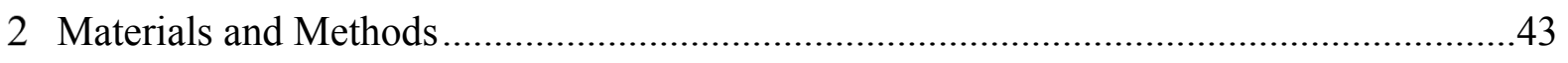

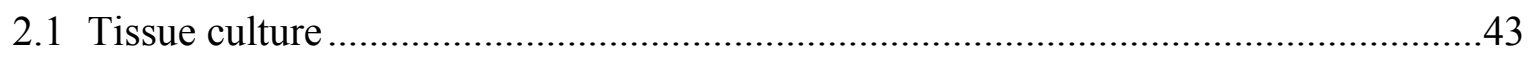

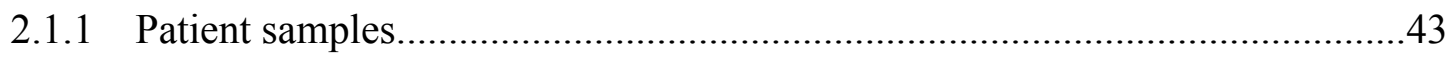

2.1.2 Blood Outgrowth Endothelial Cells ..................................................................43

2.1.3 Characterizing blood outgrowth endothelial cells by flow cytometry ..............44

2.1.4 Characterizing blood outgrowth endothelial cells by immunofluorescence....44

2.1.5 Preparation of lysates of Blood Outgrowth Endothelial Cells..........................45

2.2 Cyclosporine (CsA) treatment and complement fixation on BOEC surfaces...............46

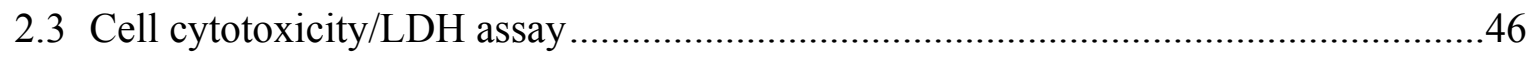

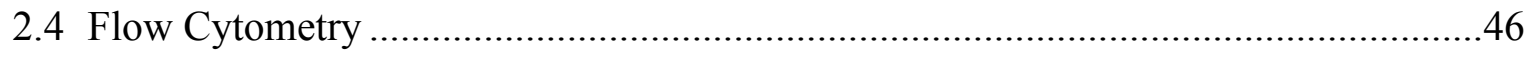

2.4.1 Antibodies used for flow cytometry ……………………….......................46

2.4.2 Flow cytometry for $\mathrm{C} 3$ deposition ................................................................4

2.4.3 Flow cytometry for C9 deposition ..............................................................48

2.4.4 Flow cytometry for membrane-bound complement regulators (MCP/CD46,

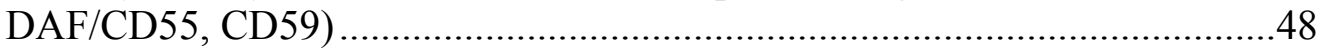

2.4.5 Flow cytometry for complement factor $\mathrm{H}$ surface binding...............................49

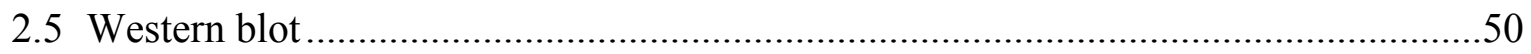


2.5.1 Antibodies used for Western blot

2.5.2 Western blot for membrane-bound complement regulators ( $\mathrm{MCP} / \mathrm{CD} 46$,

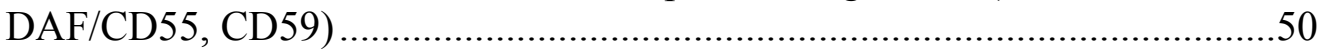

2.6 Complement factor $\mathrm{H}(\mathrm{CFH})$ cofactor assay .................................................51

2.6.1 Reagents and antibodies used for CFH cofactor assay ...............................51

2.6.2 Complement factor $\mathrm{H}$ surface cofactor activity assay .................................51

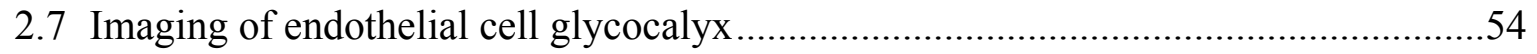

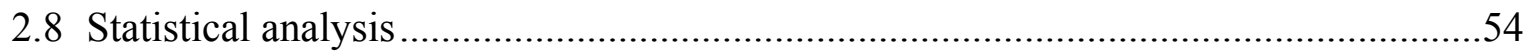

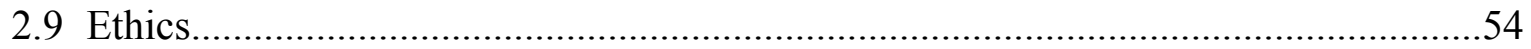

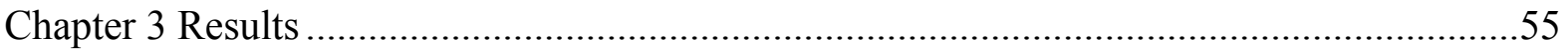

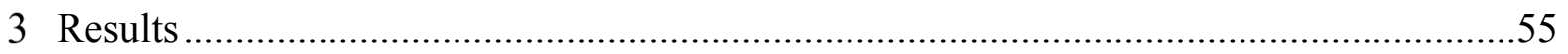

3.1 Cyclosporine treatment led to dose and time dependent endothelial cell cytotoxicity 55

3.2 Cyclosporine treatment led to increased complement deposition on endothelial cell.56

3.2.1 Cyclosporine treatment led to an increase in C3 deposition on endothelial cell

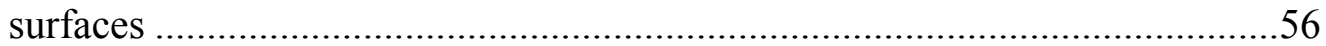

3.2.2 Serum deprivation enhanced cyclosporine-induced C3 deposition on endothelial cell surfaces.....

3.2.3 Antibody sensitization with anti-CD59 enhanced cyclosporine-induced C3 deposition on endothelial cell surfaces

3.3 Cyclosporine treatment led to increased expression of surface membrane-bound complement regulators

3.3.1 Cyclosporine treatment led to an increased expression of $\mathrm{MCP} / \mathrm{CD} 46$, DAF/CD55 and CD59 on endothelial cell surfaces

3.4 Cyclosporine treatment led to impaired complement factor $\mathrm{H}$ regulation on surfaces of endothelial cells

3.4.1 Cyclosporine treatment led to a reduction in complement factor $\mathrm{H}$ binding on surfaces of endothelial cells .

3.4.2 Cyclosporine treatment led to impaired complement factor $\mathrm{H}$ surface cofactor activity. .67

3.5 Cyclosporine treatment led to diminished endothelial cell glycocalyx .71 
3.5.1 Cyclosporine treatment led to diminished endothelial cell glycocalyx .71

3.6 Membrane cofactor protein (MCP/CD46) deficiency increased the susceptibility to cyclosporine-induced complement activation on endothelial cell surfaces .73

3.6.1 MCP BOEC possess endothelial cell characteristics and are deficient in $\mathrm{MCP} / \mathrm{CD} 46$

3.6.2 MCP-deficient BOEC were more susceptible to cyclosporine-induced complement deposition on endothelial cell surfaces .75

Chapter 4 Unifying Discussion, Conclusions and Future Directions ......................................76

4 Unifying Discussion, Conclusions and Future Directions .................................................76

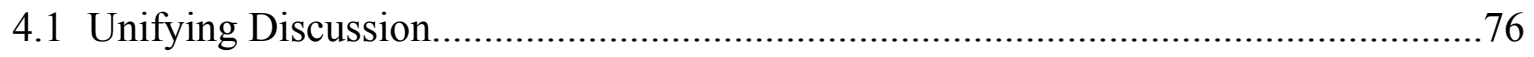

4.1.1 Relevant in vitro model to study calcineurin inhibitor-induced complement activation on endothelial cells.....................................................................78

4.1.2 Cyclosporine treatment impaired the regulation of the alternative pathway of

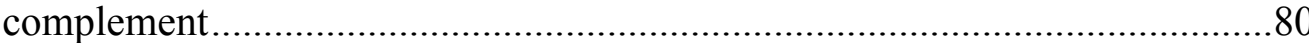

4.1.3 Cyclosporine-induced abolishment of the endothelial cell glycocalyx $-\mathrm{a}$ mechanism for impaired surface $\mathrm{CFH}$ regulation.

4.1.4 MCP/CD46 deficiency increased susceptibility to cyclosporine-induced complement activation

4.2 Conclusion

4.3 Future Directions

4.3.1 Introduction.

4.3.2 Does cyclosporine-induced complement-mediated endothelial cell injury lead to endothelial cell dysfunction? .90

4.3.3 Does Tacrolimus induce a similar complement dysregulation and complement-mediated endothelial cell injury and dysfunction?

4.3.4 Is cyclosporine-induced endothelial cell glycocalyx injury mediated by angiopoietin-2?

4.3.5 Do calcineurin inhibitors induce endothelial glycocalyx injury in vivo?

4.3.6 Are MCP/CD46 deficient BOECs derived from a patient with $\mathrm{MCP} / \mathrm{CD} 46$ mutation capable of mounting a dynamic response to cyclosporine-induced complement activation? 
4.3.7 Does the $\mathrm{MCP} / \mathrm{CD} 46$ mutation render a worst response to complementmediated injury induced by cyclosporine?

4.3.8 Will BOEC isolated from patients with CNI toxicity further our understanding of CNI-induced complement-mediated endothelial cell toxicity?

4.3.9 Establishing a role for biomarkers of endothelial glycocalyx injury for early detection of CNI-induced endothelial injury ...................................................96

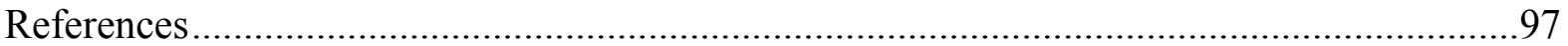




\section{List of Tables}

Table 1.1: Immunological and non-immunological causes of chronic allograft injury.............. 11

Table 1.2: The NFAT family of transcription factors are not $\mathrm{T}$ cell specific ........................... 19

Table 1.3: Classification of thrombotic microangiopathies .................................................... 24 


\section{List of Figures}

Figure 1.1: The role of calcineurin and mechanism of calcineurin inhibitor action in $\mathrm{T}$ cell activation. 5

Figure 1.2: Cyclosporine-treated patients had improved 1-year graft survival 6

Figure 1.3: 5-year survival probabilities: incident patients, adjusted for age, gender, race, ethnicity, and primary disease. Renal transplantation provides patient survival advantage when compared to end-stage renal disease and dialysis patients 7

Figure 1.4: 10-year survival probabilities: incident patients, adjusted for age, gender, race, ethnicity, and primary disease. Renal transplantation provides patient survival advantage when compared to end-stage renal disease and dialysis patients 7

Figure 1.5: All-cause graft loss yearly attrition rates in the USA, by year of transplant................ 8

Figure 1.6: Number of patients wait-listed for kidney transplant (1997-2014) and median waiting times (1997-2009)

Figure 1.7: Annual mortality rates for dialysis patients on the kidney transplant waiting list by time on the list (1997-2014). Longer waitlist time is associated with higher mortality among dialysis patients

Figure 1.8: Causes of chronic allograft injury 10

Figure 1.9: Calcineurin inhibitor use is associated with nephrotoxicity. CNI use can lead to acute and chronic tubulo-interstitial and vascular injury 13

Figure 1.10: Calcineurin inhibitor use is associated with nephrotoxicity. CNI use is associated with thrombotic microangiopathy and glomerular injury..... 14

Figure 1.11: Renal allograft function (eGFR) from the BENEFIT trial over a follow-up period of 7 years. Calcineurin inhibitor avoidance protocol is associated with improved eGFR over the course of 7 years of follow-up 
Figure 1.12: The role of calcineurin and mechanism of calcineurin inhibitor action in endothelial cells 20

Figure 1.13: The spectrum of thrombotic microangiopathies with a central pathogenic role for complement-mediated endothelial cell injury 23

Figure 1.14: Overview of the complement system and its activation 27

Figure 1.15: The regulation of complement on cell surfaces 29

Figure 1.16: Molecular structure of complement factor $\mathrm{H}(\mathrm{CFH})$ 31

Figure 1.17: Complement factor $\mathrm{H}(\mathrm{CFH})$ as cofactor for complement factor I (CFI)-catalyzed cleavage of $\mathrm{C} 3 \mathrm{~b}$ on endothelial cell surfaces

Figure 1.18: Multiple hit hypothesis for TMA pathogenesis. TMA disease manifestation is the consequence of the combination of genetic predisposition and triggering factors/conditions..... 36

Figure 1.19: Blood outgrowth endothelial cells, origins and culture 39

Figure 2.1: Complement factor $\mathrm{H}(\mathrm{CFH})$ cofactor assay on endothelial cell surfaces 52

Figure 2.2: Diagram representing cleavage of $\mathrm{C} 3 \mathrm{~b}$ to $\mathrm{iC} 3 \mathrm{~b}$ (inactive form) by CFI-catalyzed cleavage in the presence of $\mathrm{CFH}$ and $\mathrm{MCP}$ 53

Figure 2.3: Representative Western blot image of CFH cofactor assay. 53

Figure 3.1: Cyclosporine treatment led to dose and time dependent endothelial cell cytotoxicity. EC cytotoxicity detected using LDH assay

Figure 3.2: CsA led to an increase in complement deposition on EC surfaces 56

Figure 3.3: Serum deprivation enhanced CsA-induced complement deposition on EC surfaces. 57

Figure 3.4: Anti-CD59 antibody sensitization enhanced CsA-induced complement deposition on EC surfaces 58 
Figure 3.5: Anti-CD59 antibody sensitization enhanced CsA-induced terminal complement deposition on EC surfaces.

Figure 3.6: CsA led to increased expression of membrane-bound complement regulators $\mathrm{MCP} / \mathrm{CD} 46, \mathrm{DAF} / \mathrm{CD} 55$ and CD59 on endothelial cell surfaces. EC surface membrane-bound complement regulators $\mathrm{MCP} / \mathrm{CD} 46, \mathrm{DAF} / \mathrm{CD} 55$ and CD59 by flow cytometry 62

Figure 3.7: CsA led to increased expression of membrane-bound complement regulators $\mathrm{MCP} / \mathrm{CD} 46, \mathrm{DAF} / \mathrm{CD} 55$ and CD59 on endothelial cells. Membrane-bound complement regulators $\mathrm{MCP} / \mathrm{CD} 46, \mathrm{DAF} / \mathrm{CD} 55$ and CD59 in cell lysates by Western blot. 64

Figure 3.8: CsA led to decreased CFH binding on EC surface by flow cytometry 66

Figure 3.9: CsA led to impaired CFH surface cofactor activity 69

Figure 3.10: CsA led to impaired CFH surface cofactor activity.Graphical presentation of CFH surface cofactor activity assay experiments. 70

Figure 3.11: CsA led to diminished endothelial cell glycocalyx 72

Figure 3.12: CsA led to diminished endothelial cell glycocalyx. Graphical presentation of live cell imaging of endothelial cell glycocalyx with Alexa Fluor 594-conjugated wheat germ agglutinin (WGA)

Figure 3.13: MCP BOECs demonstrate endothelial cell phenotype and have decreased surface expression of membrane-bound $\mathrm{MCP} / \mathrm{CD} 46$.

Figure 3.14: MCP BOECs are deficient in membrane-bound MCP/CD46

Figure 3.15: MCP-deficient BOECs were more susceptible to CsA-induced complement deposition on endothelial cell surfaces 75

Figure 4.1: Complement regulation on endothelial cells in health 83

Figure 4.2: Proposed model of surface complement dysregulation due to cyclosporine 84

Figure 4.3: Multiple hit hypothesis for CNI-induced complement activation. 86 
Figure 4.4: Cyclosporine-induced complement-mediated cell cytotoxicity

Figure 4.5: Cyclosporine impaired scratch wound healing ..................................................... 92

Figure 4.6: Cyclosporine impaired scratch wound healing. Summary of scratch wound-healing assay 


\section{List of Abbreviations}

\begin{tabular}{|c|c|}
\hline ADAMTS13 & A Disintegrin and Metalloprotease with Thrombospondin-1 Motifs Type 13 \\
\hline aHUS & Atypical Hemolytic Uremic Syndrome \\
\hline AP & Alternative Pathway \\
\hline BOEC & Blood Outgrowth Endothelial Cell \\
\hline cEGM-2 & Endothelial Cell Growth Medium-2 \\
\hline $\mathrm{CFH}$ & Complement Factor H \\
\hline CFI & Complement Factor I \\
\hline CMV & Cytomegalovirus \\
\hline $\mathrm{CnA}$ & Calcineurin Subunit A \\
\hline $\mathrm{CnB}$ & Calcineurin Subunit B \\
\hline $\mathrm{CNI}$ & Calcineurin Inhibitor \\
\hline $\mathrm{CP}$ & Classical Pathway \\
\hline CsA & Cyclosporine \\
\hline DAF & Decay Accelerating Factor/CD55 \\
\hline DSA & Donor Specific Antibody \\
\hline EBM-2 & Endothelial Basal Medium-2 \\
\hline EBV & Ebstein-Barr Virus \\
\hline $\mathrm{EC}$ & Endothelial Cell \\
\hline FBS & Fetal Bovine Serum \\
\hline FITC & Fluorescein isothiocyanate \\
\hline FSGS & Focal Segmental Glomerulosclerosis \\
\hline GAG & Glycosaminoglycans \\
\hline GAPDH & Glyceraldehyde 3-phosphate dehydrogenase \\
\hline HBSS & Hank's Balanced Salt Solution \\
\hline
\end{tabular}




$\begin{array}{ll}\text { HIS } & \text { Heat-inactivated Serum } \\ \text { HUS } & \text { Hemolytic Uremic Syndrome } \\ \text { HUVEC } & \text { Human Umbilical Vein Endothelial Cell } \\ \text { IFTA } & \text { Interstitial Fibrosis and Tubular Atrophy } \\ \text { MAC } & \text { Membrane Attack Complex (C5b-9) } \\ \text { MCP } & \text { Membrane Cofactor Protein/CD46 } \\ \text { MFI } & \text { Median Fluorescence Intensity } \\ \text { NA } & \text { Neuraminidase } \\ \text { NFAT } & \text { Nuclear Factor of Activated T Cells } \\ \text { NFATc } & \text { Nuclear Factor of Activated T Cells (cytoplasm) } \\ \text { NFATn } & \text { Nuclear Factor of Activated T Cells (nucleus) } \\ \text { NHS } & \text { Normal Human Serum } \\ \text { PBS } & \text { Phosphate Buffered Saline } \\ \text { PECAM-1 } & \text { Platelet Endothelial Cell Adhesion Molecule 1 } \\ \text { SCR } & \text { Short Concensus Repeat } \\ \text { SFM } & \text { Serum Free Medium } \\ \text { THBD } & \text { Thrombomodulin } \\ \text { TMA } & \text { Thrombotic Microangiopathy } \\ \text { VE-cadherin } & \text { Vascular Endothelial Cadherin } \\ \text { VEGF } & \text { Vascular Endothelial Growth Factor } \\ \text { vWF } & \text { von Willebrand Factor } \\ \text { NF } & \end{array}$




\section{Chapter 1 \\ Introduction}

\section{Introduction}

This introductory chapter aims to discuss the use of calcineurin inhibitors (CNI) as an immunosuppressive agent in solid organ transplantation and describe its contribution to the improvement of early outcomes for transplant allografts and patients. It will also discuss how adverse effects of CNIs may have a significant negative impact on the longer-term outcomes for transplant allografts and patients - no significant improvements have been achieved at prolonging transplant allograft half-life over the last 3 decades since the introduction of CNIs into clinical practice. CNI use is associated with significant nephrotoxicity. This chapter will highlight the different mechanisms by which CNI use can lead to nephrotoxicity, by affecting the tubulointerstitium and vasculature, as well as its association with the development of thrombotic microangiopathy (TMA) post-transplantation.

It will then discuss the clinico-pathological entity of thrombotic microangiopathy (TMA). As injury to the microvascular endothelium, as well as its interplay with the complement system is crucial in the pathogenesis of TMAs, this chapter will introduce the complement system, its regulation and describe how complement dysregulation contributes to endothelial cell injury and TMA pathogenesis. CNI use is associated with the development of TMA post-transplantation. Evolving evidence suggests a possible link between CNI use and complement activation in propagating endothelial cell injury. Renner et.al. recently showed in vivo and in vitro evidence for CNI-inhibitor-induced endothelial cell release of alternative pathway-activating microparticles that lead to bystander endothelial cell injury, and complement-mediated kidney and vascular injury in mice.(Renner et al., 2013) However, the exact mechanism of how CNIs induce complement activation which leads to endothelial cell injury remains unknown.

At the core of this thesis is our attempt to better understand the mechanisms by which CNIs can induce complement activation, leading to endothelial cell injury. We will present findings from our work with establishing an in vitro model to study the effect of cyclosporine (CsA) exposure on complement deposition on surface of endothelial cells (blood outgrowth endothelial cells, 
BOEC, derived from healthy controls). Using that model, we studied the effect of CsA exposure on the surface-bound complement regulators membrane cofactor protein (MCP/CD46), decay accelerating factor (DAF/CD55), and protectin (CD59). This thesis will present findings from our work that suggest CsA exposure led to impaired surface binding and surface cofactor activity of complement factor $\mathrm{H}(\mathrm{CFH})$, a potent fluid-phase regulator of the alternative pathway (AP). Our findings implicate the abolishment of endothelial cell glycocalyx sialic acid by CsA as a possible pathomechanism to impaired $\mathrm{CFH}$ surface regulation of the AP. This thesis will also, for the first time, highlight findings from our work on MCP-deficient BOECs derived from patients with atypical hemolytic uremic syndrome. MCP-deficient BOECs have an increased susceptibility to complement deposition post-exposure to CsA, highlighting a 'two-hit' predisposition to CsA-induced complement-mediated endothelial cell injury.

\subsection{Calcineurin inhibitors}

\subsubsection{Introduction to calcineurin inhibitors}

Calcineurin inhibitors (CNI) such as cyclosporine (CsA) and tacrolimus are widely used immunosuppressive agents. They are most commonly used in transplantation medicine (solid organ and hematopoietic stem cell transplants) to prevent allograft rejection,(Ahsan et al., 2001; Calne, 1987; Calne et al., 1979; Canadian Multicentre Transplant Study Group, 1986; Starzl et al., 1981; Starzl et al., 1980) but are also used in the treatment of a variety of autoimmune disorders (i.e rheumatoid arthritis, psoriasis, uveitis, Behcet's disease, chronic autoimmune urticaria, atopic dermatitis) and glomerulonephritides (i.e. Steroid-dependent and steroid resistant nephrotic syndrome, lupus nephritis).(Cattran et al., 2001; Chiou et al., 2017; Ellis et al., 1991; Fathman and Myers, 1992; Hanifin et al., 2001; Masuda et al., 1989; Praga et al., 2007; Song et al., 2017; Tugwell et al., 1990; Yocum et al., 1988) Cyclosporine is a metabolite first derived from Tolypocladium inflatum, an ascomycete fungus in the mid-1970s, that had immunosuppressive and cytostatic effects on T lymphocytes.(Azzi et al., 2013; Borel et al., 1976) Tacrolimus (initially codenamed FK-506) was discovered a decade later, isolated from an actinobacteria, Streptomycin tsukubaensis.(Golo et al., 1987; Kino et al., 1987; Sawada et al., 1987) 


\subsubsection{Mechanism of action of calcineurin inhibitors - inhibition of a family of transcription factors, the nuclear factor of activated T cells (NFAT)}

As the name suggests, calcineurin inhibitors bind to and inhibit the action of calcineurin, through binding with intracellular immunophillins (cyclophilin for cyclosporine and FK-binding protein for tacrolimus). Calcineurin consists of a catalytic subunit A ( $\mathrm{CnA}$ ) with phosphatase activity and a regulatory subunit $\mathrm{B}(\mathrm{CnB})$ that regulates $\mathrm{CnA}$ activation in response to intracellular calcium.(Bram et al., 1993; Hurwitz et al., 1988; Klee et al., 1988; Wallemacq and Reding, 1993) In T lymphocytes, stimulation of the T cell receptor by a signal leads to an increase in intracellular calcium concentration that activates $\mathrm{CnB}$, in turn leading to activation of the phosphatase activity of $\mathrm{CnA}$. Once activated, $\mathrm{CnA}$ dephosphorylates cytoplasmic nuclear factor of activated T cells (NFATc), allowing its translocation into the nucleus (NFATn). In the nucleus, NFATn (a transcription factor) leads to upregulation of gene expression of various inflammatory cytokines and costimulatory molecules that lead to full activation of T cells.

The NFAT family of transcription factors consist of 5 different isoforms that are not specific to $\mathrm{T}$ cells: NFAT1, NFAT2, NFAT3, NFAT4 and NFAT5. Among them, NFAT1, NFAT2 and NFAT4 are known to be involved in transcriptional activation of genes encoding cytokines including IL-2, IL-4, and CD40 ligand which stimulates $\mathrm{T}$ cell growth and differentiation.(Rao et al., 1997; Shibasaki et al., 1996) This pathway is inhibited when the CNI-immunophillincalcineurin complex binds to $\mathrm{CnA}$, inhibiting its phosphatase activity, thus suppressing $\mathrm{T}$ cell activation (Figure 1.1). 

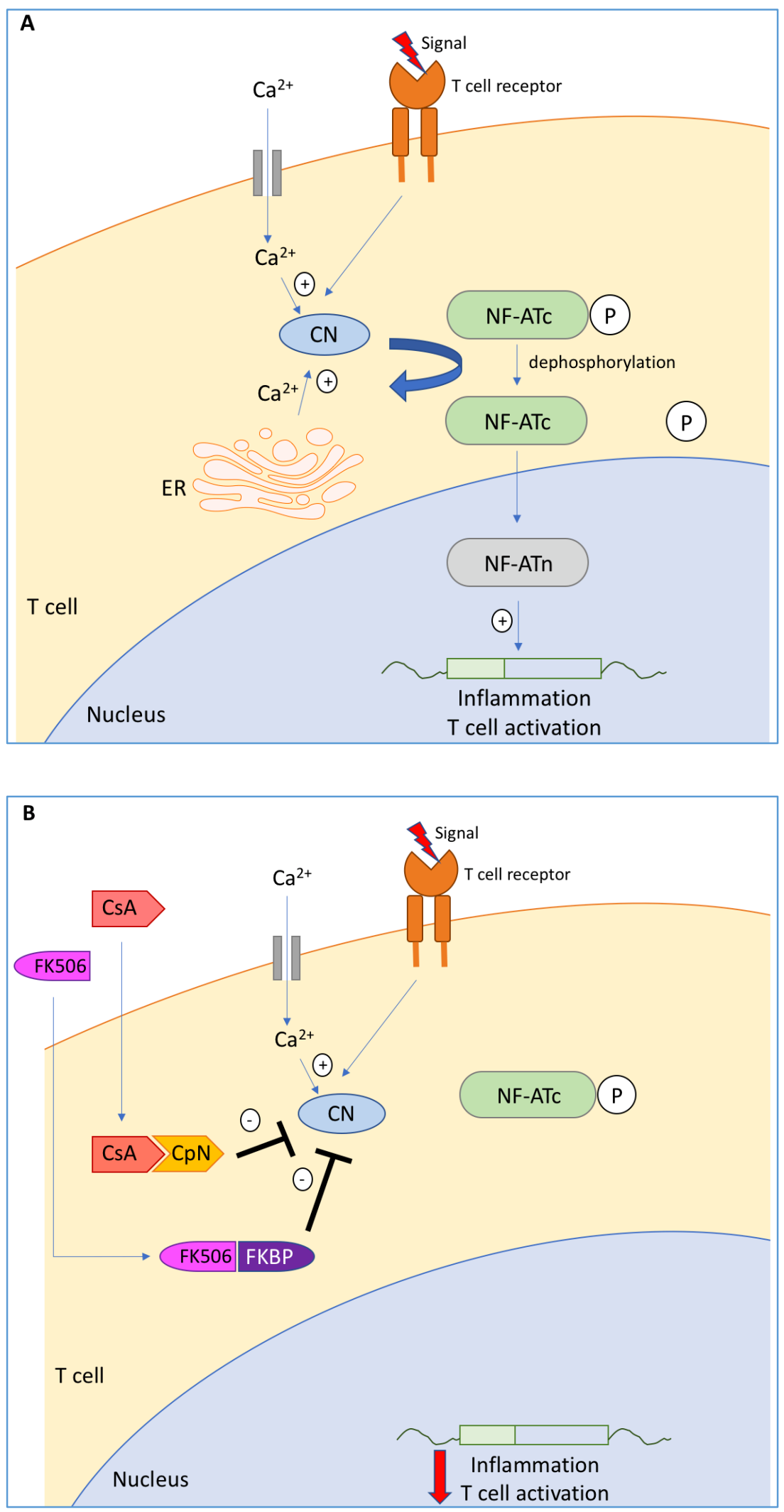
Figure 1.1: The role of calcineurin and mechanism of calcineurin inhibitor action in $T$ cell activation. A) $\mathrm{T}$ cell receptor (TCR) recognition of a signal (antigen) leads to an increase in intracellular calcium, which in turn activates calcineurin $(\mathrm{CN})$ via its calcineurin $\mathrm{B}$ subunit $(\mathrm{CnB}) . \mathrm{CnB}$ activates the phosphatase activity of the calcineurin $\mathrm{A}$ subunit $(\mathrm{CnA})$ which dephosphorylates cytoplasmic nuclear factor of activated T cells (NFATc), allowing it to translocate into the nucleus (NFATn). As a transcription factor, it acts to upregulate the expression of multiple genes involved in full activation of $\mathrm{T}$ cells (cytokines, co-stimulatory molecules) which in turn enhances the inflammatory process. B) Calcineurin inhibitors (cyclosporine - CsA, tacrolimus - FK506), bound to their respective intracellular immunophillins (cyclophilin, $\mathrm{CpN}$ for $\mathrm{CsA}$ and FK-binding protein, FKBP for FK506), binds directly to CnA to inhibit its phosphatase activity.

\subsubsection{Calcineurin inhibitors revolutionized transplantation medicine}

The introduction of cyclosporine in human kidney transplantation in the early 1980s represented a paradigm shift for immunosuppression in transplantation, significantly reducing the incidence of acute rejection.(Kolata, 1983; Starzl et al., 1981; Starzl et al., 1980) Early clinical reports in a small number of patients suggested lower rejection rates and prolonged graft survival.(Calne et al., 1979; Calne et al., 1978) When compared to azathioprine-based immunosuppression regimens (the standard immunosuppression at the time), studies with cyclosporine demonstrated superior outcomes in terms of graft and patient survival with significant decrease in acute rejection rates (Figure 1.2).(Calne, 1987; Canadian Multicentre Transplant Study Group, 1983, 1986; 1982, 1983; Starzl et al., 1981; Starzl et al., 1980; Sutherland et al., 1984) 


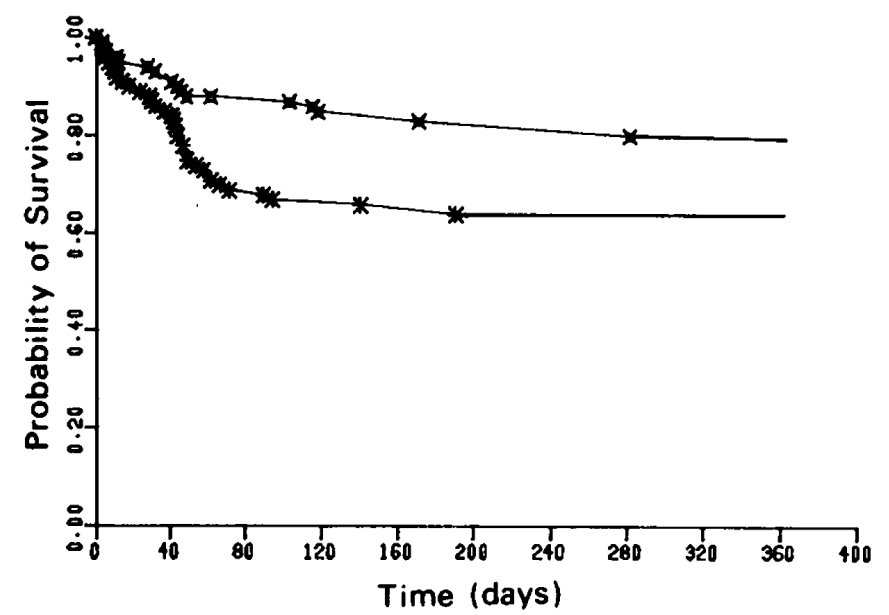

Figure 1.2: Cyclosporine-treated patients had improved 1-year graft survival. Product-limit estimates for graft survival in cyclosporine-treated patients (upper curve) and patients given standard therapy (lower curve). Reprinted with permission from (Canadian Multicentre Transplant Study Group, 1983), Copyright Massachusetts Medical Society.

Since cyclosporine use as transplant immunosuppression was approved by the US Food and Drug Administration (FDA) in 1983, calcineurin inhibitor-based immunosuppression regimens have become the mainstay of transplantation medicine. In 2015, 96.3\% of kidney transplant recipients were discharged after transplantation with a CNI-based immunosuppressive regimen.(Hart et al., 2017) A recent randomised trial assessing the possibility of weaning off tacrolimus in low risk patients (those without de novo donor specific antibodies (DSA), acute rejection or inflammation at protocol biopsy) 6 months post-kidney transplant, highlighted the importance of CNIs: the trial that was prematurely terminated due to the high rate of development of de novo donor specific antibodies (DSA) and acute rejection after CNI withdrawal.(Hricik et al., 2015) Organ transplantation is now the treatment of choice for patients with end-stage organ failure. It offers superior outcomes in patient survival, patient morbidity, and improvement in quality of life (Figures 1.3 and 1.4).(Horslen et al., 2007; Wolfe et al., 1999) 


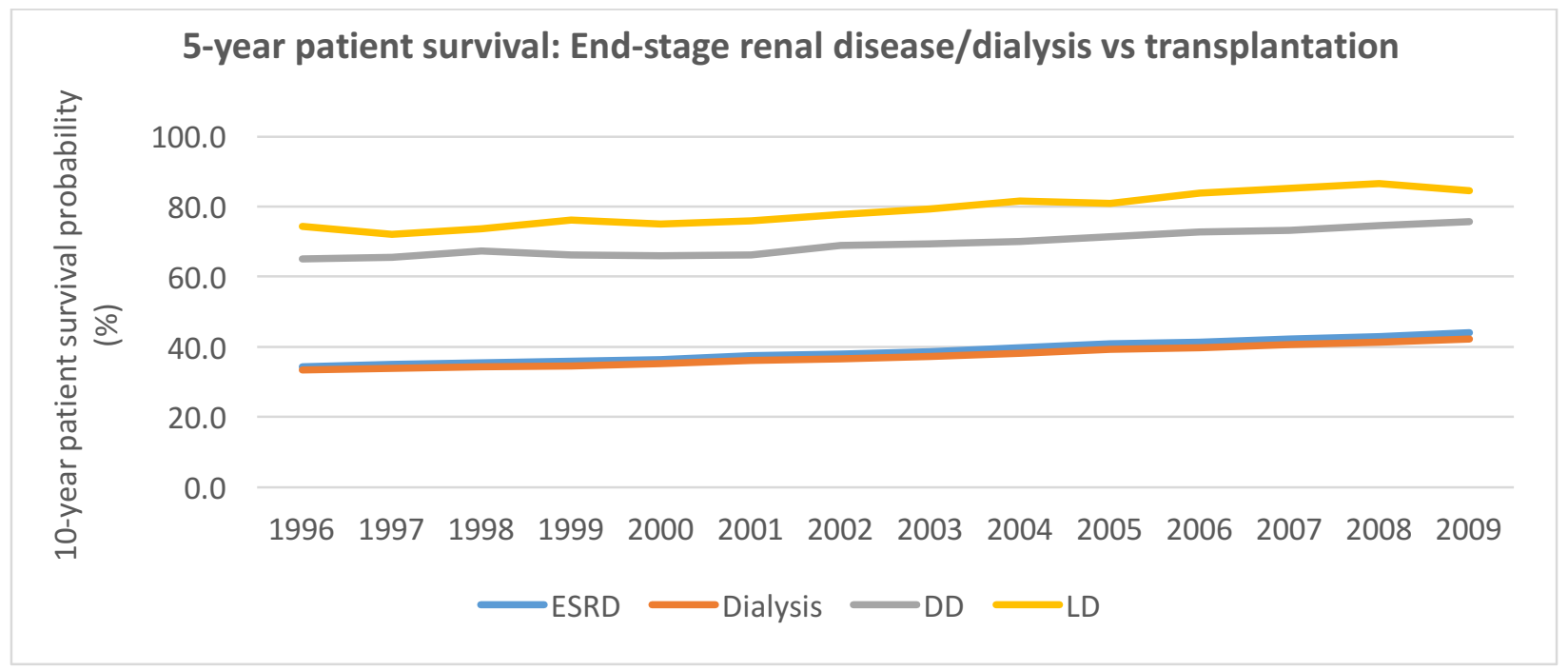

Figure 1.3: 5-year survival probabilities: incident patients, adjusted for age, gender, race, ethnicity, and primary disease. Renal transplantation provides patient survival advantage when compared to end-stage renal disease and dialysis patients. ESRD - end-stage renal disease, DD deceased donor transplant, LD - living donor transplant. Chart derived from data 2016 USRDS Annual Data Report (https://www.usrds.org/reference.aspx)

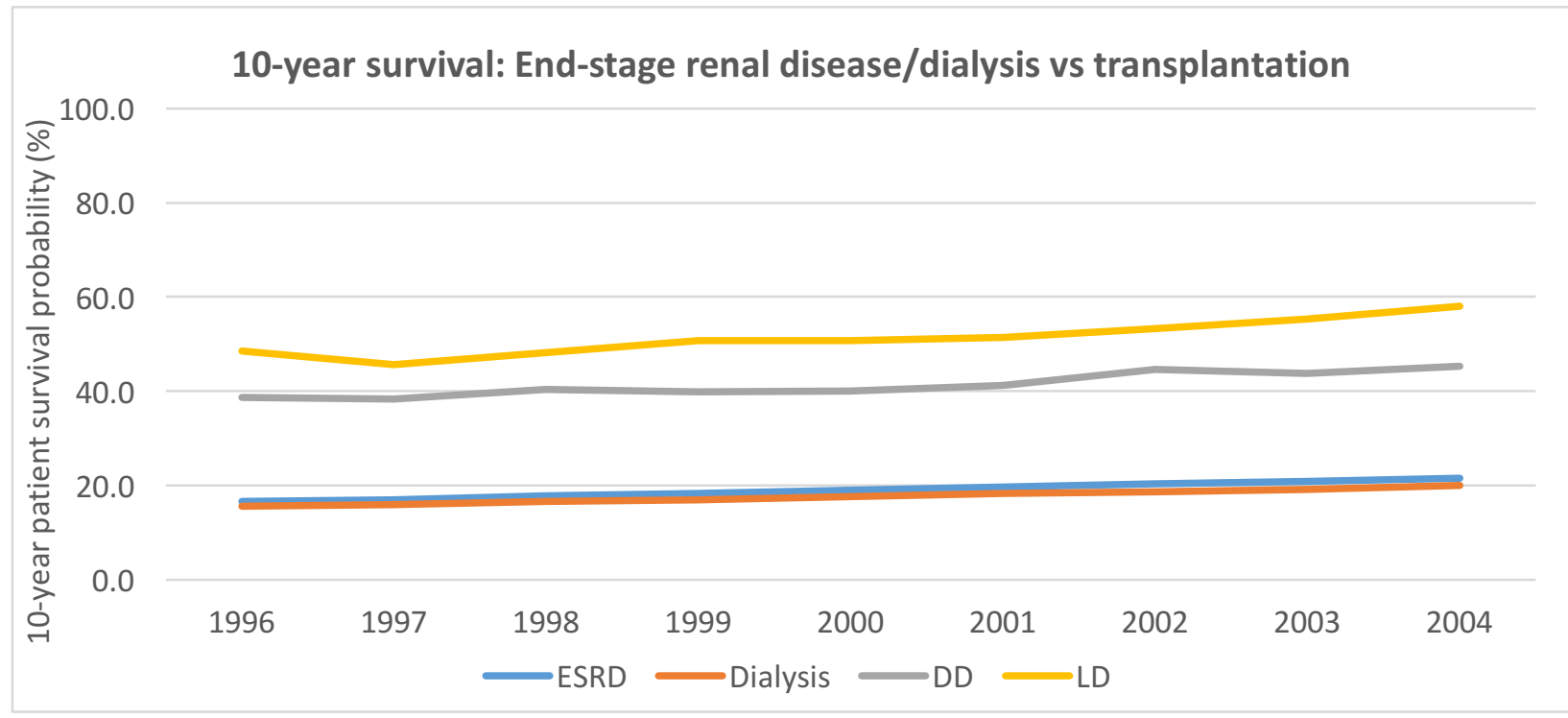

Figure 1.4: 10-year survival probabilities: incident patients, adjusted for age, gender, race, ethnicity, and primary disease. Renal transplantation provides patient survival advantage when compared to end-stage renal disease and dialysis patients. ESRD - end-stage renal disease, DD deceased donor transplant, LD - living donor transplant. Chart derived from data 2016 USRDS Annual Data Report (https://www.usrds.org/reference.aspx) 


\subsubsection{Chronic allograft injury - a major challenge in transplantation}

The significant improvement in short-term allograft and patient outcomes over the past few decades, has not been accompanied by a similar improvement in longer-term allograft survival. More than half of kidney transplant allografts are lost by 10 years post-transplant.(Eurotransplant International Foundation, 2015; Hart et al., 2017) The median allograft half-life is approximately 9 years for deceased donor allografts and 12 years for living donor allografts,(Lamb et al., 2011) and has been stagnating over the last few decades (Figure 1.5).(Meier-Kriesche et al., 2004; Wekerle et al., 2017) This issue poses a major challenge to transplantation medicine as the global rate of end-stage organ failure is rising, leading to increasing number of patients placed on organ waiting lists with significantly prolonged waiting times (Figure 1.6).(Eurotransplant International Foundation, 2015; Hart et al., 2017) Prolonged waiting times on the waitlist is associated with high rates of waitlist morbidity and mortality (Figure 1.7).(Eurotransplant International Foundation, 2015; Hart et al., 2017)

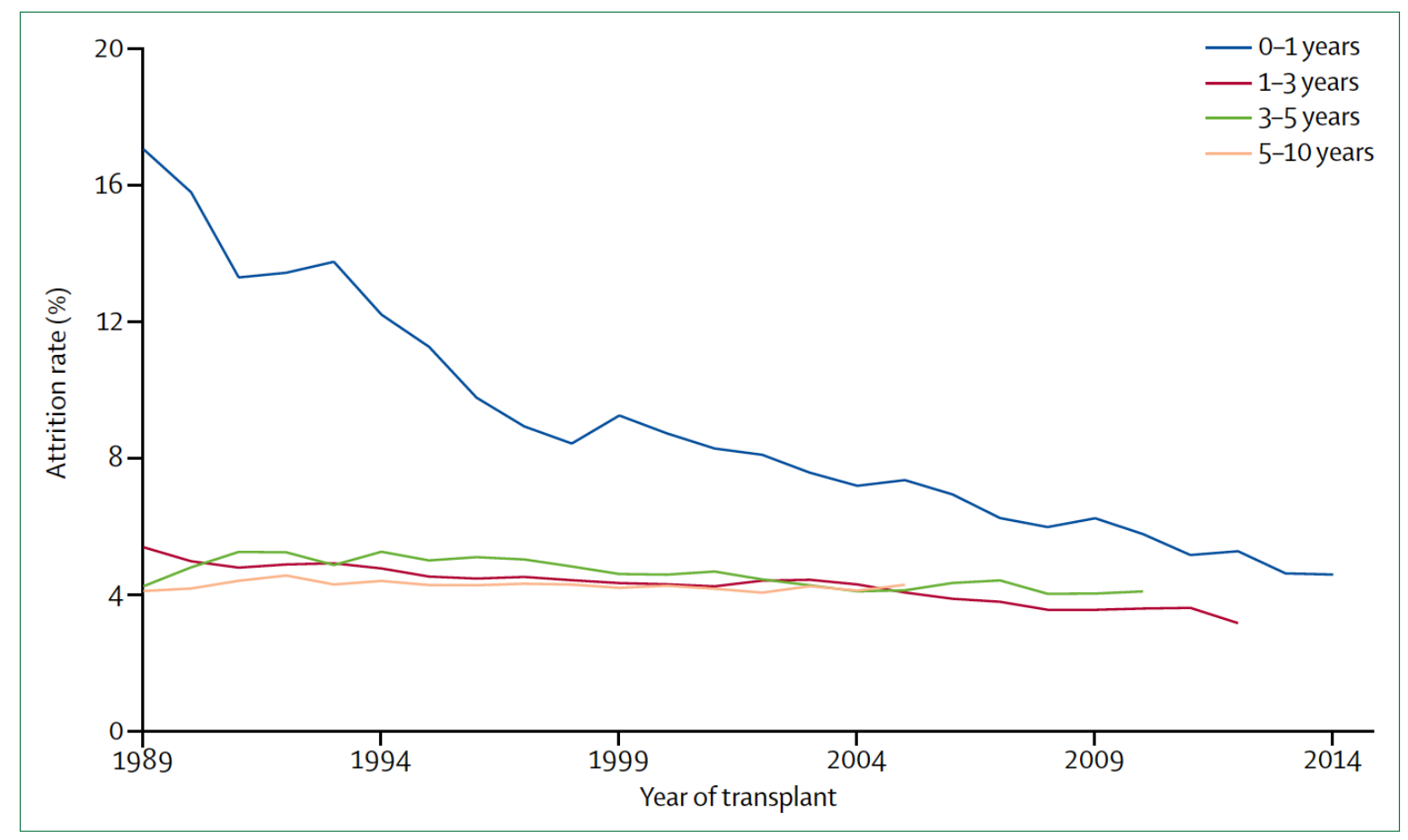

Figure 1.5: All-cause graft loss yearly attrition rates in the USA, by year of transplant.

Rates of 1-year graft loss have dropped substantially over the past 25 years, but rates of longerterm graft loss have remained relatively constant. Reprinted with permission from (Wekerle et al., 2017), Copyright 2017 with permission from Elsevier. 


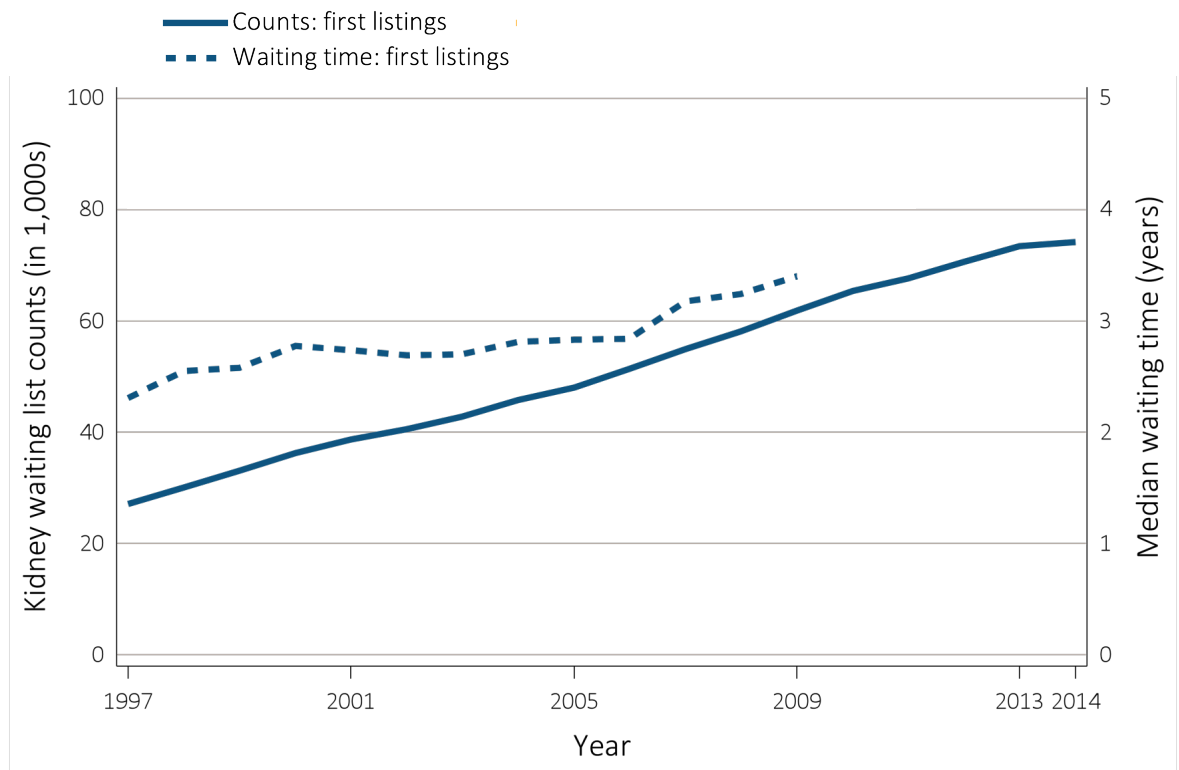

Figure 1.6: Number of patients wait-listed for kidney transplant (1997-2014) and median waiting times (1997-2009). There are increasing number of patients listed on the kidney transplant waiting list, leading to increased waitlist times. Chart adapted from 2016 USRDS Annual Data Report (https://www.usrds.org/2016/view/Default.aspx)

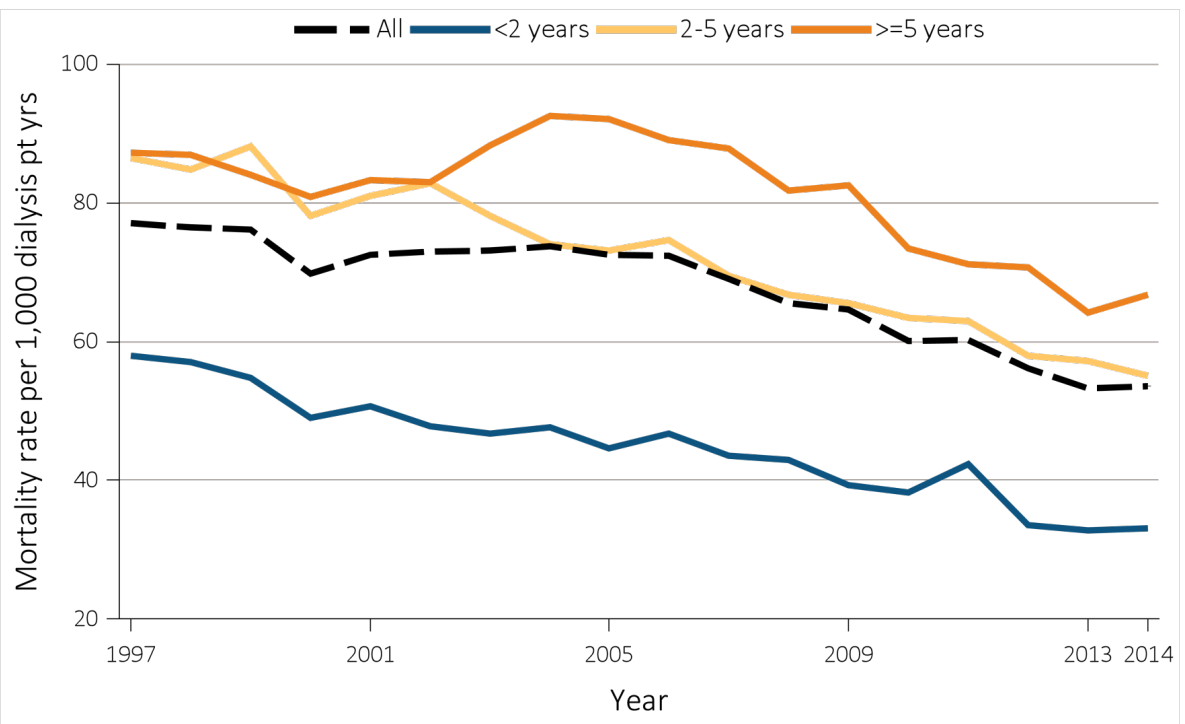

Figure 1.7: Annual mortality rates for dialysis patients on the kidney transplant waiting list by time on the list (1997-2014). Longer waitlist time is associated with higher mortality among dialysis patients. Chart taken from 2016 USRDS Annual Data Report (https://www.usrds.org/2016/view/Default.aspx) 
Chronic allograft injury (previously termed chronic allograft nephropathy) was a term coined by the Banff 2005 classification system to define a multifactorial clinico-pathological condition that leads to dysfunction of kidney allografts, often manifesting clinically with decrease in glomerular filtration rate, proteinuria and/or hypertension.(Solez et al., 2007) It encompasses both immunological and non-immunological causes of allograft injury (Figure 1.8).(Madariaga and Riella, 2017; Riella et al., 2017)

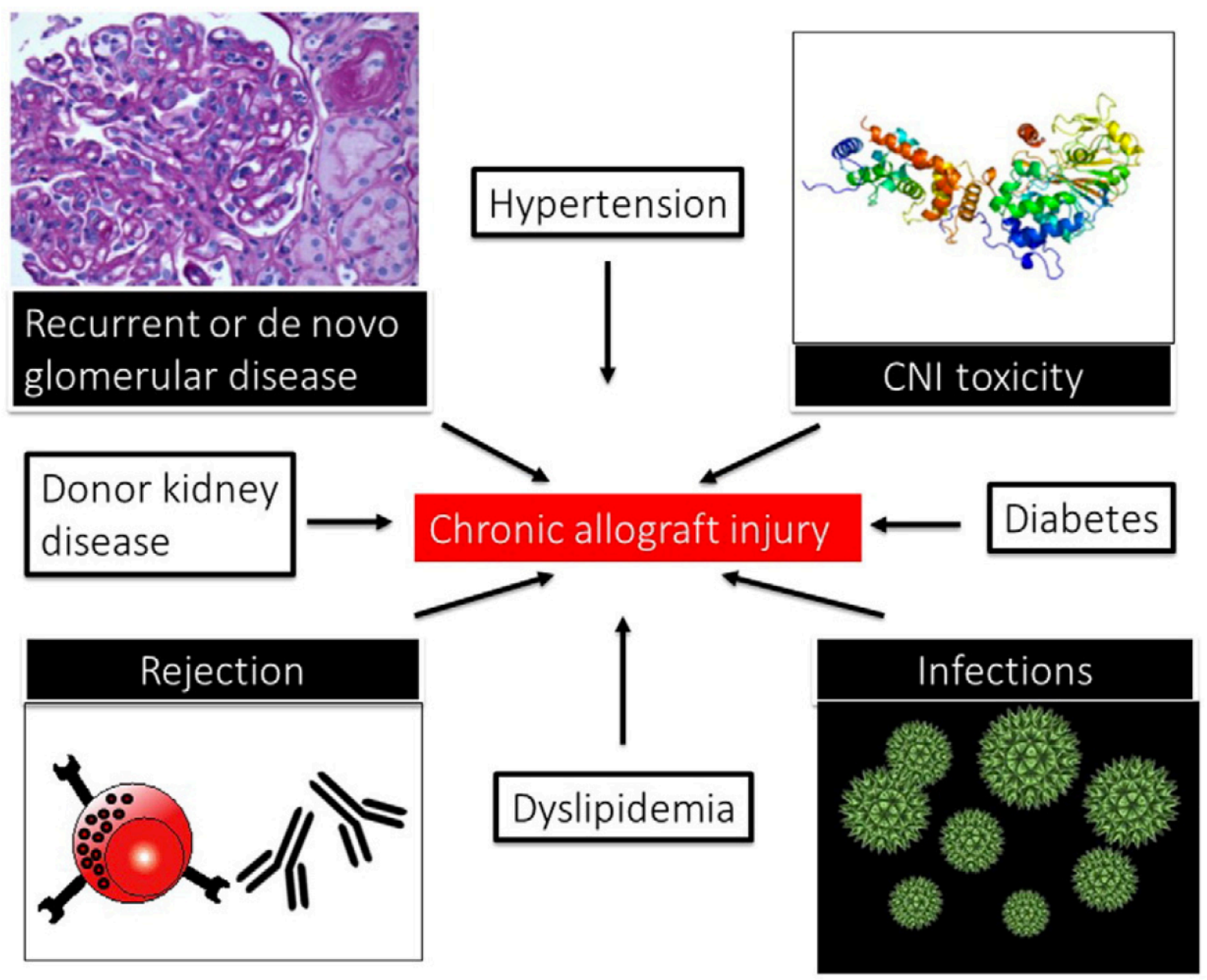

Figure 1.8: Causes of chronic allograft injury. Reprinted with permission from (Riella et al., 2017), Copyright 2017 with permission from Elsevier. 


\begin{tabular}{|l|l|}
\hline Non-immunological & Immunological \\
\hline $\begin{array}{l}\text { Recipient's inherent risks } \\
\text { (cardiovascular/metabolic - hypertension, } \\
\text { hyperlipidemia, diabetes mellitus) }\end{array}$ & $\begin{array}{l}\text { Donor-specific antibodies (pre-formed and } \\
\text { de-novo) }\end{array}$ \\
\hline $\begin{array}{l}\text { Allograft factors: prolonged ischaemia, } \\
\text { ischaemia-reperfusion injury, significant } \\
\text { size mismatch between recipient and donor } \\
\text { kidney, poor quality graft from donor }\end{array}$ & Acute rejection \\
\hline Calcineurin inhibitor toxicity & Antibody-mediated rejection \\
\hline Urological issues & $\begin{array}{l}\text { Recurrent infections: Viral (BK, CMV, } \\
\text { EBV) and bacterial }\end{array}$ \\
\hline Allograft renal artery stenosis & $\begin{array}{l}\text { Recurrent glomerular disease (FSGS, } \\
\text { atypical HUS) }\end{array}$ \\
\hline Acute kidney injury & \\
\hline
\end{tabular}

Table 1.1: Immunological and non-immunological causes of chronic allograft injury.

\subsubsection{Calcineurin inhibitor toxicity impacts on long-term allograft survival}

Calcineurin inhibitor (CNI) use is a known contributing cause of chronic allograft injury. Its use is associated with significant nephrotoxicity, ranging from acute vasoconstriction to chronic tubular and vascular injury, and less commonly, thrombotic microangiopathy (TMA).(AlMassarani et al., 2008; Al-Nouri et al., 2015; Bren et al., 2005; Cortina et al., 2015; Jiang et al., 2014; Lin et al., 2003; Naesens et al., 2009; Rodrigues-Diez et al., 2016; Zarifian et al., 1999) $\mathrm{CNI}$ toxicity negatively impacts allograft survival and may be a contributory factor to the lack of improvement in long-term allograft survival which has remained stagnant over the last few decades. 
In the long term, CNI use is associated with the development of interstitial fibrosis and tubular atrophy (IFTA), glomerulosclerosis, and arteriolar hyalinosis (Figure 1.9 and 1.10).(Madariaga and Riella, 2017; Naesens et al., 2009; Riella et al., 2017) In the BENEFIT trial, where a CNIavoidance regimen (co-stimulatory blockade with Belatacept) is compared to the more standard CNI-based regimen (cyclosporine), Vincenti et.al. showed improved long-term renal allograft function over a follow-up period of 7 years with CNI-avoidance in selected patients (Figure 1.11).(Vincenti et al., 2016) This improvement in renal allograft function occurred despite a higher rate of biopsy-proven acute rejection in the Belatacept group. The ELITE-Symphony trial compared CNI-based regimens (low-dose tacrolimus, standard-dose and low-dose cyclosporine) and a CNI-free regimen (Sirolimus), all of which also received mycophenolate mofetil and corticosteroids.(Ekberg et al., 2009; Ekberg et al., 2007) All groups except the standard-dose cyclosporine group received induction therapy with daclizumab during the first 2 months posttransplant. Results from this study showed that the low-dose tacrolimus group, with a median achieved tacrolimus trough level of $7 \mathrm{ng} / \mathrm{ml}$ (range 4.3-10.0 ng/ml; target 3-7 ng/ml), achieved the best outcomes with lower rejection rate, lower rate of fibrosis and improved renal function at 1 year of follow-up.(Ekberg et al., 2007) Despite ongoing improvement in rejection rate, the rate of fibrosis and improvement in renal function lost statistical significance after extension of follow-up to 3 years.(Ekberg et al., 2009) In a retrospective analysis of 141 kidney transplant recipients comparing long-term histological changes in those treated with $(n=48)$ to those without ( $\mathrm{n}=93$ ) cyclosporine (CsA), late biopsies (10 years post-transplant) revealed higher prevalence of arteriolar hyalinosis (92\% in those with CsA vs $65 \%$ in those without CsA).(Snanoudj et al., 2011)

The adverse effects of CNIs are not confined to kidney transplant recipients only. It is also a main concern in non-renal solid organ transplantation and many other diseases that require treatment with CNIs.(Dieterle et al., 1990; Furmanczyk et al., 2009; Goldstein et al., 1997; Ojo et al., 2003; Parissis et al., 2010; Van Buren et al., 1994) 


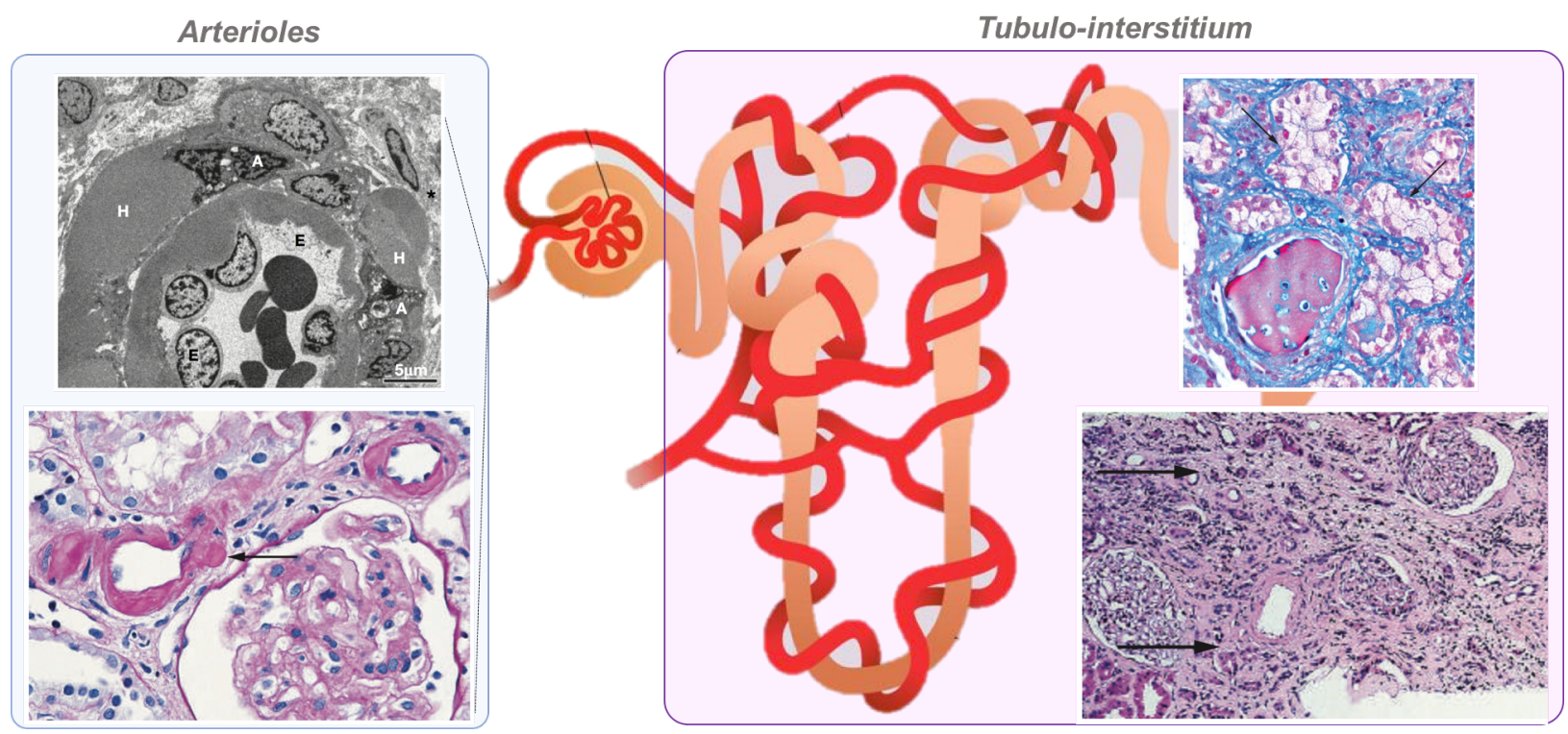

Figure 1.9: Calcineurin inhibitor use is associated with nephrotoxicity. CNI use can lead to acute and chronic tubulo-interstitial and vascular injury. Vascular/arteriolar: Lesions from acute toxicity are usually confined to the afferent arteriole with swelling and vacuolation of endothelial cells, necrosis and/or apoptosis and early replacement of damaged myocytes with rounded plasma protein insudates (hyalinisation). Immunohistochemical staining of insulates are usually positive for IgM and C3. Chronic changes usually affect the afferent arterioles and distal small interlobular arteries. Beaded medial hyalinosis (arrow in bottom left image) represent damaged smooth muscle cells that are replaced by beaded hyaline deposits on the outer aspect of the media that bulge into the adventitia. Immunohistochemistry detects IgM and C3. The electron micrograph (upper left image) shows swollen endothelial cells with hyaline arteriolopathy (A: apoptotic myocytes, E: endothelial cells, H: hyaline). Tubulo-intertitial: Morphological changes associated with acute toxic tubulopathy shows focal isometric tubular vacuolation (dilations of the endoplasmic reticulumpredominantly affecting the proximal straight tubules (arrows in upper right image). Focal tubular calcification may also occur. Chronic CNIinduced tubulo-interstitial toxicity leads to interstitial fibrosis and tubular atrophy (area to the right of the arrows in bottom right image). Figure adapted and images taken with permission from (Liptak and Ivanyi, 2006), Copyright 2006. 


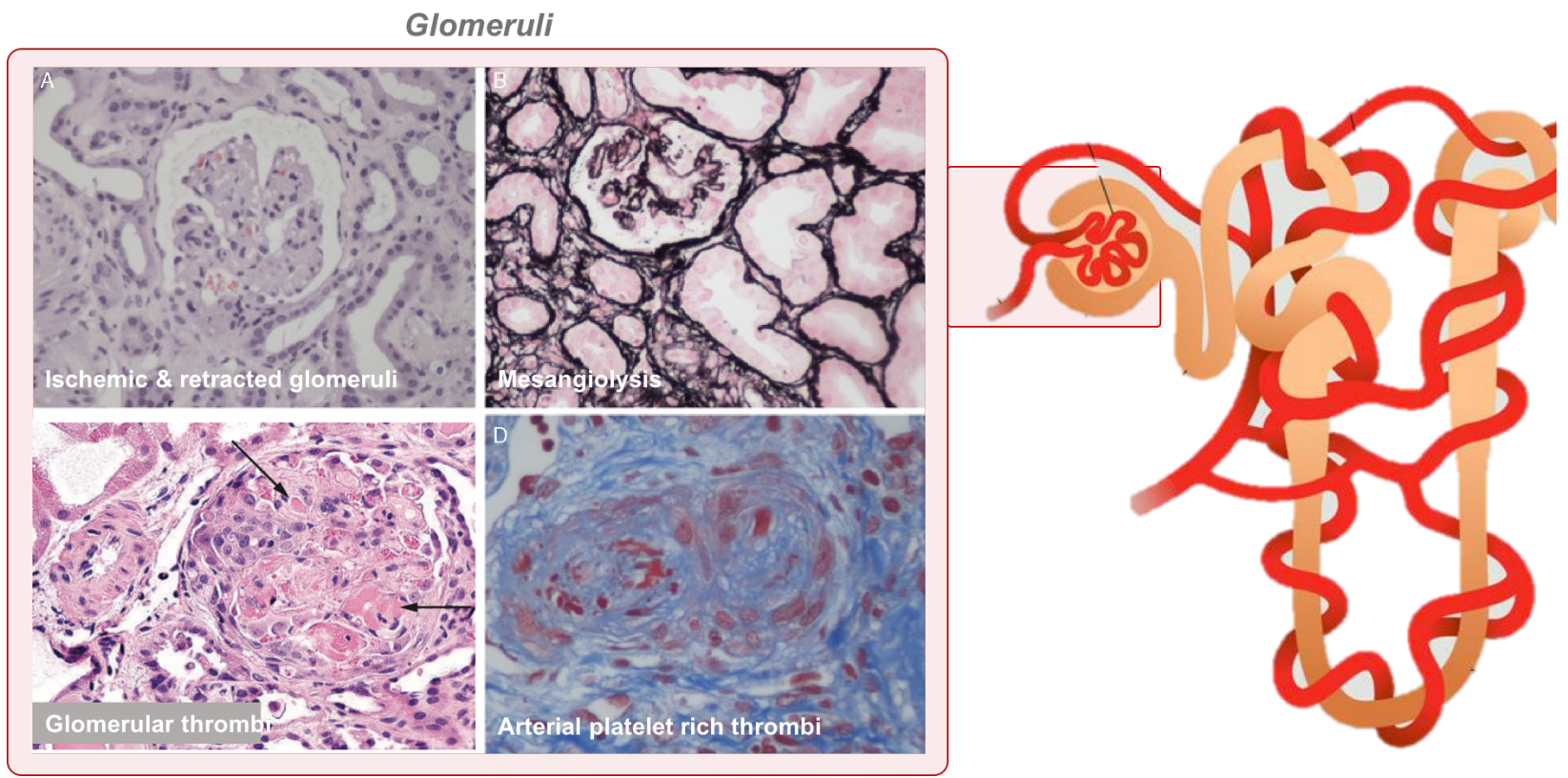

Figure 1.10: Calcineurin inhibitor use is associated with nephrotoxicity. CNI use is associated with thrombotic microangiopathy and glomerular injury. CNI vascular nephrotoxicity can present with hemolytic-uremic syndrome and in severe cases can lead to graft loss. Biopsy findings of thrombotic microangiopathy (TMA) is characterised by thrombi in arterioles and glomerular capillaries. Chronic CNI-induced glomerular injury tend to be non-specific with lesions like compensatory glomerular hypertrophy, mesangial matrix expansion, capillary collapse, focal segmental and/or global sclerosis. Figure adapted and images taken with permission from (Campistol et al., 2013; Liptak and Ivanyi, 2006) 


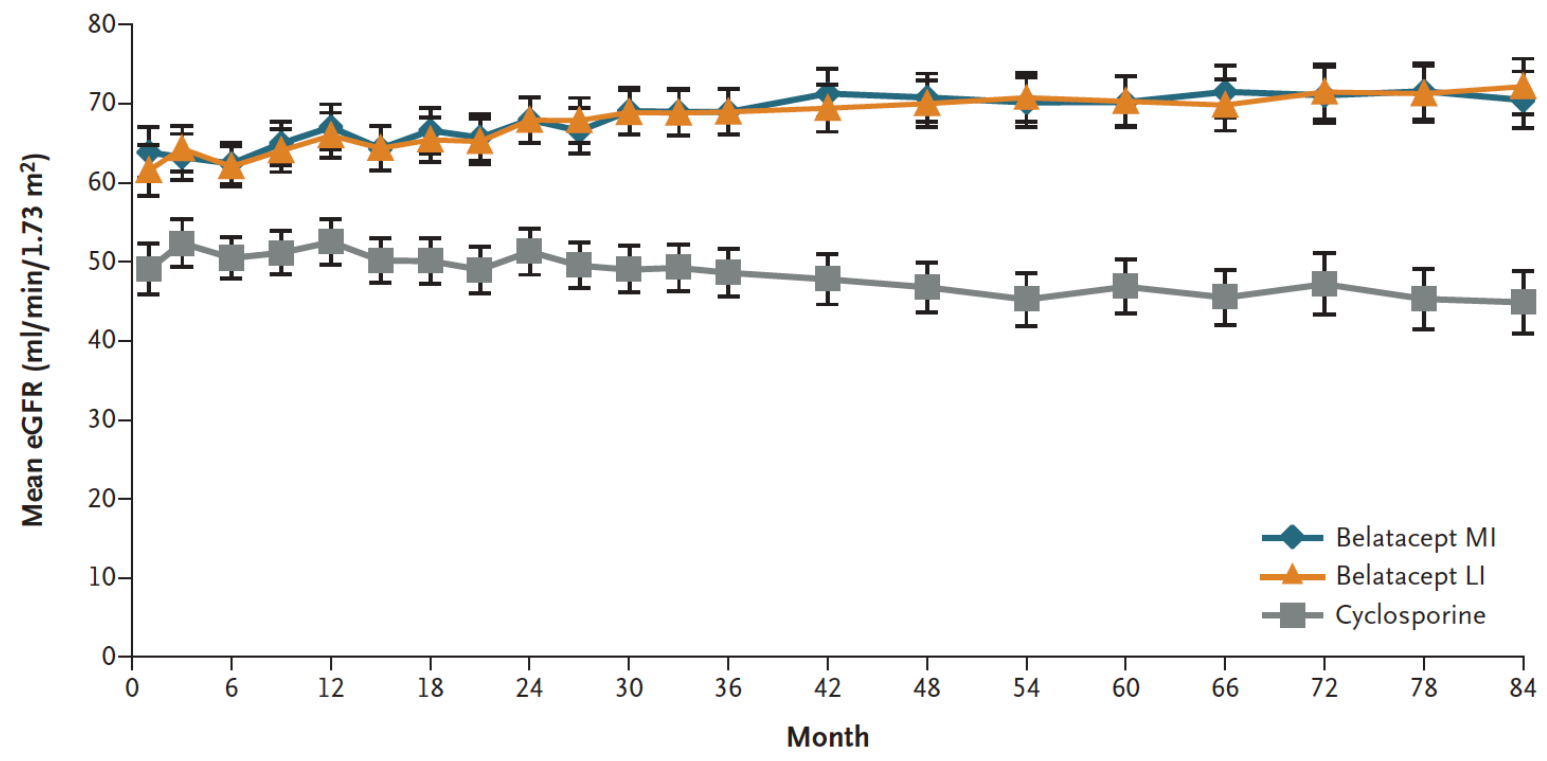

Figure 1.11: Renal allograft function (eGFR) from the BENEFIT trial over a follow-up period of 7 years. Calcineurin inhibitor avoidance protocol is associated with improved eGFR over the course of 7 years of follow-up. Reprinted with permission from (Vincenti et al., 2016), Copyright Massachusetts Medical Society. 


\subsubsection{Calcineurin inhibitors lead to endothelial cell injury}

The NFAT family of transcription factors and calcineurin are not specific to $\mathrm{T}$ cells, and serve various essential functions in vascular endothelial cells (Table 1.2). Angiogenesis requires cell proliferation, migration and differentiation, and involves the organisation and branching of endothelial cells, with vascular smooth muscle cell recruitment.(Mancini and Toker, 2009; Nagy et al., 2007) Early data from NFAT3 and NFAT4 knockout mice underpinned the importance of NFAT signalling for angiogenesis and appropriate formation of an intact vasculature during development.(Graef et al., 2001) These mice die in the embryonic stage due to defects in angiogenesis characterised by defects in vascular patterning and vascular instability. Mice with a mutation in the calcineurin $\mathrm{B}(\mathrm{CnB})$ gene (unable to activate the phosphatase activity of $\mathrm{CnA}$ ), were found to have a more severe phenotype. Transcript arrays from the NFAT3/4 null mice demonstrated over expression of several vascular growth factors including vascular endothelial growth factor A (VEGF-A). A similar pattern was also identified when cyclosporine (CsA) was administered to the mothers of these mice, suggesting that NFAT signalling either suppresses expression of the VEGF-A gene or activates a repressor of VEGF-A production.(Graef et al., 2001) Other groups have also demonstrated the importance of the calcineurin-NFAT pathway in mediating intracellular VEGF signalling.(Hernández et al., 2001; Hesser et al., 2004; Minami et al., 2004; Suehiro et al., 2014) In endothelial cells, VEGF activation of the VEGF receptor (VEGFR2) leads to increased intracellular calcium and activation of calcineurin, which in turn leads to dephosphorylation of cytoplasmic NFAT, allowing its entry into the nucleus to activate pro-angiogenic genes.(Minami et al., 2004) In physiologic conditions, this is followed by up regulation of the Down syndrome candidate region 1 (DSCR1) gene which creates a negative feedback loop to minimise endothelial cell activation in the presence of VEGF.(Minami et al., 2006) CsA is known to inhibit VEGF-induced nuclear translocation of NFAT, activation of p44/42 mitogen activated protein kinase family (MAPK), Jun N-terminal kinases (JNK) and p38 MAPK, with complete blockade of COX-2 expression which is integral to angiogenesis (Figure 1.12).(Rafiee et al., 2004) 


\begin{tabular}{|c|c|c|c|}
\hline NFAT family & Tissue/cell type & Function/target gene & Reference \\
\hline \multirow[t]{3}{*}{ NFAT1 } & Endocardial cells & $\begin{array}{l}\text { Perpetuation of heart } \\
\text { valves and septum } \\
\text { morphogenesis }\end{array}$ & $\begin{array}{l}\text { (Chang et al., 2004; } \\
\text { de la Pompa et al., } \\
\text { 1998; Ranger et al., } \\
\text { 1998) }\end{array}$ \\
\hline & Endothelial cells & $\begin{array}{l}\text { Regulation of VCAM- } \\
1 \text { expression, } \\
\text { monocyte adhesion, } \\
\text { endothelial cell } \\
\text { proliferation and tube } \\
\text { formation. Regulation } \\
\text { of DSCR-1 gene } \\
\text { expression. Tissue } \\
\text { factor }\end{array}$ & $\begin{array}{l}\text { (Hesser et al., 2004; } \\
\text { Johnson et al., 2003; } \\
\text { Minami et al., 2004; } \\
\text { Minami et al., 2006) }\end{array}$ \\
\hline & $\begin{array}{l}\text { Vascular smooth } \\
\text { muscle cells (VSMC) }\end{array}$ & Interleukin 6 & (Abbott et al., 2000) \\
\hline NFAT1, NFAT2 & Endothelial cells & $\begin{array}{l}\text { Regulation of } \\
\text { angiogenesis, tissue } \\
\text { factor, COX-2, GM- } \\
\text { CSF }\end{array}$ & $\begin{array}{l}\text { (Armesilla et al., } \\
\text { 1999; Bochkov, } \\
\text { 2002; Cockerill et al., } \\
\text { 1995; Hernández et } \\
\text { al., 2001) }\end{array}$ \\
\hline NFAT2 & $\begin{array}{l}\text { Pulmonary } \\
\text { arteries/Pulmonary } \\
\text { artery smooth muscle } \\
\text { cells }\end{array}$ & $\begin{array}{l}\text { Down regulation of } \\
\text { Kv1.5 channels, } \\
\text { pulmonary } \\
\text { vasoconstriction and } \\
\text { apoptosis resistance } \\
\text { (bcl-2) }\end{array}$ & (Bonnet et al., 2007) \\
\hline
\end{tabular}




\begin{tabular}{|c|c|c|c|}
\hline $\begin{array}{l}\text { NFAT2, NFAT3, } \\
\text { NFAT4 }\end{array}$ & Myocardial cells & $\begin{array}{l}\text { Repression of VEGF } \\
\text { allowing } \\
\text { transformation of } \\
\text { endocardial cells into } \\
\text { mesenchymal cells } \\
\text { during initiation of } \\
\text { heart valve } \\
\text { morphogenesis }\end{array}$ & (Chang et al., 2004) \\
\hline NFAT3, NFAT4 & $\begin{array}{l}\text { Mesenchymal cells, } \\
\text { Vascular smooth } \\
\text { muscle cells (VSMC), } \\
\text { Endothelial cells }\end{array}$ & $\begin{array}{l}\text { Recruitment and } \\
\text { differentiation of } \\
\text { mesenchymal cells } \\
\text { into pericytes and } \\
\text { VSMCs for proper } \\
\text { vessel assembly and } \\
\text { patterning }\end{array}$ & (Graef et al., 2001) \\
\hline \multirow[t]{2}{*}{ NFAT3 } & $\begin{array}{l}\text { Vascular smooth } \\
\text { muscle cells (VSMC) }\end{array}$ & $\begin{array}{l}\text { Promotes VSMC } \\
\text { proliferation }\end{array}$ & $\begin{array}{l}\text { (Lipskaia et al., 2003; } \\
\text { Nilsson et al., 2007) }\end{array}$ \\
\hline & $\begin{array}{l}\text { Mesenteric and } \\
\text { cerebral arteries }\end{array}$ & $\begin{array}{l}\text { Down regulation of } \beta 1 \\
\text { subunit of large } \\
\text { conductance, } \mathrm{Ca}^{2+} \\
\text { activated } \mathrm{K}^{+} \text {channels } \\
\text { and Kv2.1 subunit of } \\
\text { voltage-dependent } \mathrm{K}^{+} \\
\text {channels leading to } \\
\text { increased membrane } \\
\text { excitability, arterial } \\
\text { dysfunction and } \\
\text { hypertension }\end{array}$ & $\begin{array}{l}\text { (Amberg et al., 2004; } \\
\text { Nieves-Cintron et al., } \\
2007 \text { ) }\end{array}$ \\
\hline
\end{tabular}




\begin{tabular}{|l|l|l|l|}
\hline & Pulmonary arteries & $\begin{array}{l}\text { Remodelling of } \\
\text { pulmonary arteries, up } \\
\text { regulation of SM- } \alpha- \\
\text { actin, pulmonary } \\
\text { arterial hypertension }\end{array}$ & $\begin{array}{l}\text { (de Frutos et al., } \\
\text { 2007) }\end{array}$ \\
\cline { 3 - 5 } & $\begin{array}{l}\text { Aorta and mesenteric } \\
\text { arteries }\end{array}$ & $\begin{array}{l}\text { Intermittent hypoxia- } \\
\text { induced hypertension }\end{array}$ & $\begin{array}{l}\text { (de Frutos et al., } \\
\text { 2008) }\end{array}$ \\
\hline
\end{tabular}

Table 1.2: The NFAT family of transcription factors are not $\mathbf{T}$ cell specific. They are also expressed in various tissue and cell types as summarised in the table. Table adapted with permission from (Nilsson et al., 2008)

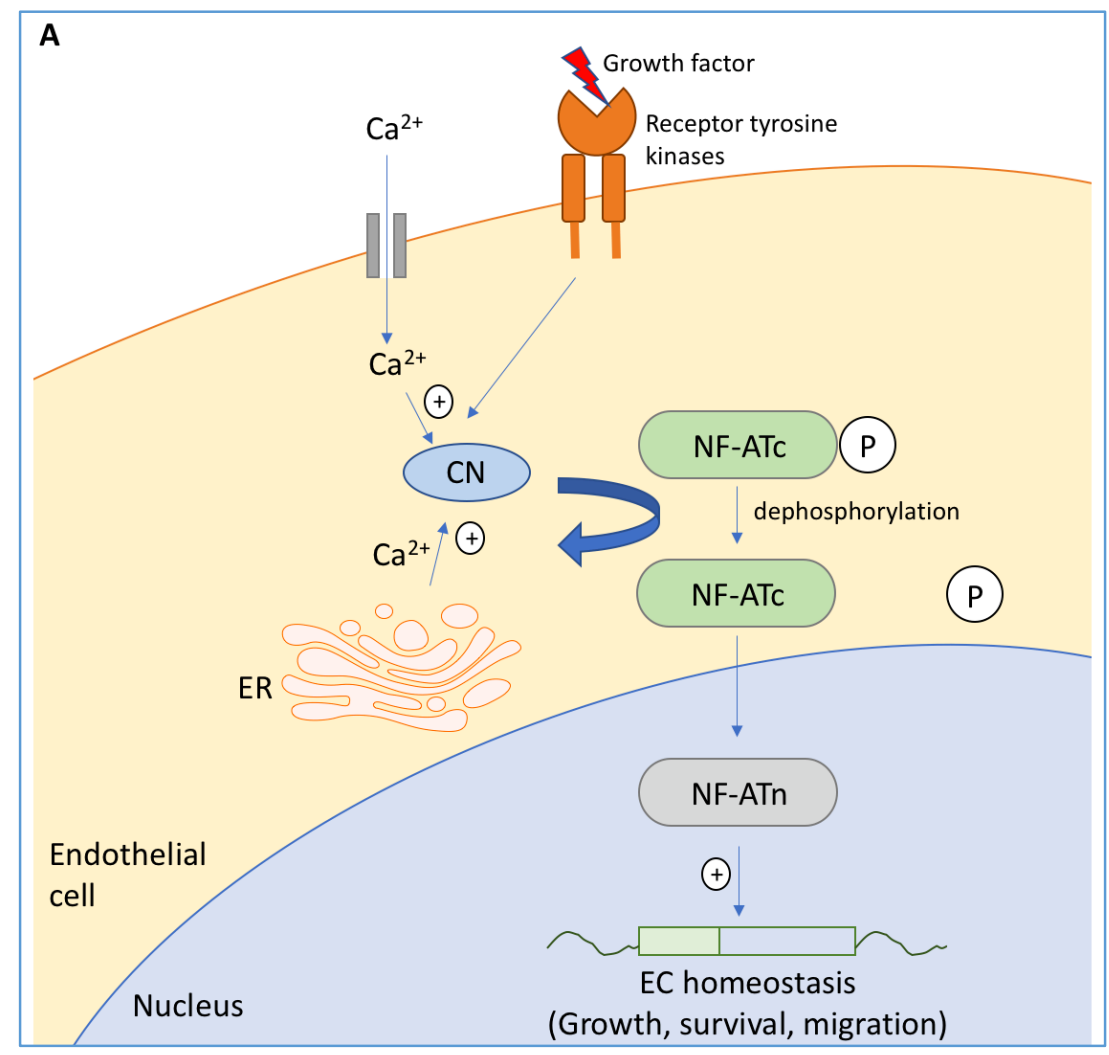




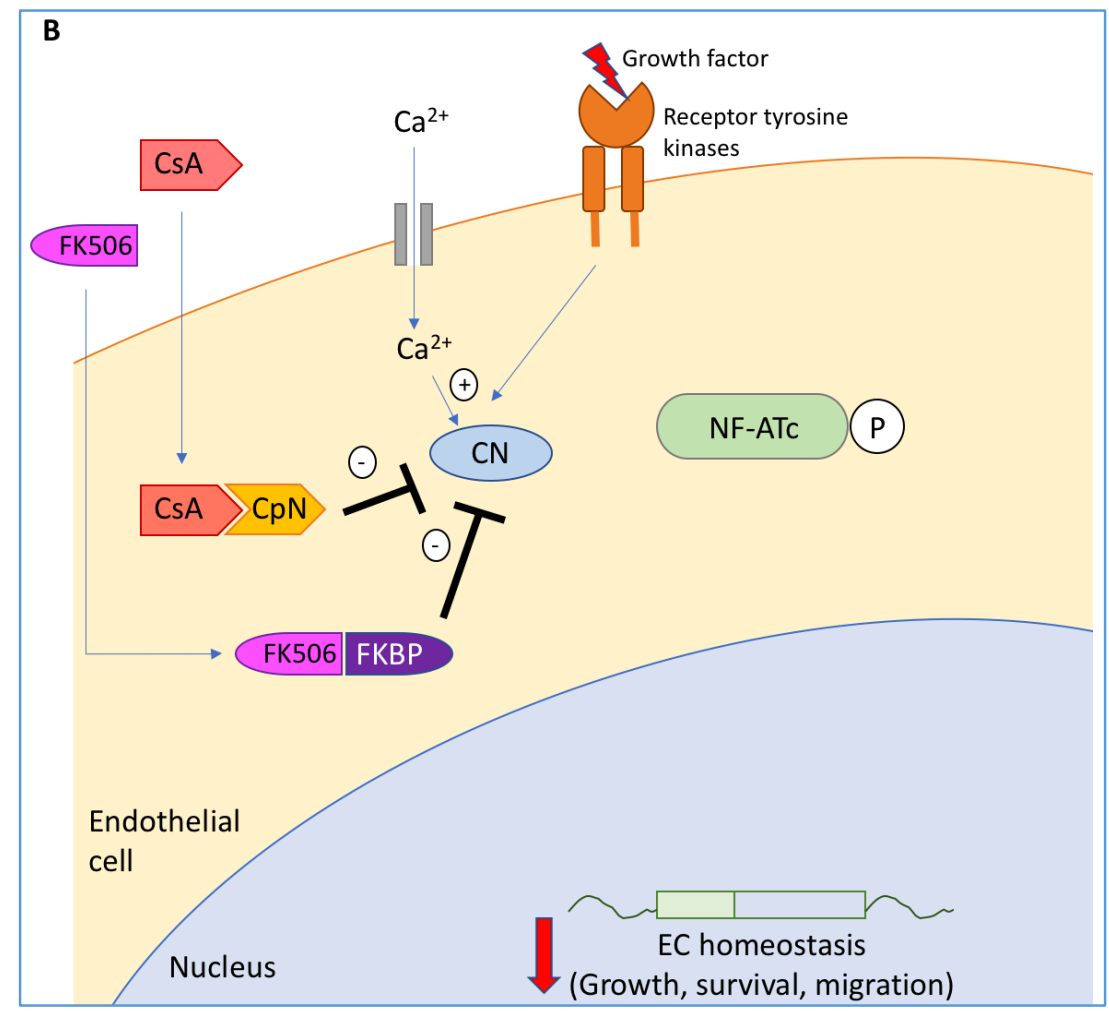

Figure 1.12: The role of calcineurin and mechanism of calcineurin inhibitor action in endothelial cells. A) In endothelial cells, interaction between growth factors and their respective receptors (I.e. VEGF and VEGFR) leads to an increase in intracellular calcium, which in turn activates calcineurin $(\mathrm{CN})$ via its calcineurin $\mathrm{B}$ subunit $(\mathrm{CnB})$. $\mathrm{CnB}$ activates the phosphatase activity of the calcineurin A subunit (CnA) which dephosphorylates cytoplasmic nuclear factor of activated T cells (NFATc), allowing it to translocate into the nucleus (NFATn). As a transcription factor, it acts to upregulate the expression of multiple genes involved in angiogenesis (I.e. Cyclooxygenase-2) which is essential for EC homeostasis. B) Calcineurin inhibitors (cyclosporine - CsA, tacrolimus - FK506), bound to their respective intracellular immunophillins (cyclophilin, $\mathrm{CpN}$ for CsA and FK-binding protein, FKBP for FK506), binds directly to $\mathrm{CnA}$ to inhibit its phosphatase activity, resulting in reduction in NFAT signalling and detrimental effects for EC growth, survival and migration. 


\subsubsection{Calcineurin inhibitor use associated with thrombotic microangiopathy}

CNIs are an important risk factor for the development of post-transplant TMA.(Al-Nouri et al., 2015; Bren et al., 2005; Cortina et al., 2015; Lin et al., 2003; Ponticelli, 2007) TMA associated with the use of CNIs can present with a clinical picture resembling acute hemolytic-uremic syndrome, which in severe cases can lead to transplant allograft loss.(Ali et al., 2013; Caires et al., 2012; Furmanczyk et al., 2009; Gray and Ameduri, 2016; Parissis et al., 2010; Said et al., 2010) However, TMA can also occur without overt systemic clinical manifestations.(Ali et al., 2013) Zarifian et.al. found up to $14 \%$ of renal graft biopsies affected by TMA associated with the use of cyclosporine ( $90 \%$ of patients did not have systemic evidence of TMA).(Zarifian et al., 1999) Biopsy findings show TMA, characterized by arteriolar and glomerular microthrombi, although prominent arterial intimal changes are not typical of CNI-induced TMA.(Liptak and Ivanyi, 2006) Endothelial injury secondary to vasoconstriction-associated ischaemia, increased platelet aggregation and activation of prothrombotic factors have been suggested as possible causes.(Naesens et al., 2009)

\subsection{Thrombotic microangiopathy (TMA)}

\subsubsection{Introduction to thrombotic microangiopathy}

Thrombotic microangiopathies (TMA) are defined by their common clinical feature:

microangiopathic hemolytic anaemia, non-immune thrombocytopenia, and organ injury.(George and Nester, 2014; Meri, 2013; Riedl et al., 2014a) The term thrombotic microangiopathy (TMA) was proposed by Symmers in 1952 to indicate "the location and the most striking feature of the characteristic histological lesions without mentioning inconsistent and controversial features of this clinic-pathological entity".(Symmers, 1952) They are systemic conditions with the potential for multi-organ involvement, including the kidneys, brain, gastrointestinal tract, respiratory tract and skin; and they affect both children and adults. TMA can be an acute life-threatening disease with serious long-term sequelae, and in some forms, can recur.(Cataland and $\mathrm{Wu}, 2014$; Riedl et al., 2014a; Rosove, 2014) Crucial to the development of TMA is injury to the microvascular endothelium: endothelial cell injury and activation leads to platelet and neutrophil recruitment which eventually leads to thrombus formation, inflammation and subsequent organ failure.(Markiewski et al., 2007; Riedl et al., 2014b; Tsai, 2013) 


\subsubsection{Thrombotic microangiopathy - a spectrum of complement-mediated disorders}

Thrombotic microangiopathies were historically classified into two entities which were clinically distinct, but pathologically indistinguishable, dependent on whether brain or kidney lesions predominate: thrombotic thrombocytopenic purpura (TTP) and hemolytic uremic syndrome (HUS).

TTP was first described in 1923 by Moschowitz, in a 16 year old girl with an acute febrile illness with anemia, petechiae, paralysis and coma. Autopsy findings in the girl revealed hyaline thrombi in terminal arterioles and capillaries throughout most organs including the kidneys.(Moschcowitz, 1952) The condition is now known to be secondary to ADAMTS13 (a disintegrin and metalloproteinase with a thrombospondin type 1 motif, member 13) deficiency. ADAMTS13 is a protease that cleaves von Willebrand factor (vWF) multimers upon shear stress-induced conformational change and endothelial cell release.(Hassenpflug et al., 2014; Knobl, 2014)

The initial description of HUS was provided by Gasser et.al. in 1955, in 5 children with the clinical triad of hemolytic anemia, thrombocytopenia, and acute renal failure.(Gasser et al., 1955) Shiga toxin-producing (enterohemorrhagic) Escherichia coli (STEC) associated HUS represents the main cause of TMA in childhood (90\% of all HUS cases).(Scheiring et al., 2010; Würzner et al., 2014) The term atypical HUS (aHUS) was later used to refer to all non-STECassociated cases of HUS, which usually follow a more severe, recurrent clinical course with a poorer outcome. Complement genetic mutations leading to complement dysregulation were subsequently found in patients with aHUS.(Noris and Remuzzi, 2009; Warwicker et al., 1998a; Warwicker et al., 1998b)

Secondary forms of TMA that occur after trigger events such as pregnancy, transplantation and drug-induced (e.g. CNI) were not initially thought to involve complement dysregulation. However, underlying complement genetic mutations and dysregulation are now increasingly recognized in patients with secondary TMA (Table 1.3).(Riedl et al., 2014a; Teoh et al., 2016)

The historical classification of TMA that emphasizes distinct differences in the individual pathogenesis of disease is problematic. There is increasing evidence that these conditions have 
shared pathogenetic mechanisms, with complement dysregulation playing a key role in the pathogenesis of TMA (Figure 1.13).

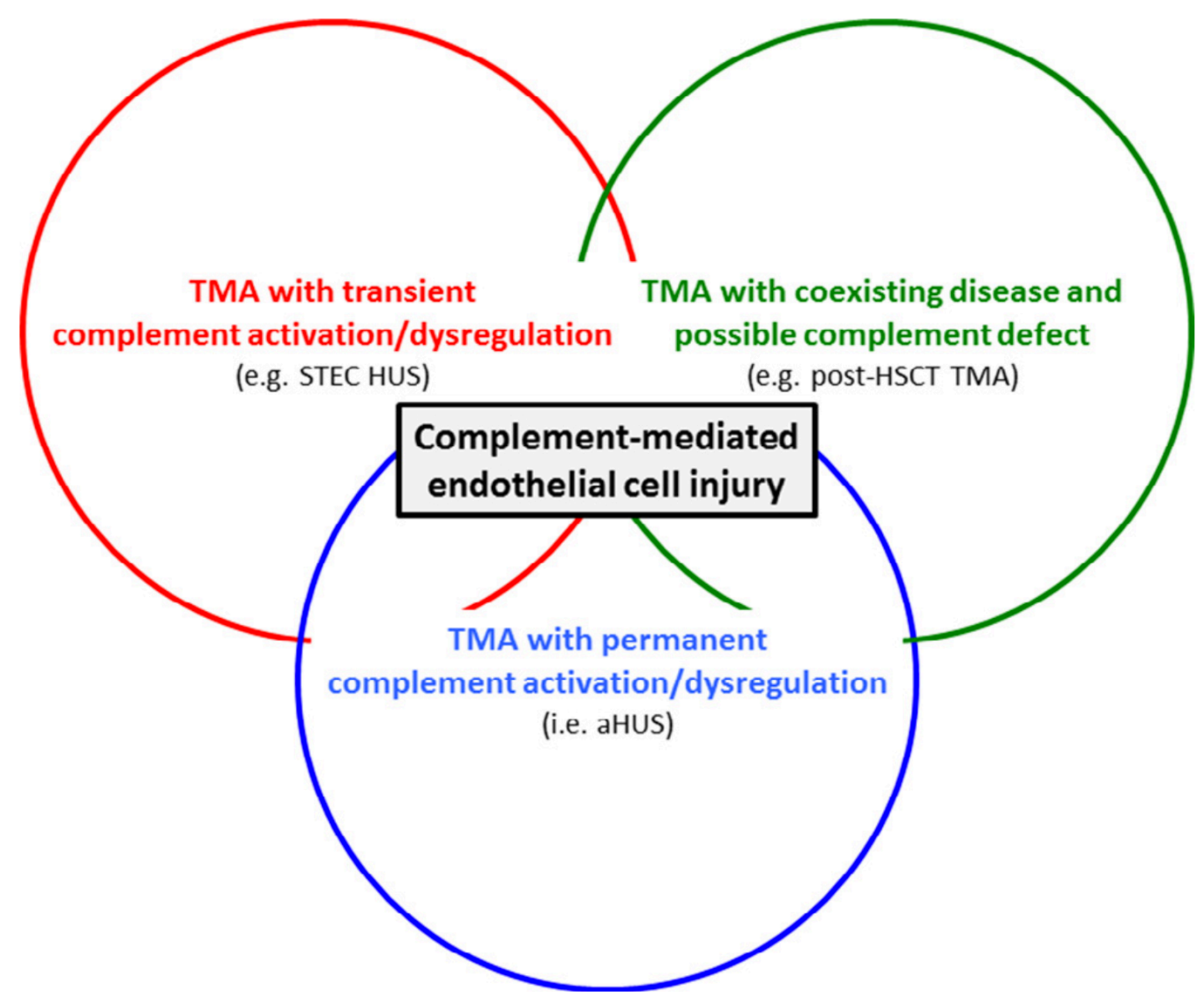

Figure 1.13: The spectrum of thrombotic microangiopathies with a central pathogenic role for complement-mediated endothelial cell injury: 1) complement-driven TMA (i.e. atypical HUS) where there is an underlying complement defect, 2) complement-enhanced TMA (i.e. Shiga toxin, CNI-induced) with transient activation of complement, and 3) TMAs with coexisting disease (i.e. SLE, pregnancy). Reprinted with permission from (Teoh et al., 2016), Copyright 2016 with permission from Elsevier. 


\section{Classification of Thrombotic Microangiopathies}

Thrombotic thrombocytopenic purpura (TTP) - ADAMTS13 deficiency

- Hereditary

- Autoimmune

Atypical haemolytic uremic syndrome - complement-mediated

- Hereditary (complement genetic mutations: CFH, CFI, CFB, C3, MCP)

- Autoimmune (CFH autoantibodies)

Infection-induced TMA

- Shiga-toxin (enterohemorrhagic) E. coli (STEC)-associated HUS

- Shigella dysenteriae HUS

- Streptococcus pneumoniae HUS

- HUS associated with other pathogens: Influenza A/H1N1, EBV, CMV, Mycoplasma pneumoniae, Bordetella pertussis, Parvovirus B19, Varicella zoster, HIV

TMA associated with transplantation

- De novo TMA post-solid organ transplantation

- TMA associated with hematopoietic stem cell transplantation

TMA associated with glomerulopathies

- C3 glomerulopathy

- IgA nephropathy

- Focal segmental glomerulosclerosis (FSGS)

- Membranous nephropathy

TMA associated with vasculitides

- Systemic lupus erythematosus

- Antiphospholipid syndrome

- ANCA-associated vasculitis

TMA associated with pregnancy

TMA associated with metabolic diseases

- Cobalamin C deficiency

TMA associated with malignant hypertension

Drug-induced TMA

- Calcineurin inhibitors (cyclosporine, tacrolimus)

- Chemotherapy (cisplatin, anti-VEGF)

- Others (ticlopidine, quinine)

Other forms of TMA

- DGKE

Table 1.3: Classification of thrombotic microangiopathies. Adapted from (Riedl et al., 2014a; Teoh et al., 2016) 


\subsection{Introduction to the complement system}

The complement system is a part of the innate immune system which has several important physiological functions: 1) initiating and mediating an inflammatory reaction, 2) targeting invading microorganisms for removal by phagocytosis (opsonisation), and 3) killing of invading microorganisms via the formation of the membrane attack complex.(Teoh et al., 2016; Walport, 2001a; Zipfel and Skerka, 2009) It also functions as a link between the innate and adaptive immune system by augmenting antibody-mediated pathogen killing, as well as aid in the clearance of immune complexes and cellular debris.(Walport, 2001a) The complement system consists of inactive components and serine proteases that are linked and can be activated in a sequential cascade - a process that is tightly regulated by fluid-phase and surface membranebound regulators to prevent host cell injury.

\subsubsection{Activation of the complement system}

There are 3 main pathways by which the complement system can be activated, the mannosebinding lectin (MBL), the classical (CP) and the alternative pathways (AP) (Figure 1.14). When activated, these 3 pathways converge to cleave C3 (most abundant plasma complement protein) by the generation of $\mathrm{C} 3$ convertases $(\mathrm{C} 4 \mathrm{~b} 2 \mathrm{a}$ and $\mathrm{C} 3 \mathrm{bBb})$. When the cascade is activated via the $\mathrm{MBL}$ or $\mathrm{CP}, \mathrm{C} 4 \mathrm{~b} 2 \mathrm{a}$ (the classical pathway $\mathrm{C} 3$ convertase) is generated to cleave $\mathrm{C} 3$ to $\mathrm{C} 3 \mathrm{a}$ and C3b.

The activation of the MBL is mediated through binding of mannose residues on surfaces of microorganisms by either MBL or ficolins. MASP-1 and MASP-2, serine proteases that are phylogenetically analogous to the $\mathrm{C} 1$ complex, are also capable of cleaving and activating both C4 and C2.(Matsushita et al., 2013; Wallis, 2007)

The activation of the $\mathrm{CP}$ is triggered by the binding of immune complexes ( $\operatorname{IgM}$ or IgG antibodyantigen complexes) with $\mathrm{Clq}$ (part of the $\mathrm{C} 1$ protein complex that includes the serine proteases $\mathrm{C} 1 \mathrm{~s}$ and $\mathrm{C} 1 \mathrm{r}$ ). The binding of antigen-antibody complexes with $\mathrm{C} 1 \mathrm{q}$ results in the cleavage of $\mathrm{C} 4$ into $\mathrm{C} 4 \mathrm{a}$ and $\mathrm{C} 4 \mathrm{~b}$. $\mathrm{C} 4 \mathrm{~b}$ then binds $\mathrm{C} 2$, leading to cleavage into $\mathrm{C} 2 \mathrm{a}$ and $\mathrm{C} 2 \mathrm{~b}$ by the serine protease $\mathrm{C} 1 \mathrm{~s}$. The remaining $\mathrm{C} 4 \mathrm{~b} 2 \mathrm{a}$ (classical pathway $\mathrm{C} 3$ convertase), can then hydrolyse $\mathrm{C} 3$ into the anaphylatoxin $\mathrm{C} 3 \mathrm{a}$, and $\mathrm{C} 3 \mathrm{~b}$. 
In contrast, the AP is constitutively active, generating $\mathrm{C} 3 \mathrm{~b}$ which indiscriminately bind to pathogens, non-self and self cell surfaces.(Teoh et al., 2016; Walport, 2001b; Zipfel and Skerka, 2009) Spontaneous activation of C3 occurs in the fluid phase via a 'tick-over mechanism' related to the instability of the thioester bond within the $\mathrm{C} 3$ alpha chain, which when exposed and hydrolysed, associate with $\mathrm{H}_{2} \mathrm{O}$. $\mathrm{C} 3\left(\mathrm{H}_{2} \mathrm{O}\right)$ binds complement factor $\mathrm{B}$, forming $\mathrm{C} 3\left(\mathrm{H}_{2} \mathrm{O}\right) \mathrm{B}$. The alternative pathway $\mathrm{C} 3$ convertase $(\mathrm{C} 3 \mathrm{bBb})$ is formed when $\mathrm{C} 3\left(\mathrm{H}_{2} \mathrm{O}\right) \mathrm{B}$ is subsequently cleaved by factor D.(Degn and Thiel, 2013; Ricklin et al., 2010) The AP C3 convertase is further stabilized by properdin, enhancing the amplification of this pathway.(Muller-Eberhard, 1988)

When the activation of the complement cascade is allowed to progress, the same enzymes that cleave $\mathrm{C} 3$ (the classical and alternative pathway $\mathrm{C} 3$ convertases, $\mathrm{C} 4 \mathrm{~b} 2 \mathrm{a}$ and $\mathrm{C} 3 \mathrm{bBb}$ ) can bind additional $\mathrm{C} 3 \mathrm{~b}$ molecules to form the $\mathrm{C} 5$ convertases $(\mathrm{C} 4 \mathrm{~b} 2 \mathrm{a} 3 \mathrm{~b}$ and $\mathrm{C} 3 \mathrm{bBb} 3 \mathrm{~b})$ that activate $\mathrm{C} 5$ further downstream in the cascade to generate $\mathrm{C} 5 \mathrm{a}$ (a potent anaphylatoxin) and $\mathrm{C} 5 \mathrm{~b}$ that can initiate the terminal pathway with formation of the membrane attack complex (MAC), C5b-9, by assembling with complement components 6, 7, 8 and 9 (Figure 1.14).(Teoh et al., 2016; Zipfel and Skerka, 2009) The MAC forms transmembrane channels that disrupt target cell membranes, leading to cell lysis and death.(Loirat and Frémeaux-Bacchi, 2011; Peitsch and Tschopp, 1991)

Regardless of how the complement cascade is activated, all 3 pathways converge to hydrolyse $\mathrm{C} 3$. Activation of $\mathrm{C} 3$ can occur in the fluid phase and on cell surfaces. The formation and deposition of $\mathrm{C} 3 \mathrm{~b}$ of target cell surfaces is followed by the formation of $\mathrm{C} 3 \mathrm{bBb}(\mathrm{C} 3$ convertase), which is capable of cleaving more $\mathrm{C} 3$. The deposition of $\mathrm{C} 3 \mathrm{~b}$ on cells is indiscriminate and occurs within seconds to minutes. Bound C3b (like C4b) is an opsonin and can 'label' cells and/or pathogens for processing by antigen-presenting cells or for phagocytosis. Alternatively, the terminal cascade of complement can be initiated (as described above), leading to the formation of the membrane attack complex, C5b-9.(Pangburn et al., 2008; Walport, 2001a) Because $\mathrm{C} 3 \mathrm{~b}$, the activation product of $\mathrm{C} 3$, can generate new $\mathrm{C} 3 \mathrm{bBb}$ (the alternative pathway $\mathrm{C} 3$ convertase) with factor B via this 'tick-over mechanism', priming the system to continually generate more $\mathrm{C} 3 \mathrm{~b}$ molecules, the $\mathrm{AP}$ acts to amplify the activation of the complement system, therefore requiring tight regulation (discussed below).

A fourth pathway of complement activation was recently recognised. In contrast to the other MBL, CP and AP, this pathway bypasses C3 activation. In this fourth C3-independent pathway, 
thrombin, a serine protease, catalyzes the conversion of fibrinogen to insoluble fibrin strands to aid coagulation.(Huber-Lang et al., 2006) Thrombin can cleave C3 to form the anaphylatoxin C3a.(Amara et al., 2008) In addition, thrombin (when acted upon by the C5 convertase) can generate $\mathrm{C} 5 \mathrm{a}$ and a unique $\mathrm{C} 5$ split product $\left(\mathrm{C}_{5} \mathrm{~b}_{\mathrm{T}}\right)$ that can result in formation of a membrane attack complex with increased lytic activity $\left(\mathrm{C} \mathrm{b}_{\mathrm{T}}-9\right)$.(Krisinger et al., 2012)

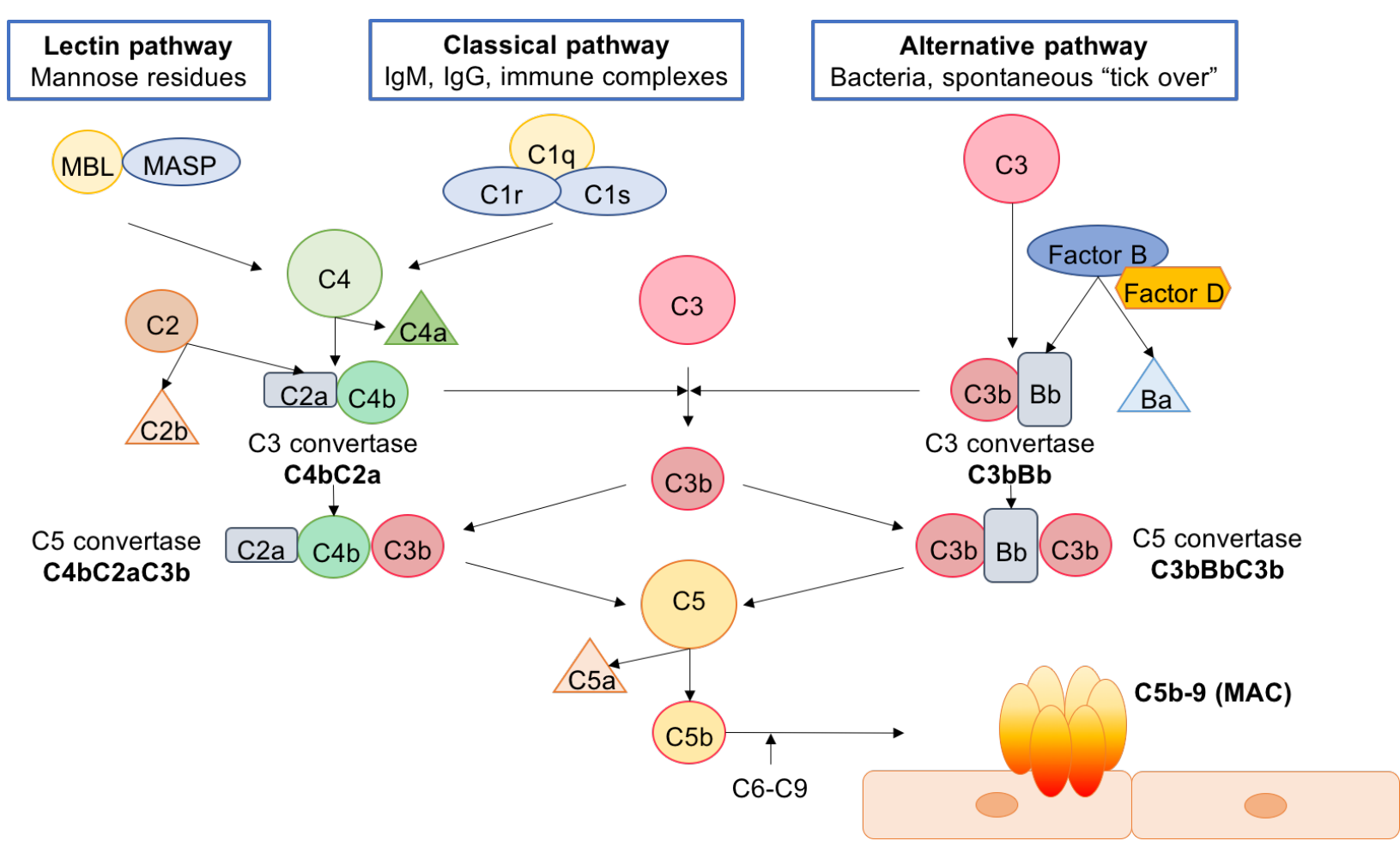

Figure 1.14: Overview of the complement system and its activation. The complement system can be activated via 3 pathways: the lectin, classical and alternative pathway. Upon activation, all pathways converge to cleave $\mathrm{C} 3$ to $\mathrm{C} 3 \mathrm{a}$ and $\mathrm{C} 3 \mathrm{~b}$. The alternative pathway is constitutively active, providing an efficient means to amplify the cleavage of $\mathrm{C} 3$, generating more $\mathrm{C} 3 \mathrm{~b}$ and the $\mathrm{C} 5$ convertase $(\mathrm{C} 3 \mathrm{bBbC} 3 \mathrm{~b})$ to activate $\mathrm{C} 5$ further downstream in the cascade to generate $\mathrm{C} 5 \mathrm{a}$ (a potent anaphylatoxin) and the formation of the membrane attack complex (C5b-9). Reprinted with permission from (Teoh et al., 2016). 


\subsubsection{Regulation of the alternative pathway of the complement system}

The alternative pathway (AP) of complement is constitutively active (spontaneous tick-over), indiscriminate and efficiently coats unprotected cell surfaces with significant amounts of covalently bound $\mathrm{C} 3 \mathrm{~b}$ within a few minutes. Tight regulation of this activation is required to protect host cells from complement-mediated injury.(Teoh et al., 2016; Walport, 2001b; Zipfel and Skerka, 2009) The regulation of AP is achieved by a combination of fluid-phase (in plasma) and surface membrane-bound regulators (Figure 1.15).(Teoh et al., 2016; Zipfel and Skerka, 2009) Homeostasis is achieved with the maintenance of a delicate balance between activation and inhibition.

Complement factor $\mathrm{H}(\mathrm{CFH})$ is the primary fluid-phase regulator that inhibits complement activation in the fluid-phase and on cell surfaces. CFH acts as a cofactor to complement factor I (CFI) to cleave $\mathrm{C} 3 \mathrm{~b}$ into its inactive form $\mathrm{iC} 3 \mathrm{~b}$, promotes disintegration of $\mathrm{C} 3 \mathrm{bBb}$ and competitively prevents C3b deposition on cell surfaces.(Makou et al., 2013; Rodriguez de Cordoba et al., 2004; Schmidt et al., 2008a) CFI is a serine protease with proteolytic activity for $\mathrm{C} 3 \mathrm{~b}$ and $\mathrm{C} 4 \mathrm{~b}$ in the presence of a cofactor $\mathrm{CFH}$ for $\mathrm{C} 3 \mathrm{~b}, \mathrm{C} 4$ binding protein for $\mathrm{C} 4 \mathrm{~b}$ and membrane cofactor protein/CD46 for both),(Liszewski et al., 1991; Nagasawa and Stroud, 1977; Pangburn et al., 1977; Ross et al., 1982; Shiraishi and Stroud, 1975; Whaley and Ruddy, 1976) inhibiting both the AP and CP.(Kavanagh et al., 2008) This is a key regulatory mechanism of the $\mathrm{AP}$ because inactivating $\mathrm{C} 3 \mathrm{~b}$ and preventing the formation of the $\mathrm{C} 3$ and $\mathrm{C} 5$ convertases inhibits the feedback loop that is triggered by C3b deposition on surfaces of target cells.

While the fluid-phase complement regulators are usually more specific and act almost exclusively on $\mathrm{C} 3$ or $\mathrm{C} 4$, regulating either the alternative, classical or lectin pathway; surface membrane-bound complement regulators complement receptor 1 (CR1/CD35), membrane cofactor protein (MCP/CD46), decay accelerating factor (DAF/CD55), protectin (CD59), and thrombomodulin (THBD) inactivate both $\mathrm{C} 3$ and $\mathrm{C} 4$ and regulate all 3 pathways of activation.(Teoh et al., 2016; Zipfel and Skerka, 2009) Complement receptor 1 (CR1/CD35) promotes the inactivation of $\mathrm{C} 3 \mathrm{~b}$ to $\mathrm{iC} 3 \mathrm{~b}$ and membrane cofactor protein $(\mathrm{MCP} / \mathrm{CD} 46)$ acts as a cofactor to CFI and CFH for inactivation of C3b. Decay accelerating factor (DAF/CD55) accelerates the disintegration of the $\mathrm{C} 3$ and $\mathrm{C} 5$ convertases while protectin (CD59) serves to prevent the formation of the membrane attack complex by binding to $\mathrm{C} 8$, preventing the 
assembly with C9. Through enhancement of thrombin activatable fibrinolysis inhibitor (TAFI), thrombomodulin contributes to inactivation of C3a and C5a (anaphylatoxins generated from activation of the complement cascade).(Campbell et al., 2002; Nishimura et al., 2007) Thrombomodulin also has the ability to bind $\mathrm{C} 3 \mathrm{~b}$ and $\mathrm{CFH}$, negatively regulating the alternative pathway through CFI-mediated inactivation of C3b.(Delvaeye et al., 2009)

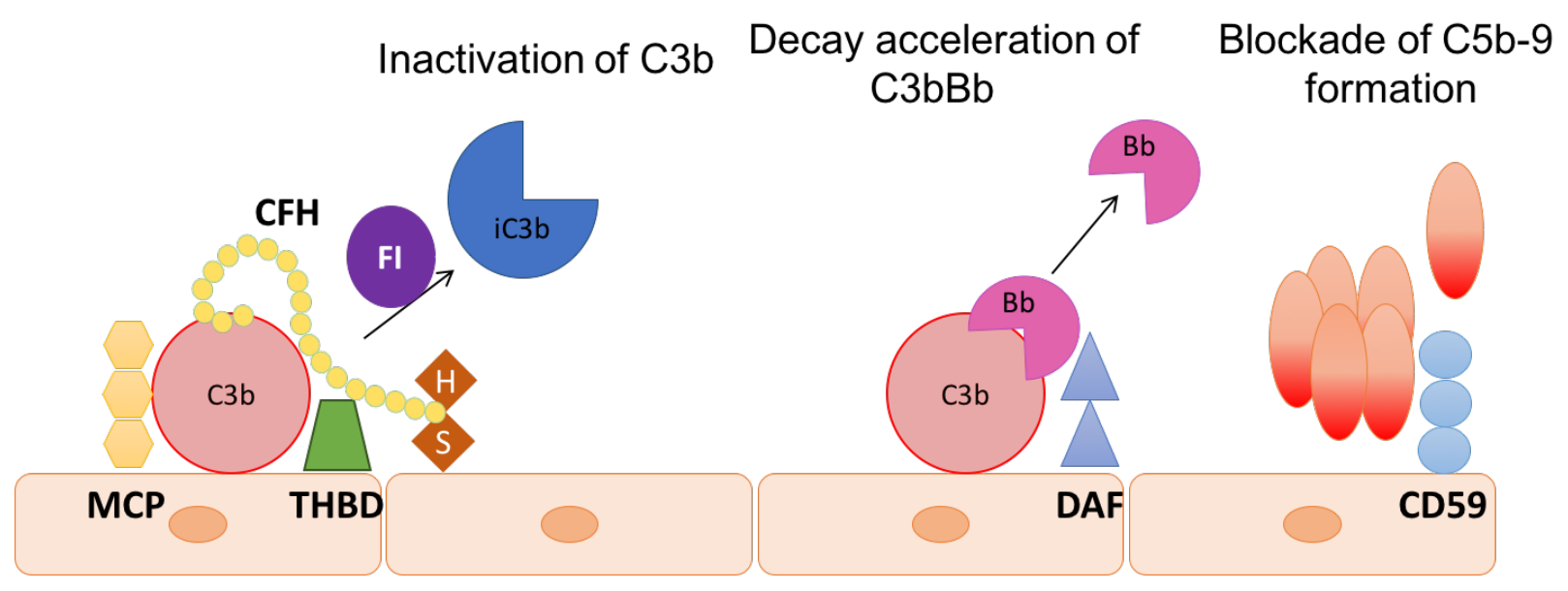

Figure 1.15: The regulation of complement on cell surfaces. Surface complement regulation follows three main principles: (I) inactivation of $\mathrm{C} 3 \mathrm{~b}$ via the serine protease complement factor I (CFI), a step that requires the presence of cofactors, soluble complement factor $\mathrm{H}(\mathrm{CFH})$ and the membrane-bound membrane cofactor protein (MCP/CD46). CFH binds to HS (heparan sulfate and sialic acid within endothelial cells glycocalyx) and C3b. Thrombomodulin (THBD) enhances $\mathrm{CFH}$ in CFI-mediated inactivation of $\mathrm{C} 3 \mathrm{~b}$; (ii) acceleration of the physiological decay of the $\mathrm{C} 3$ convertase $(\mathrm{C} 3 \mathrm{bBb})$ via soluble $\mathrm{CFH}$ and the membrane-bound decay accelerating factor (DAF/CD55); and (iii) blockade of the formation of the membrane attack complex (MAC/C5b-9) via CD59. Reprinted with permission from (Teoh et al., 2016). 


\subsubsection{Functional dynamics of complement factor $\mathrm{H}$ binding and regulation}

Prevention of $\mathrm{C} 3 \mathrm{~b}$ amplification on surfaces of host cells by the alternative pathway is vital to

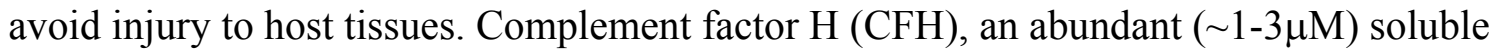
glycoprotein that circulates in blood plays a key role in controlling $\mathrm{C} 3 \mathrm{~b}$ amplification in the fluid phase.(Esparza-Gordillo et al., 2004; Makou et al., 2013; Sofat et al., 2013) In addition, CFH can act on cell surfaces including the extracellular matrix by pattern recognition of host-specific molecular signatures.(Meri and Pangburn, 1990) When recruited to surfaces of cells, CFH competitively (with complement factor B) binds to $\mathrm{C} 3 \mathrm{~b}$, recruiting complement factor I (CFI) for the cleavage of $\mathrm{C} 3 \mathrm{~b}$ to $\mathrm{iC} 3 \mathrm{~b}$.(Pangburn, 2000) $\mathrm{CFH}$ also inhibits the initiation and accelerates the decay of the $\mathrm{C} 3$ convertase (C3bBb).(Weiler et al., 1976; Whaley and Ruddy, 1976) The importance and potency of $\mathrm{CFH}$ as a regulator of the alternative pathway of complement is highlighted by the observations that many microorganisms and neoplastic cells avoid complement-mediated killing by sequestering CFH.(Blom et al., 2009) Mutations and polymorphisms of the CFH gene, as well as auto-antibodies to $\mathrm{CFH}$, affecting its function leads to complement-mediated disorders i.e. atypical hemolytic uremic syndrome.(Ricklin and Lambris, 2013; Ricklin et al., 2016)

$\mathrm{CFH}$ is a $155 \mathrm{kD}$ plasma protein produced predominantly in the liver, but also secreted by endothelial and retinal epithelial cells.(Chen et al., 2007) It consists of 20 complement control proteins (CCP) or short consensus repeats (SCR) domains that are approximately 60 residues in length (Figure 1.16).(Clark et al., 2013; Perkins et al., 2014) Functional regions of CFH containing binding sites for $\mathrm{C} 3$ and its cleavage products $\mathrm{C} 3 \mathrm{~b}, \mathrm{C} 3 \mathrm{c}$ and $\mathrm{C} 3 \mathrm{~d}$, focuses on SCR 14, SCR 12-14 and SCR 19-20.(Schmidt et al., 2008b) CFH SCR 1-4 binds to C3b and acts as a cofactor for CFI-catalyzed cleavage of $\mathrm{C} 3 \mathrm{~b}$ to iC3b (Figure 1.17).(Pangburn and MullerEberhard, 1983) It also has decay accelerating activity for the $\mathrm{C} 3$ convertase $(\mathrm{C} 3 \mathrm{bBb})$.(Gordon et al., 1995; Kuhn and Zipfel, 1996) CFH SCR 19-20 binds with stronger affinity to C3b, and less avidly with iC3b and C3d.(Perkins et al., 2014) When both C3b binding sites (SCR 1-4 and 1920) are occupied, there is tighter CFH binding to C3b.(Makou et al., 2013) C3c (structurally stable fragment of C3b), is proposed to bind to CFH SCR 12-14.(Schmidt et al., 2008b) 


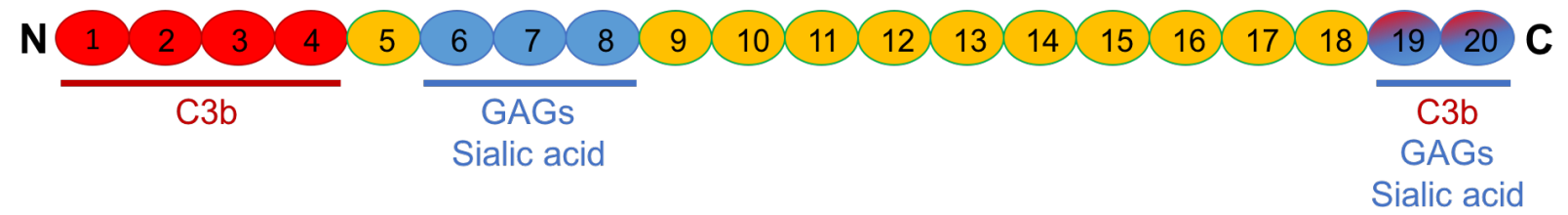

Figure 1.16: Molecular structure of complement factor $\mathbf{H}$ (CFH). CFH consists of 20 short consensus repeats (SCR). Binding sites for C3b are SCR 1-4 and SCR 19-20. Binding sites of glycosaminoglycans (GAGs) and/or sialic acid are SCR 6-8 and SCR 19-20.

\section{Inactivation of $\mathrm{C} 3 \mathrm{~b}$}

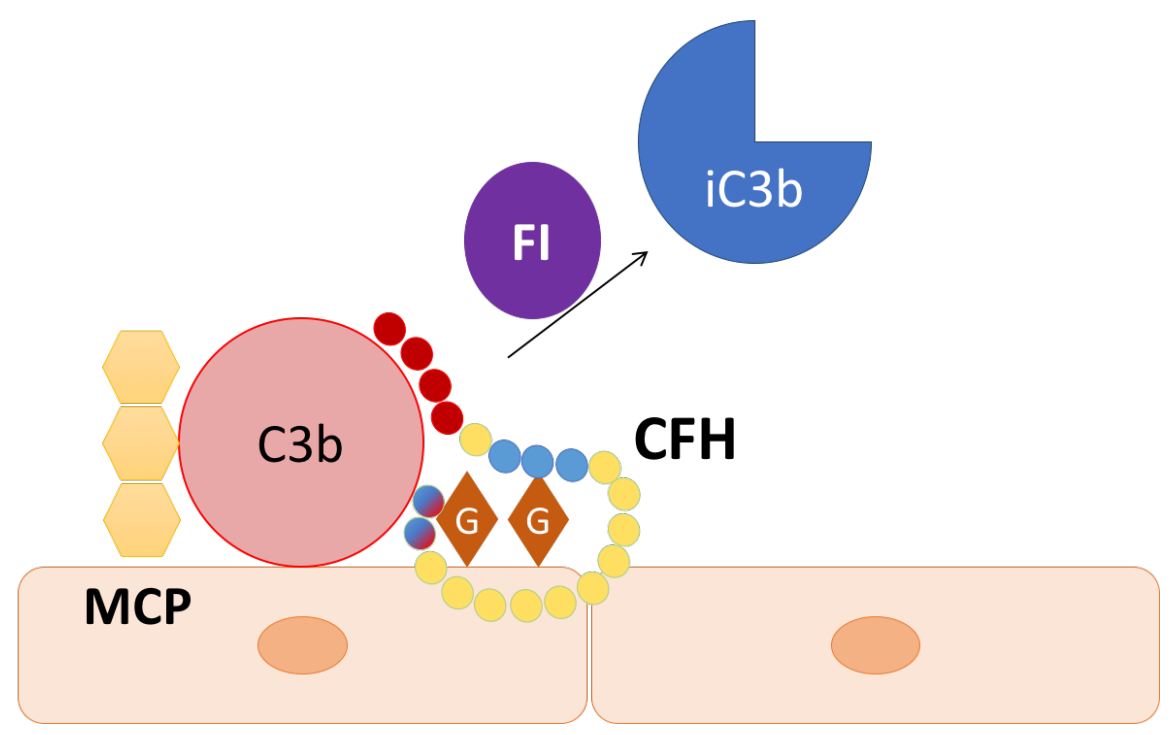

Figure 1.17: Complement factor $\mathrm{H}(\mathrm{CFH})$ as cofactor for complement factor I (CFI)catalyzed cleavage of C3b on endothelial cell surfaces. CFH binds to C3b via SCR 1-4 (red) and to glycosaminoglycans $(\mathrm{G})$ and sialic acid on endothelial cells via SCR 6-8, and SCR 19-20 (blue/red) which binds to both $\mathrm{C} 3 \mathrm{~b}$ and glycosaminoglycans. When bound, CFH acts as a cofactor for CFI-catalyzed cleavage of $\mathrm{C} 3 \mathrm{~b}$ to iC $3 \mathrm{~b}$. 
CFH recognizes and is recruited to the host surfaces mainly via binding of SCR 6-8 and SCR 1920 to glycosaminoglycans and sialic acid clusters within the glycocalyx.(Kazatchkine et al., 1979; Perkins et al., 2014; Schmidt et al., 2008b) This is illustrated by the finding that sheep erythrocytes with intact membrane sialylation were protected by $\mathrm{CFH}$ from complementmediated lysis.(Fearon, 1978; Kazatchkine et al., 1979; Pangburn and Muller-Eberhard, 1978) In these experiments, alternative pathway mediated lysis was dramatically enhanced on cells that were exposed to neuraminidase, a glycoside hydrolase enzyme that hydrolyzes sialic acid.(Coats et al., 2011) CFH bound 10-fold more avidly to sheep erythrocytes in the presence of sialic acid.(Kazatchkine et al., 1979; Pangburn and Muller-Eberhard, 1983) The publication of the crystal structure of CFH SCR 19-20 bound to sialylated trisaccharide and C3d further strengthened the link between CFH and sialic acid binding.(Blaum et al., 2015) Removal of surface sialic acid from cultured endothelial cells by neuraminidase also decreased the ability of recombinant CFH SCR 19-20 to regulate surface C3b.(Hyvarinen et al., 2016) CFH SCR 6-8 and SCR 19-20 (compared to other fragments of CFH) bound most avidly to polyanions such as highly sulfated glycosaminoglycans (heparin, heparan sulfate, and dermatan sulfate), and the full length of CFH is presumed to utilize those 2 sites to bind to glycosaminoglycans.(Clark et al., 2013; Meri and Pangburn, 1994; Saito and Munakata, 2005; Schmidt et al., 2008b) Differential specificities to sulfate likely explains the finding that SCR 19-20 is predominantly responsible for CFH binding to kidney, whereas SCR 6-8 for binding to macula in the eye.(Clark et al., 2013) These data corroborate with the finding that mutations that affect the CFH C-terminal domain impair the function of CFH (not quantitative deficiency of $\mathrm{CFH}$ ) and predispose to atypical hemolytic uremic syndrome.(Ferreira et al., 2009; Herbert et al., 2012; Jozsi et al., 2006; Kavanagh et al., 2013)

The dynamics of the interaction between $\mathrm{CFH}$ and sialic acid and/or glycosaminoglycans remain controversial. The interaction of CFH and heparin was found not to be inhibited by high concentrations of fetuin (a highly sialylated glycoprotein) or colominic acid (a bacterial polysialic acid), suggesting that the glycosaminoglycan heparan sulfate may be a likely ligand on endothelial cells, rather than sialic acid.(Jokiranta et al., 2005) In contrast, removal of glycosaminoglycans from human glomerular tissue sections did not completely abolish the binding of CFH SCR 19-20.(Clark et al., 2013) Although Hyvarinen et.al. showed that removal of sialic acid from endothelial cell surfaces by neuraminidase decreased the ability of CFH SCR 
19-20 to regulate surface $\mathrm{C} 3 \mathrm{~b}$, they stopped short of providing direct evidence of reduced $\mathrm{CFH}$ binding.(Hyvarinen et al., 2016) In addition, the role of heparin in the interaction of CFH SCR 19-20 was not investigated.

\subsubsection{Complement dysregulation is central to thrombotic microangiopathies}

Crucial to the development of TMA is injury to the microvascular endothelium: endothelial cell injury and activation leads to platelet and neutrophil recruitment which eventually leads to thrombus formation, inflammation and subsequent organ failure.(Markiewski et al., 2007; Riedl et al., 2014b; Tsai, 2013) The regulation of complement activation is critical in maintaining endothelial cell integrity. Loss of regulation favours complement activation which results in activation of endothelial cells, neutrophils, platelets and the coagulation cascade.(Camous et al., 2011; Frimat et al., 2009; Markiewski et al., 2007; Teoh et al., 2016) The role of complement dysregulation is increasingly recognised in patients within the spectrum of TMAs. It may be due to a primary complement regulatory defect caused by complement genetic mutations and/or autoantibodies, or secondary to an event which acts to trigger the activation of complement.

In atypical hemolytic uremic syndrome (aHUS), a complement-mediated TMA, genetic mutations in complement regulators (complement factor $\mathrm{H}, \mathrm{CFH}$; complement factor I, CFI; membrane cofactor protein, $\mathrm{MCP} / \mathrm{CD} 46$; thrombomodulin, $\mathrm{THBD}$ ) and activators (complement factor B, CFB; C3), are known to affect 34-53\% of patients.(Bresin et al., 2013; FremeauxBacchi et al., 2013; Loirat and Frémeaux-Bacchi, 2011; Maga et al., 2010; Noris and Remuzzi, 2009) Auto-antibodies to $\mathrm{CFH}$, associated with deletions in complement factor $\mathrm{H}$ related proteins (CFHR1, CFHR3), are also reported in 3-25\% of patients.(Hofer et al., 2013; Loirat, 2014; Moore et al., 2010) In an Indian cohort of aHUS patients, up to 56\% were found to have autoantibodies to CFH.(Sinha et al., 2014) In a predominantly pediatric cohort, mutations in complement regulatory genes or auto-antibodies to $\mathrm{CFH}$ were found in $71 \%$ of familial and $66 \%$ of sporadic cases.(Fremeaux-Bacchi et al., 2013)

Post-renal transplantation, complement genetic abnormalities were found in $68 \%$ of those with recurrent HUS and in 29\% of patients who had de-novo HUS.(Le Quintrec et al., 2008; Le Quintrec et al., 2013) It was also reported in a patient with severe TMA and steroid-, thymoglobulin- and plasmapheresis-resistant acute antibody-mediated rejection.(Noone et al., 2012) 
Complement was also implicated in TMA associated with hematopoietic stem cell transplantation (HSCT): of 9 patients, 3 had auto-antibodies to CFH, and 6 had heterozygous CFHR1 deletion.(Jodele et al., 2014; Jodele et al., 2013) In a more recent prospective study, genetic variants known to play a role in complement activation was found in $65 \%$ of patients with TMA, as compared to $9 \%$ of patients without TMA post-HSCT.(Jodele et al., 2016)

Complement-mediated TMA is also known to occur in association with glomerular disorders. In patients with systemic lupus erythematosus, up to $24 \%$ of renal biopsies were found to have TMA (4\% of patients had systemic features of TMA).(Chen et al., 2011; Song et al., 2013) In a cohort of patients with IgA nephropathy, 53\% had TMA lesions on biopsy and $12 \%$ with laboratory evidence of TMA.(El Karoui et al., 2012) In anti- neutrophil cytoplasmic antibodies (ANCA)-associated vasculitis, $\mathrm{C} 5 \mathrm{a}$ and $\mathrm{C} 5 \mathrm{a}$ receptor $(\mathrm{C} 5 \mathrm{aR} / \mathrm{CD} 88)$ play a key pathogenetic role.(Furuta and Jayne, 2013; Halbwachs and Lesavre, 2012; Jayne et al., 2017; Kettritz, 2014) C5a, acting on the C5aR is a potent neutrophil chemoattractant.(Hammerschmidt et al., 1981) In the presence of ANCA, C5a can lead to a decrease in neutrophil deformability, which in turn slows their ability to migrate across small blood vessels.(Tse et al., 2005) C5a can activate neutrophils,(Schreiber et al., 2009) which themselves can release more C5a in response to inflammatory cytokines such as TNFa.(Camous et al., 2011) C5a also activated endothelial cells leading to retraction and increased vascular permeability.(Foreman et al., 1994; Schraufstatter et al., 2002) Complement-mediated TMA was a feature in approximately $15 \%$ of patients with ANCA-associated vasculitis.(Manenti et al., 2013; Manenti et al., 2015) In up to 50\% of patients with C3 glomerulopathy, mutations of, or antibodies to the alternative pathway complement components were found.(Barbour et al., 2016; Medjeral-Thomas et al., 2013; Pickering et al., 2013; Skerka et al., 2009) Complement abnormalities have also been described in patients with focal segmental glomerulosclerosis (Benz et al., 2007; Bokenkamp et al., 1992) and membranous nephropathy.(Noris et al., 2010)

Complement abnormalities were also detected in $86 \%$ of patients with pregnancy-associated HUS,(Fakhouri et al., 2010) in 43\% of patients with cobalamin C deficiency,(Bouts et al., 2010; Geraghty et al., 1992; Komhoff et al., 2013) and in malignant hypertension.(Totina et al., 2013) Complement also has a role in medication-related TMAs. Variants of CFH were found in 4 patients with ticlopidine-associated TTP.(Chapin et al., 2013) Mutation in MCP/CD46 was found in a child with TMA following cisplatin and carboplatin therapy.(Gilbert et al., 2013) CFH risk 
polymorphisms were found in a patient with CNI-induced thrombotic microangiopathy postkidney transplant.(Cortina et al., 2015)

\subsubsection{Genetic susceptibility predispose to manifestation with thrombotic microangiopathy}

Genetic mutations in complement regulators and activators (as described above) increase the patient's susceptibility to develop TMA events.(Dragon-Durey et al., 2005; Loirat and Frémeaux-Bacchi, 2011; Mele et al., 2014; Noris and Remuzzi, 2009; Rodriguez de Cordoba et al., 2014) There is however variable penetrance described in patients within a pedigree who carry complement mutations, suggesting a 'multiple-hit hypothesis' whereby an environmental hit may be necessary to trigger TMA manifestation in a genetically susceptible patient (Figure 1.18).(Rodriguez de Cordoba et al., 2014) Among events that precede the onset of TMA are respiratory and gastrointestinal tract infections, and pregnancy.(Fakhouri et al., 2010; Loirat and Frémeaux-Bacchi, 2011) TMA post-transplant is associated with ischemia-reperfusion injury, antibody-mediated rejection, and immunosuppressive medications (calcineurin inhibitors).(Cortina et al., 2015; Noone et al., 2012; Noris and Remuzzi, 2010; Ponticelli, 2014; Sacks and Zhou, 2012) However, the understanding of the complex interplay between genetic mutations and environmental triggers remain incompletely understood. 


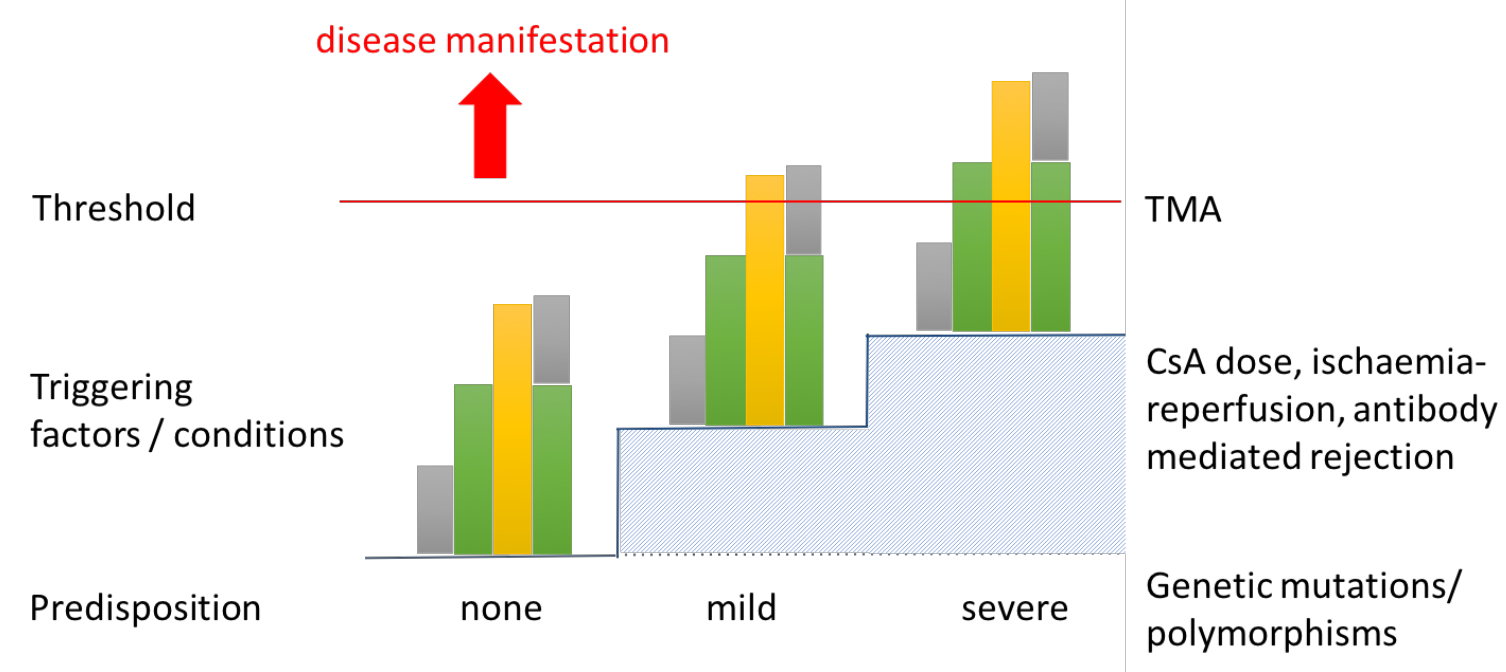

Figure 1.18: Multiple hit hypothesis for TMA pathogenesis. TMA disease manifestation is the consequence of the combination of genetic predisposition and triggering factors/conditions. Predisposition can be mild or severe, in the form of genetic mutations/polymorphisms, autoimmunity, or as yet unknown host factors. Triggering factors/conditions also range from mild to severe, and can occur alone or in combination i.e. exposure to medications, ischaemiareperfusion injury, antibody-mediated rejection, pregnancy, infections, metabolic diseases, and glomerulopathies. Figure adapted with permission from (Riedl et al., 2014a). 


\subsubsection{Implications for a role for complement in calcineurin inhibitor toxicity}

As previously discussed in Section 1.1, CNI use is associated with nephrotoxicity, vascular toxicity, endothelial cell injury and the development of TMA which has a significant negative impact on transplant allograft survival and patient outcomes.(Al-Nouri et al., 2015; Ali et al., 2013; Bren et al., 2005; Caires et al., 2012; Cortina et al., 2015; Furmanczyk et al., 2009; Gray and Ameduri, 2016; Lin et al., 2003; Parissis et al., 2010; Ponticelli, 2007; Said et al., 2010; Zarifian et al., 1999) Evolving evidence suggest a central role for complement dysregulation in the pathogenesis of microvascular endothelial injury which is crucial for the development of TMA. The interplay between an individual's genetic predisposition and triggering factors accumulated through life may account for clinical manifestations with TMA.(Riedl et al., 2014a; Rodriguez de Cordoba et al., 2014; Teoh et al., 2016)

Kidney biopsy findings from patients affected by CNI nephrotoxicity show evidence of tubulointerstitial and vascular/arteriolar injury. There's evidence of complement C3 deposition in areas of endothelial injury on immunohistochemistry.(Liptak and Ivanyi, 2006) CFH risk polymorphisms were reported in a patient with CNI-induced thrombotic microangiopathy postkidney transplant.(Cortina et al., 2015) Although CNI-induced TMA can be sub-clinical, manifestation with systemic signs resembling hemolytic uremic syndrome can occur.(Ali et al., 2013; Caires et al., 2012; Furmanczyk et al., 2009; Gray and Ameduri, 2016; Parissis et al., 2010; Said et al., 2010)

Renner et.al. recently showed in vivo and in vitro evidence for cyclosporine-induced endothelial cell release of alternative pathway-activating microparticles that lead to bystander endothelial cell injury, and complement-mediated kidney and vascular injury in mice.(Renner et al., 2013) In that study, wild-type mice exposed to cyclosporine were shown to have worse renal function, systemic vascular injury (as measured by serum asymmetric dimethylarginine, ADMA levels), and glomerular injury (as evidenced by mesangial proliferation and expansion, hyaline deposition at vascular poles and increased glomerular $\mathrm{C} 3$ deposition). In contrast, factor B deficient (fB-/-) mice were mitigated from cyclosporine-induced nephro-, vascular-, and glomerular toxicity, suggesting a role for intraglomerular complement activation via the alternative pathway in cyclosporine-treated mice.(Renner et al., 2013) Exposure of murine 
endothelial cells that were treated with cyclosporine to serum also caused C3 deposition on the cells, C3a generation and complement-mediated cell lysis.

\subsection{Blood outgrowth endothelial cells (BOEC)}

\subsubsection{Introduction to blood outgrowth endothelial cells}

Blood outgrowth endothelial cells (BOEC) are progenies of endothelial colony-forming cells (ECFC) isolated from circulating peripheral blood mononuclear cells (PBMC) (Figure 1.19).(Hebbel, 2017; Lin et al., 2000)These cells are considered by some to be true endothelial cell precursors, with a distinct transcript signature compared to early endothelial progenitor cells (EPCs), and have a high proliferative potential. Populations of BOECs can be expanded over multiple passages for up to 4 months with retention of their endothelial cell genotypic and phenotypic traits, without undergoing any transformation.(Fuchs et al., 2010; Fuchs et al., 2006; Timmermans et al., 2009) The origins of their precursor, the ECFC, has yet to be clarified, but the prevailing argument is that they are marrow-derived.(Hebbel, 2017; Lin et al., 2000) As they phenotypically resemble mature ECs, but with a much greater proliferative potential, it remains possible that they originate from blood vessels in vivo.(Tura et al., 2013) 


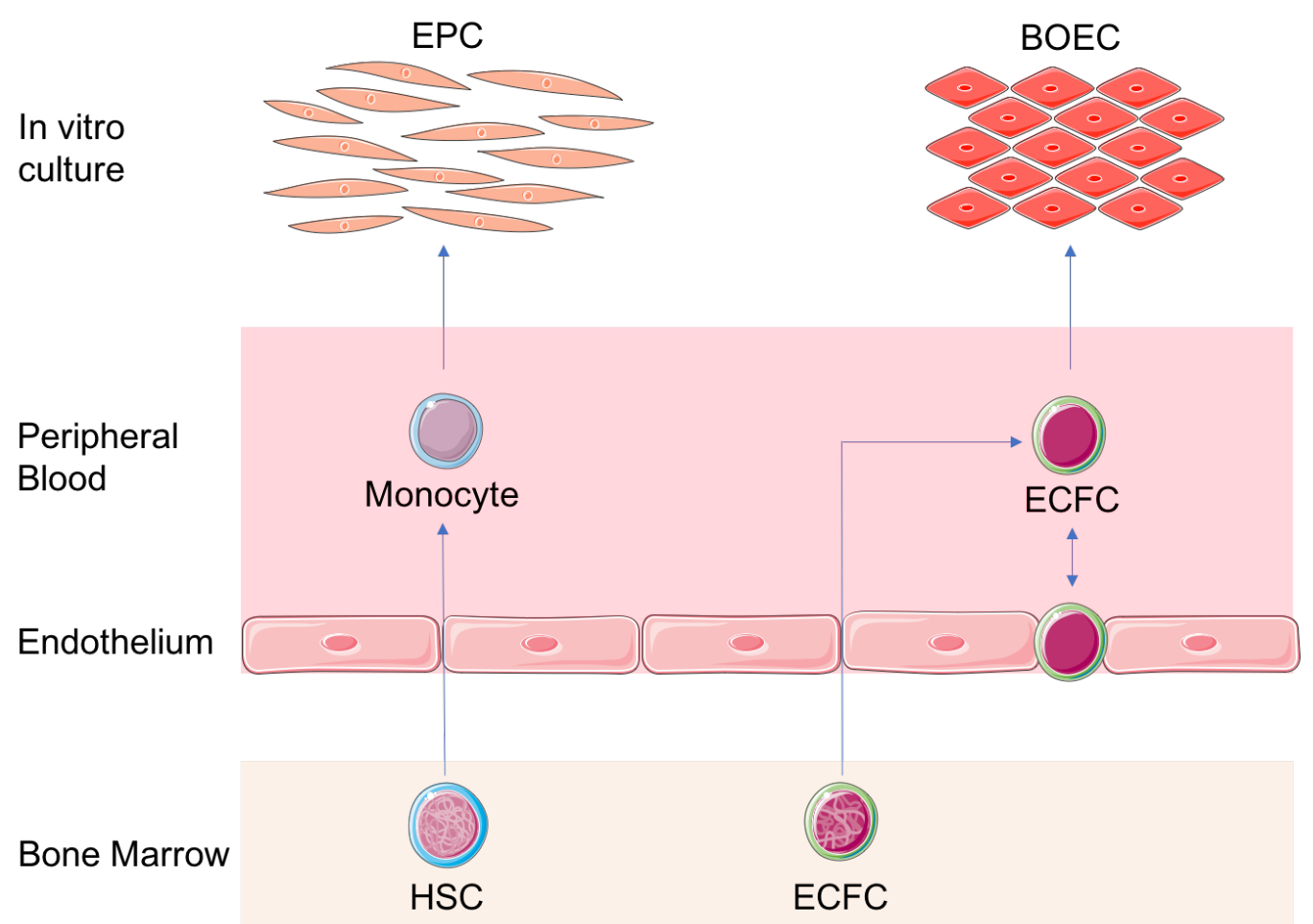

Figure 1.19: Blood outgrowth endothelial cells, origins and culture. Blood outgrowth endothelial cells (BOEC) are the progeny of endothelial colony-forming cells (ECFC), a marrow-derived progenitor cell that are found in blood and within in situ endothelium. BOECs in culture have all the characteristics of mature endothelial cells. The other relevant cell appearing from culture of peripheral blood mononuclear cells are endothelial progenitor cells (EPC) which are of hematopoietic stem cell (HSC) origin, with limited proliferative potential and an inability to produce endothelial cells. Figure adapted with permission from (Hebbel, 2017) 


\subsubsection{The utility of blood outgrowth endothelial cells to study endothelial disease}

BOECs are useful in studies of vascular disease. Several genes related to endothelial biology that may influence susceptibility to shear stress and cardiovascular disease were detected in expression array analysis of BOECs.(Ahmann et al., 2011; Ensley et al., 2012; Mazzolai et al., 2011) Trancriptome analysis of BOECs isolated from patients with proliferative diabetic retinopathy, with diminished migratory capacity and integration into the retinal endothelium revealed upregulation of disease-relevant genes.(Tan et al., 2010) BOECs can be used to model in vitro studies of cell-cell interaction under pathological conditions such as ischemiareperfusion and high shear stress. High numbers of BOECs that bear close affinities to their donor's vascular endothelial cells can be easily isolated from relatively small volumes of peripheral blood.(Martin-Ramirez et al., 2012; Reinisch et al., 2009) BOECs have been used in a model to study the functional symbiosis between glomerular endothelium and epithelium mediated by VEGF secreted by podocytes.(Hirschberg et al., 2008) In models relating to thrombotic disease, BOECs under shear stress were found to alter their cytoskeletal structure and antithrombogenic potential (Ensley et al., 2012), and showed altered expression of receptors for urokinase, tissue plasminogen activator and various adhesion molecules.(Ahmann et al., 2011; Mazzolai et al., 2011) BOECs have been used to study the effects of genes expressed in endothelial cells i.e. von Willebrand factor (vWF) deficiency.(Groeneveld et al., 2015; Noone et al., 2016; Othman et al., 2010; Wang et al., 2013) There is evidence that suggest BOECs and other EPCs enhances the recovery from thrombotic diseases like cerebrovascular accidents (CVA).(Yang et al., 2012a) In the field of regenerative medicine, several groups have experimented with the therapeutic potential of BOEC and EPC transplantation, antithrombotic endothelialization and gene therapy. (Coppens et al., 2013; Hughes et al., 2009; Kaneko et al., 2012; Lin et al., 2002; Yoon et al., 2005)

BOECs are a valuable source for gene expression analysis and the search for disease-associated gene variants. (Fernandez et al., 2005; Medina et al., 2010; Tan et al., 2010) Microarray profiles of BOECs isolated from patients with a defined genetic phenotype can be used to study mechanisms underlying the disease in question at the level of endothelial cells.(Medina et al., 2010) Different subjects exhibit different combinations of polymorphisms that affect endothelial cell gene expression and biologic systems.(Enenstein et al., 2010) Chang Milbauer used BOECs 
from sickle cell patients to study the differences in stroke risk portended by genetically predetermined differences in endothelial biology.(Chang Milbauer et al., 2008) Of note, early expansion stages of BOEC may reveal a transiently acquired phenotype in the context of active disease.(Kahlenberg et al., 2011) For instance, BOEC colonies isolated from burn patients secreted more VEGF than their normal counterparts.(Rignault-Clerc et al., 2013) This transiently acquired phenotype may be washed out as demonstrated by Chang Milbauer, when some upregulated genes returned to normal expression levels after a ten-fold expansion in number of cells.(Chang Milbauer et al., 2008) Expanded BOECs reflect culture conditions and the inherent genotype of the donor.(Dauwe et al., 2016) These cells can remain viable after cryopreservation for up to 2 years at -80 degrees Celcius.(Wagner and Myrup, 2005)

\subsubsection{Blood outgrowth endothelial cells - a relevant model to study thrombotic microangiopathy}

Other endothelial cell lines i.e. human umbilical vein endothelial cells (HUVEC) and glomerular endothelial cells (GEC), have been previously established in experimental studies of the pathogenesis of thrombotic microangiopathy.(Frimat et al., 2013; Louise and Obrig, 1994; Ray et al., 2006) We and others have established the use of BOECs to the study the pathogenesis of thrombotic microangiopathy relatively recently.(Bowman et al., 2017; Noone et al., 2016) BOECs have a robust and stable endothelial cell phenotype over multiple passages, and have great regenerative capacity. Phenotypically BOECs resemble microvascular endothelial cells, making it the ideal cell line to study the pathogenesis of TMA which is a disease of the microvascular endothelium.(Gremmels et al., 2011; Jiang et al., 2007; Toshner et al., 2014) Most importantly, BOECs have the distinct advantage of being isolated from patients, reflecting the specific genetic characteristics of the individual donors, therefore allowing the study of specific patient susceptibility factors.(Hebbel, 2017) 


\subsection{Knowledge gap, hypothesis and thesis aims}

While clinical, kidney biopsy findings and animal models suggest a possible role for complement dysregulation and complement-mediated vascular endothelium injury in the pathogenesis of CNI-induced toxicity, the principal knowledge gap revolves around the explanation of how CNI use can lead to loss of complement regulation on endothelial cell surfaces resulting in complement-mediated injury. While published literature postulate the release of alternative pathway-activating endothelial cell microparticles, induced by cyclosporine, as a mechanism of further propagation of complement-mediated bystander endothelial cell injury, the exact mechanism by which CNI induces complement activation remain poorly understood. The fact that there is variable disease penetrance associated with CNI-induced toxicity suggests that additional insults may be required.

The specific hypothesis tested are:

1. Exposure of endothelial cells to cyclosporine leads to:

a. complement activation and deposition on surfaces of endothelial cells

b. impaired complement regulation on endothelial cell surfaces

2. In an individual with a functionally relevant $\mathrm{MCP} / \mathrm{CD} 46$ mutation leading to an additional complement regulatory defect, acts as an additional insult that increases the susceptibility to cyclosporine-induced complement-mediated endothelial cell injury.

The primary aim of this thesis is to examine whether cyclosporine exposure lead to complementmediated endothelial cell injury and to elucidate the mechanism by which complement dysregulation is induced. To achieve this, we used an in vitro model of disease that utilizes human blood outgrowth endothelial cells (BOEC), because they are an endothelial progenitor cell that can be isolated from patients.

The secondary aim is to evaluate the contribution of an additional complement genetic predisposition, $\mathrm{MCP} / \mathrm{CD} 46$, to the pathogenesis of cyclosporine-induced complement-mediated endothelial cell injury. 


\section{Chapter 2 \\ Materials and Methods}

\section{Materials and Methods}

\subsection{Tissue culture}

\subsubsection{Patient samples}

Blood outgrowth endothelial cells (BOECs) were isolated from the peripheral blood of 3 healthy adult volunteers (control BOECs) and from a patient with atypical hemolytic uremic syndrome secondary to a c.747dupA (p.Ala250Serfs*6) change in the MCP/CD46 gene, a frameshift variant in a gene where loss of function is a known mechanism of disease.

\subsubsection{Blood Outgrowth Endothelial Cells}

Control (healthy donors) and MCP/CD46 deficient (individual with atypical HUS secondary to MCP/CD46 mutation) BOECs were isolated by a standard protocol (Martin-Ramirez et al., 2012; Noone et al., 2016) Briefly, $48 \mathrm{ml}$ of blood was drawn into cell preparation tube (CPT) vacutainers (Becton Dickinson, Franklin Lakes, USA) and mononuclear cell layer was obtained by centrifugation at $1600 \mathrm{G}$ for 30 minutes. Cells were washed twice in 10\% fetal bovine serum (FBS): Sigma-Aldrich, St. Louis, USA) in phosphate buffered saline (PBS, WISENT, St. Bruno, Canada), resuspended in cEGM-2 media with supplements (Lonza, Walkersville, USA: Cat no. 362753 ) and 10\% FBS, and seeded on 6-well tissue culture plates (Becton Dickinson, Franklin Lakes, USA) coated with $0.05 \mathrm{mg} / \mathrm{ml}$ of rat tail collagen type I in $0.02 \mathrm{M}$ glacial acetic acid (Becton Dickinson, Franklin Lakes, USA). The number of cells were quantified using Trypan Blue (Sigma-Aldrich, St. Louis, USA) and a hematocytometer (Hausser Scientific, Horsham, USA): $3-5 \times 10^{7}$ cells were aliquoted into each well in a 6-well tissue culture plate. Cells were maintained at 37 degrees Celcius and in an environment with 5\% carbon dioxide $\left(\mathrm{CO}_{2}\right)$. For the first 7 days after seeding the cells, $3.5 \mathrm{ml}$ of media is aspirated carefully, $2 \mathrm{ml}$ of pre-warmed media is gently added, and then carefully aspirated before replacing with $4 \mathrm{ml}$ of media daily. Thereafter media is replaced on alternate days for 2-3 weeks until other blood cells die off. BOEC monolayers were identified after 1-2 weeks by their endothelial cobblestone morphology. Passages 3 to 14 were used for experiments. 


\subsubsection{Characterizing blood outgrowth endothelial cells by flow cytometry}

Alexa Fluor 488-conjugated mouse anti-human CD31 (PECAM-1) (5 $\mu 1 /$ test), PE-conjugated mouse anti-human CD144 (VE-Cadherin) (12 $\mu 1 /$ test), Alexa Fluor 647-conjugated mouse antihuman CD14 (5 $\mu 1 /$ test) and APC-H7-conjugated mouse anti-human CD45 (3 $\mu 1 /$ test) were used for surface staining of the BOEC, with Alexa Fluor 488 mouse IgG2 $\kappa$, PE mouse IgG1 $\kappa$, Alexa Fluor 647 mouse IgG2b $\kappa$ and APC H7 mouse IgG1 $\kappa$, as isotype controls. Cells were stained with Fixable Viability Dye eFluor 450 (eBioscience, San Diego, USA), fixed with 2\% PFA/PBS and blocked with $200 \mu \mathrm{g} / \mathrm{ml}$ final volume of purified mouse serum IgG (Sigma-Aldrich, St. Louis, USA) prior to specific or isotype antibody incubations. A minimum of 60,000 live cells were collected using a Beckman Coulter Gallios flow cytometer (Beckman Coulter, Brea, USA), equipped with 4 excitation lasers (405nm, $488 \mathrm{~nm}, 561 \mathrm{~nm}, 633 \mathrm{~nm}$ ). Data was analyzed with Kaluza software (Beckman Coulter).

\subsubsection{Characterizing blood outgrowth endothelial cells by immunofluorescence}

BOEC at about $80-90 \%$ confluence were washed once with HBSS (Gibco, Life Technologies, Carlsbad, USA), trypsinized (with $0.05 \%$ trypsin/0.53mM EDTA, WISENT, St Bruno, Canada) then resuspended in cEGM-2 (BOEC) media to a concentration of $0.5 \AA \sim 106$ cells $/ \mathrm{ml} .500 \mu \mathrm{l}$ of the BOEC suspension is added to $2.5 \mathrm{ml}$ of cEGM-2 (BOEC) media already pre-warmed in each well of a 6 -well tissue culture dish containing previously collagen-coated 22x22-mm cover slips (VWR International, Radnor, USA). BOEC adhere to the cover slips after overnight incubation $\left(37^{\circ} \mathrm{C}, 5 \% \mathrm{CO} 2\right)$. Samples were washed with ice-cold PBS then fixed with $4 \%(\mathrm{w} / \mathrm{v})$ paraformaldehyde (Electron Microscopy Sciences, Fort Washington, USA) in PBS. Samples were blocked with 2\% (w/v) donkey serum (Jackson ImmunoResearch, West Grove, USA) either alone or with $0.2 \%(\mathrm{v} / \mathrm{v})$ Triton X-100 (for permeabilization) for 60 minutes. Samples were stained overnight with the relevant primary antibodies made up in the relevant blocking solution. Samples were washed in PBS and incubated with respective donkey-anti secondary antibodies with Alexa Fluor ${ }^{\circledR} 488$ conjugate (Invitrogen, Life Technologies, Carlsbad, USA). Cell nuclei were stained by either DAPI $(1 \mu \mathrm{g} / \mathrm{ml})$ or $0.12 \mu \mathrm{g} / \mathrm{ml}$ Hoechst stain (Thermo Fisher Scientific, Waltham, USA) for ten minutes. Samples were washed in PBS and cover slips were mounted with Dako Fluorescence Mounting Media (Dako, Glostrup, Denmark) for analysis with either a Nikon Eclipse Ti microscope (Leika Microsystems, Wetzlar, Germany) or spinning disk 
confocal microscopy. The latter is equipped with an Olympus IX81 inverted fluorescence microscope using a 60./1.35 oil immersion objective equipped with a Hamamatsu C9100-13 back-thinned EMCCD camera and Yokogawa CSU X1 spinning disk confocal scan head (with upgrade from Spectral Aurora Borealis, Richmond Hill, Canada). The unit is equipped with 4 separate diode-pumped solid state laser lines (Spectral Applied Research, Richmond Hill, Canada, $405 \mathrm{~nm}, 491 \mathrm{~nm}, 561 \mathrm{~nm}$, and $642 \mathrm{~nm}$ ) with emission filters: $447 \mathrm{~nm} \pm 60,525 \mathrm{~nm} \pm 50$, $593 \mathrm{~nm} \pm 40,620 \mathrm{~nm} \pm 60,676 \pm 29$ and $700 \mathrm{~nm} \pm 75$, and 1.5X magnification lens (Spectral Applied Research). Confocal images were taken with an Improvision Piezo Focus Drive. Zstacks were taken at $0.25 \mu \mathrm{m}$. Images taken using the spinning disk confocal microscope were deconvolved by iterative restoration using Volocity Software (PerkinElmer, Waltham, USA) with confidence limit set to $95 \%$ and iteration limit set to 20 .

The following antibodies were used for IF: sheep anti-human VWF (1:1000 dilution, Abd Serotec, Oxford, UK, AHP062), goat anti-human P-selectin (CD62P, 1:100 dilution; Santa Cruz Biotechnology, Dallas, USA; sc-6943), rabbit polyclonal antibody to MCP (1:50 dilution; Santa Cruz Biotechnology, Dallas, USA; sc-9098,), rat polyclonal antibody to CD59 (1:1000 dilution; Abd Serotec, Oxford, UK; MCA715G), and goat polyclonal antibody to CD55 (1:50 dilution; R\&D Systems, Minneapolis, USA; AF2009). Nuclei of cells were stained with $0.12 \mu \mathrm{g} / \mathrm{ml}$ Hoechst stain (Thermo Fisher Scientific, Waltham, USA) for ten minutes. All secondary antibodies utilized were conjugated to either Alexa Fluor 488 or Alexa Fluor 555 (Life Technologies, Carlsbad, USA) dyes.

\subsubsection{Preparation of lysates of Blood Outgrowth Endothelial Cells}

Fully confluent BOECs were lysed using RIPA buffer with 2x protease inhibitor cocktail (Roche). 


\subsection{Cyclosporine ( $\mathrm{Cs} A)$ treatment and complement fixation on BOEC surfaces}

BOECs were cultured to confluence in 6-well plates and then exposed to treatment either with media (control), CsA $10 \mu \mathrm{g} / \mathrm{ml}$, CsA $20 \mu \mathrm{g} / \mathrm{ml}$, CsA $50 \mu \mathrm{g} / \mathrm{ml}$ or CsA $100 \mu \mathrm{g} / \mathrm{ml}$ for up to 24 hours, depending on experiments. CsA stock solution (Sandimmune ${ }^{\circledR}$ IV, Novartis, 50 mg/ml) was kindly provided by the pharmacy at the Hospital for Sick Children, Toronto, Canada, was reconstituted with media to prepare the various concentrations of CsA used in experiments. For experiments involving complement fixation on BOEC surfaces, they were then sequentially exposed to $50 \%$ normal human serum (NHS) [1:1 in serum free media (SFM)] for 30 minutes. In certain experiments that utilise antibodies specifically blocking the membrane-anchored complement regulator CD59 (BRIC229, IgG2b, International Blood Group Reference Laboratory, NHS Blood and Transplant, Bristol, UK), cells were incubated with the respective blocking antibody prior to exposure to $50 \%$ NHS. Blocking antibody was used at a concentration of $5 \mu \mathrm{g} / \mathrm{ml}$, diluted in SFM for 30 minutes in all experiments. The concentration of blocking antibodies used and the sequence of incubation was derived from a previously established method of complement fixation on BOECs.(Noone et al., 2016)

\subsection{Cell cytotoxicity/LDH assay}

To assess the effect of CsA treatment on cell cytotoxicity, we utilized a commercially available LDH cytotoxicity assay kit. Cells were seeded overnight in a 96 well ELISA plate (Sarstedt) to confluence. Cells were then treated with various concentrations of CsA for up to 24 hours. Pierce LDH cytotoxicity assay kit (Thermo Fisher Scientific, Waltham, USA) was used according to the manufacturer's instructions. OD was normalized to positive control and displayed in percent.

\subsection{Flow Cytometry}

\subsubsection{Antibodies used for flow cytometry}

The following primary antibodies were used for flow cytometry: Alexa Fluor 488 conjugated mouse anti-human CD31 (PECAM-1) [5 $\mu \mathrm{l} /$ test], PE conjugated mouse anti-human CD144 (VECadherin) [12 $\mu 1 /$ test], Alexa Fluor 647 conjugated mouse anti-human CD14 [5 $\mu 1 /$ test] and APC-H7 conjugated mouse anti-human CD45 [3 $\mu 1 /$ test] were used for surface staining of BOECs, with Alexa Fluor 488 mouse IgG2 $\kappa$, PE mouse IgG1 $\kappa$, Alexa Fluor 647 mouse IgG2b 
$\kappa$ and APC $\mathrm{H} 7$ mouse IgG1 $\kappa$, as isotype controls. Antibodies were purchased from BD Pharmigen (San Diego, USA).

For detection of complement regulators, we used rabbit anti-CD46, 1:50 dilution (Santa Cruz Biotechnology, Dallas, USA, sc-9098); goat anti-CD55, 1:100 dilution (R\&D Systems, Minneapolis, USA, AF2009); and rat anti-CD59, 1:100 dilution (AbD Serotec, Oxford, UK, MCA715G). Corresponding species-specific secondary Alexa Fluor 488 antibodies were used at a dilution of 1:200.

For detection of complement deposition, we used a rabbit polyclonal anti-C3c antibody directly conjugated with FITC (abcam, ab4212); and goat anti-C9, 1:100 dilution (Complement Technology Inc, Texas, USA, A226). Anti-goat secondary Alexa Fluor 488 antibody was used at a dilution of 1:200.

We used purified CFH (CSL Behring, Marburg, Germany) that was tagged with Alexa Fluor 488 (concentration $2 \mathrm{mg} / \mathrm{mL}$ ). For each $100 \mu \mathrm{L}$ of cell suspension, we added $2 \mu \mathrm{L}$ (4 $\mu \mathrm{g}$ ) of Alexa Fluor 488-tagged CFH.

Fixable Viability Dye eFluor780 (eBioscience, San Diego, USA, 1:1000 dilution reconstituted in PBS) was used to label dead cells.

\subsubsection{Flow cytometry for C3 deposition}

$\mathrm{C} 3 \mathrm{c}$ deposition was demonstrated by FACS using an antibody to $\mathrm{C} 3 \mathrm{c}$ detecting the $\mathrm{C} 3 \mathrm{c}$ portion of native $\mathrm{C} 3$ and $\mathrm{C} 3 \mathrm{~b}$. Cells were cultured to confluence on 6-well plates and exposed to cyclosporine treatment and complement fixation as described. Cells were washed twice with phosphate-buffered saline (PBS) and incubated with Fixable Viability Dye eFluor780 (eBioscience, San Diego, USA, 1:1000 dilution reconstituted in PBS) at 4 degrees Celcius for 30 minutes. They were then washed once with PBS, scraped off and washed again with PBS. The primary antibody (C3c-FITC conjugated antibody, abcam, ab4212, 1:50 dilution) was reconstituted in PBS and incubated at 4 degrees Celcius for 30 minutes. At least 10,000 events of BOEC population were recorded using Attune Acoustic Focusing Cytometer (Life Technologies) and analysed using FlowJo software (Version 10.2; FlowJo, LLC, Ashland, USA). Results are expressed as median fluorescence intensity (MFI). Cells were gated for live cells (red laser 536 $\mathrm{nm}$, emission channel 2), single cells (FSC-A vs FSC-H) and finally through forward scatter and 
side scatter to determine the BOEC population. C3c-FITC was recorded via blue laser $488 \mathrm{~nm}$, emission channel 1. Color compensation was performed each time to correct for spectral overlap during multicolour flow cytometry experiments.

\subsubsection{Flow cytometry for C9 deposition}

C9 deposition was demonstrated by FACS using an antibody to C9. Cells were cultured to confluence on 6-well plates and exposed to cyclosporine treatment and complement fixation as described. Cells were washed twice with phosphate-buffered saline (PBS) and incubated with Fixable Viability Dye eFluor780 (eBioscience, San Diego, USA, 1:1000 dilution reconstituted in PBS) at 4 degrees Celcius for 30 minutes. They were then washed once with PBS, scraped off and washed again with PBS. The primary antibody (goat anti-C9, Complement Technologies Inc, Texas, USA, A226, 1:100 dilution) and species-specific secondary antibody were reconstituted in PBS and incubated at 4 degrees Celcius for 30 minutes. At least 10,000 events of BOEC population were recorded using Attune Acoustic Focusing Cytometer (Life Technologies) and analysed using FlowJo software (Version 10.2; FlowJo, LLC, Ashland, USA). Results are expressed as median fluorescence intensity (MFI). Cells were gated for live cells (red laser 536 $\mathrm{nm}$, emission channel 2), single cells (FSC-A vs FSC-H) and finally through forward scatter and side scatter to determine the BOEC population. C9 was recorded via blue laser $488 \mathrm{~nm}$, emission channel 1. Color compensation was performed each time to correct for spectral overlap during multicolour flow cytometry experiments.

\subsubsection{Flow cytometry for membrane-bound complement regulators (MCP/CD46, DAF/CD55, CD59)}

Expression of surface-bound complement regulators on BOECs were demonstrated by FACS using antibodies to CD46, CD55 and CD59. Cells were cultured to confluence on 6-well plates and exposed to cyclosporine as described. The cells were subsequently washed once in Hank's balanced salt solution (HBSS) and then trypsinized for 3 minutes. Cells were first incubated with the respective primary antibodies, washed with PBS and subsequently incubated with speciesspecific secondary Alexa Fluor 488 antibodies and Fixable Viability Dye eFluor780 (eBioscience, San Diego, USA, 1:1000 dilution reconstituted in PBS). The primary and secondary antibodies were reconstituted in PBS and incubated at 4 degrees Celsius for 30 minutes. At least 10,000 events of BOEC population were recorded using Attune Acoustic 
Focusing Cytometer (Life Technologies) and analysed using FlowJo software (Version 10.2; FlowJo, LLC, Ashland, USA). Results are expressed as median fluorescence intensity (MFI). Cells were gated for live cells (red laser $536 \mathrm{~nm}$, emission channel 2), single cells (FSC-A vs FSC-H) and finally through forward scatter and side scatter to determine the BOEC population. CD46, CD55 and CD59 were recorded via blue laser $488 \mathrm{~nm}$, emission channel 1. Color compensation was performed each time to correct for spectral overlap during multicolour flow cytometry experiments.

\subsubsection{Flow cytometry for complement factor $\mathrm{H}$ surface binding}

Binding of $\mathrm{CFH}$ to BOEC surfaces were demonstrated by FACS from a previously described method,(Hyvarinen et al., 2016) using purified CFH (CSL Behring, Marburg, Germany) that was tagged with Alexa Fluor 488. Cells were cultured to confluence on 6-well plates and exposed to cyclosporine as described. Cells exposed to $500 \mathrm{mU} / \mathrm{mL}$ neuraminidase (MilliporeSigma; N2876) were used as negative control. Cells were washed twice with PBS and scraped off. The cells were then incubated with Fixable Viability Dye eFluor780 (eBioscience, San Diego, USA, 1:1000 dilution reconstituted in PBS) at 4 degrees Celcius for 30 minutes. They were then washed with PBS, and resuspended in $100 \mu \mathrm{L}$ of PBS. Each sample was then incubated with 4 $\mu \mathrm{g}$ of Alexa Fluor 488-tagged CFH for 1 min, after which 500-1000 $\mu \mathrm{L}$ of Attune focusing fluid (Thermo Fisher Scientific, 4449791) was added. At least 10,000 events of BOEC population were recorded using Attune Acoustic Focusing Cytometer (Life Technologies) and analysed using FlowJo software (Version 10.2; FlowJo, LLC, Ashland, USA). Results are expressed as mean fluorescence intensity (MFI). Cells were gated for live cells (red laser $536 \mathrm{~nm}$, emission channel 2), single cells (FSC-A vs FSC-H) and finally through forward scatter and side scatter to determine the BOEC population. Alexa Fluor 488-conjugated CFH was recorded via blue laser $488 \mathrm{~nm}$, emission channel 1. Color compensation was performed each time to correct for spectral overlap during multicolour flow cytometry experiments. 


\subsection{Western blot}

\subsubsection{Antibodies used for Western blot}

For detection of complement regulators, we used rabbit anti-CD46, 1:500 dilution (Santa Cruz

Biotechnology, Dallas, USA, sc-9098); goat anti-CD55, 1:2000 dilution (R\&D Systems, Minneapolis, USA, AF2009); and rat anti-CD59, 1:1000 dilution (AbD Serotec, Oxford, UK, MCA715G). Mouse anti-glyceraldehyde 3-phosphate dehydrogenase (GAPDH), 1:2000 dilution (EMD Milipore, MAB374) was used as loading control. Corresponding species-specific secondary HRP-conjugated antibodies were used at a dilution of 1:2000 for anti-CD46 and antiCD59; dilution of 1:3000 for anti-CD55; and dilution of 1:5000 for anti-GAPDH.

\subsubsection{Western blot for membrane-bound complement regulators (MCP/CD46, DAF/CD55, CD59)}

Cells were cultured to confluence on 6-well plates and exposed to cyclosporine as described.

Cells were then lysed using RIPA buffer with 2x protease inhibitor cocktail (Roche). The amount of protein in each sample were quantified with a bicinchoninic acid (BCA) assay. Cell lysates $(10 \mu \mathrm{g})$ were then separated by $15 \%$ SDS-PAGE under non-reducing conditions and subsequently transferred onto a nitrocellulose membrane which was blocked with 5\% milk. The primary antibodies we used to detect surface complement regulators were rabbit anti-CD46, 1:500 dilution (Santa Cruz Biotechnology, Dallas, USA, sc-9098); goat anti-CD55, 1:2000 dilution (R\&D Systems, Minneapolis, USA, AF2009); and rat anti-CD59, 1:1000 dilution (AbD Serotec, Oxford, UK, MCA715G). Mouse anti-GAPDH, 1:2000 dilution (EMD Milipore, MAB374) was used as loading control. Corresponding species-specific secondary HRPconjugated antibodies were used at a dilution of 1:2000 for anti-CD46 and anti-CD59; dilution of 1:3000 for anti-CD55; and dilution of 1:5000 for anti-GAPDH. Membranes were imaged with the Odyssey® Fc Imaging System. Mean gray area of each band was measured with ImageJ software (Wayne Rasband, National Institutes of Health, USA). 


\subsection{Complement factor $\mathrm{H}(\mathrm{CFH})$ cofactor assay}

\subsubsection{Reagents and antibodies used for CFH cofactor assay}

For CFH surface cofactor activity assays, we used purified complement factor H (CSL Behring, Marburg, Germany) at a concentration of $10 \mu \mathrm{g} / \mathrm{ml}$, complement factor I (EMD Milipore Corp., MA, USA, 341280) at a concentration of $10 \mu \mathrm{g} / \mathrm{ml}$, and C3b (EMD Milipore Corp., MA, USA, 204860 ) at a concentration of $3.3 \mu \mathrm{g} / \mathrm{ml}$. For detection of C3 on Western blot, we used goat antiC3, 1:1000 dilution (Complement Technology Inc, Texas, USA, A213) with corresponding antigoat secondary HRP-conjugated antibody at a dilution of 1:5000.

\subsubsection{Complement factor $\mathrm{H}$ surface cofactor activity assay}

To determine CFH cofactor activity on the surfaces (Figure 2.1), BOECs were cultured to confluence, and exposed to cyclosporine as described. Cells exposed to $500 \mathrm{mU} / \mathrm{mL}$ neuraminidase (MilliporeSigma; N2876) were used as negative control. Surface cofactor activity assay was adapted from a previously described method.(Heinen et al., 2007) Cells were subsequently incubated with $10 \mu \mathrm{g} / \mathrm{ml}$ complement factor H (CSL Behring, Marburg, Germany) at 37 degrees Celsius for 1 hour. Cells were then thoroughly washed three times with PBS and incubated with $10 \mu \mathrm{g} / \mathrm{ml}$ complement factor I (EMD Milipore Corp., MA, USA, 341280) and 3.3 $\mu \mathrm{g} / \mathrm{ml} \mathrm{C3b}$ (EMD Milipore Corp., MA, USA, 204860). Supernatant at baseline and various time points (up to $180 \mathrm{~min}$ ) was transferred to reduced sample buffer and separated by $10 \%$ SDSPAGE. The appearance of $\mathrm{C} 3 \mathrm{~b}$ degradation fragments were detected by Western blotting (Figure 2.2 and 2.3). Primary goat anti-C3, 1:1000 dilution (Complement Technology Inc, Texas, USA, A213) with corresponding secondary HRP-conjugated antibody at a dilution of 1:5000 were used. 


\section{Inactivation of $\mathrm{C} 3 \mathrm{~b}$}

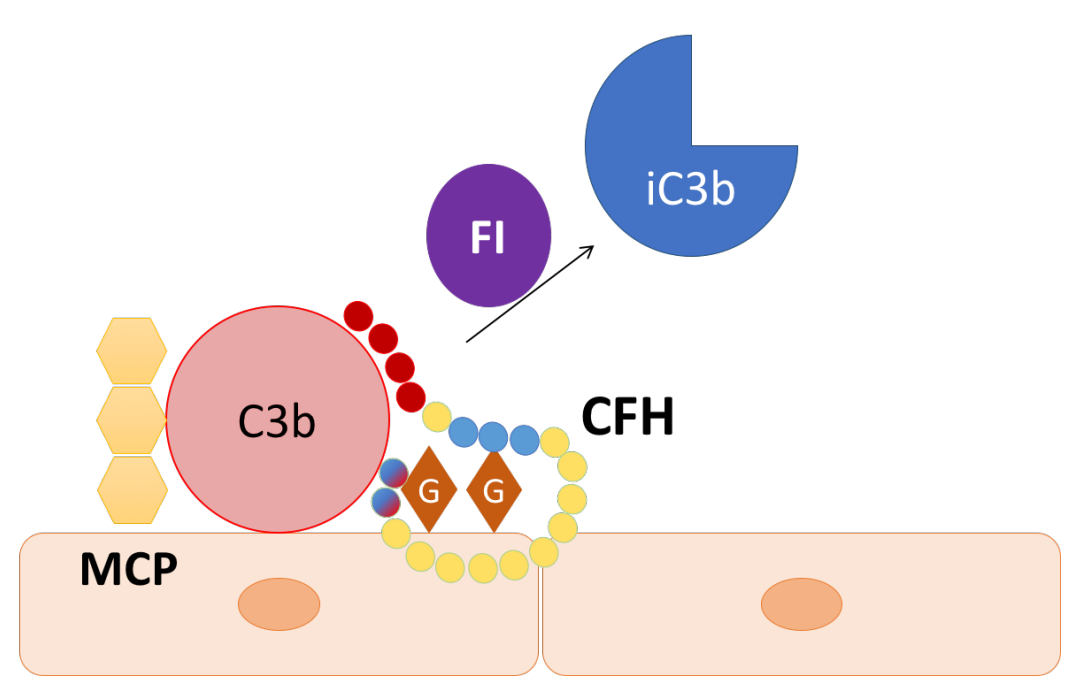

Figure 2.1: Complement factor $\mathrm{H}(\mathrm{CFH})$ cofactor assay on endothelial cell surfaces. When bound to $\mathrm{C} 3 \mathrm{~b}$ and the surface of endothelial cells via glycosaminoglycans and/or sialic acid, $\mathrm{CFH}$ acts as a cofactor for CFI-catalyzed cleavage of $\mathrm{C} 3 \mathrm{~b}$ to iC $3 \mathrm{~b}$. In the surface cofactor assay, endothelial cells are first incubated with CFH $10 \mu \mathrm{g} / \mathrm{ml}$ at 37 degrees Celcius for 1 hour. Cells are then throroughly washed with PBS to remove unbound CFH. Subsequently, cells are incubated with CFI $10 \mu \mathrm{g} / \mathrm{ml}$ and C3b $3.3 \mu \mathrm{g} / \mathrm{ml}$ at 37 degrees Celcius. Supernatant at baseline and various time points (up to $180 \mathrm{~min}$ ) was transferred to reduced sample buffer and separated by $10 \%$ SDS-PAGE. 


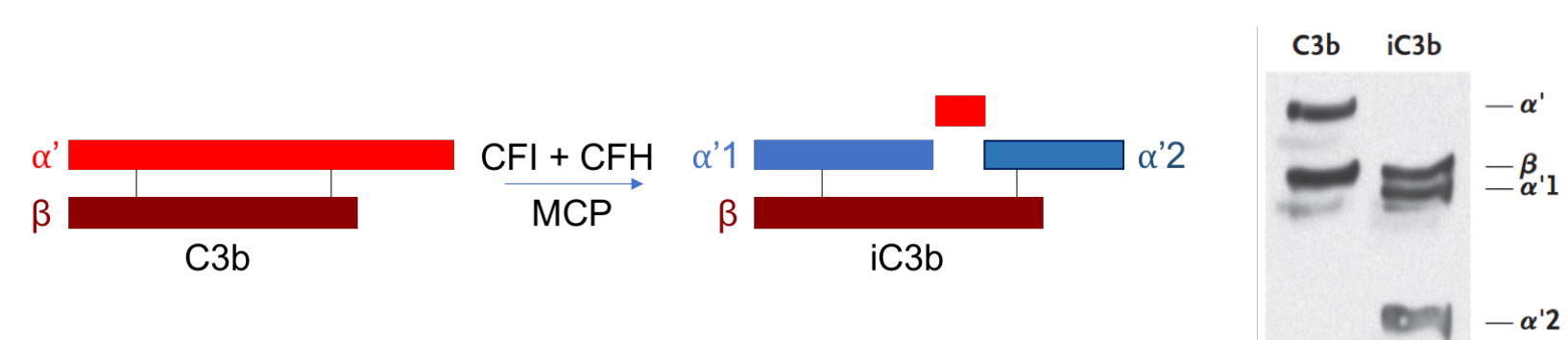

Figure 2.2: Diagram representing cleavage of $\mathrm{C} 3 \mathrm{~b}$ to $\mathrm{iC3b}$ (inactive form) by CFI-catalyzed cleavage in the presence of CFH and MCP. The Western blot image depicts the fragments of reduced purified $\mathrm{C} 3 \mathrm{~b}$ and $\mathrm{iC} 3 \mathrm{~b}$. Figure adapted with permission from (Delvaeye et al., 2009), Copyright Massachusetts Medical Society.

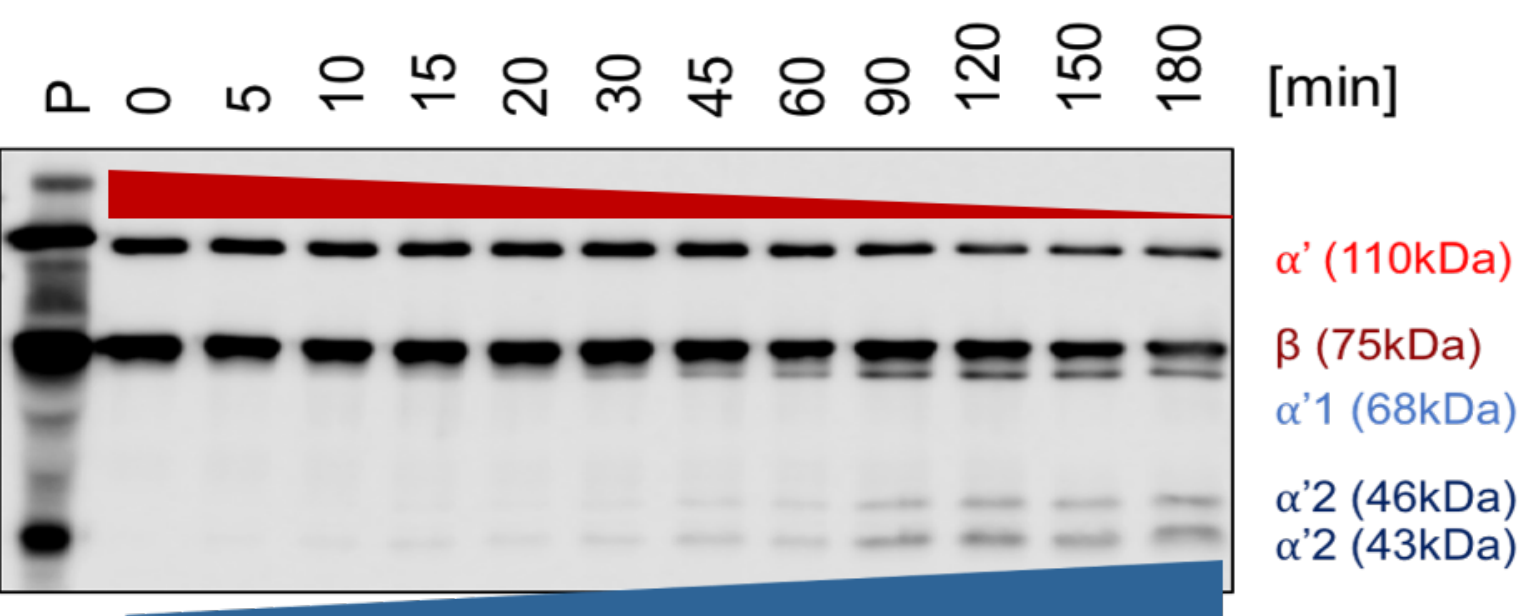

Figure 2.3: Representative Western blot image of CFH cofactor assay. After sequential incubation with $\mathrm{CFH}, \mathrm{CFI}$ and $\mathrm{C} 3 \mathrm{~b}$ as described above, supernatant baseline and at various time points were transferred to reduced sample buffer and separated by $10 \%$ SDS-PAGE. The appearance of $\mathrm{C} 3 \mathrm{~b}$ degradation products were detected by Western blot. As more $\mathrm{C} 3 \mathrm{~b}$ is cleaved to $\mathrm{iC} 3 \mathrm{~b}$ over time, the $\alpha^{\prime}(110 \mathrm{kDa})$ band (representing $\left.\mathrm{C} 3 \mathrm{~b}\right)$ progressively disappears (depicted by the red tapering bar), while there is progressive appearance of the $\alpha$ '2 (46 kDa) and $\alpha^{\prime} 2$ (43 $\mathrm{kDa}$ ) band (representing $\mathrm{iC} 3 \mathrm{~b}$ ) (depicted by the blue widening bar). 


\subsection{Imaging of endothelial cell glycocalyx}

To image BOEC glycocalyx, we used an Alexa Fluor 594-conjugated wheat germ agglutinin (Thermo Fischer Scientific, W11262, dilution 1:500). Cells were cultured to confluence on cover slips (Superior Marienfeld Laboratory Glassware, 0117580, 18 mm, 170 +/- $5 \mu \mathrm{m}$, No. 1.5H), and exposed to cyclosporine as described. Cells exposed to $500 \mathrm{mU} / \mathrm{mL}$ neuraminidase (MilliporeSigma; N2876) were used as negative control. Cells were washed twice with HBSS (Multicell, WISENT, St. Bruno, ON, Canada) and incubated with Alexa Fluor 594-conjugated wheat germ agglutinin (Thermo Fischer Scientific, W11262, $2 \mu \mathrm{g} / \mathrm{ml}$ ) for $5 \mathrm{~min}$ on ice. After incubation, cells were washed twice with ice-cold HBSS and the coverslips were mounted in a Chamlide magnetic chamber (Life Cell Instrument, Seoul, Korea) and overlaid with media.

Images were taken using an IX81 inverted microscope (Olympus Corp., Tokyo, Japan) with a 60/1.35 oil immersion objective and a C9100-13 back-thinned EM-CCD camera (Hamamatsu Photonics, Hamamatsu City, Shizuoka Pref., Japan) with a CSU X1 spinning disk confocal scan head (Yogokawa, Yokogawa Canada Inc., Alberta, Canada). With an Improvision Piezo Focus Drive $0.4 \mu \mathrm{m}$ slices were captured on Volocity Software (Perkin Elmer) and total fluorescence intensity was measured using ImageJ software (Wayne Rasband, National Institutes of Health, USA).

\subsection{Statistical analysis}

Figures were generated with GraphPad Prism (Version 6.0c; GraphPad Software, La Jolla, USA) and displayed as mean and standard deviation. Statistical analysis was performed using either paired t-test or two-way ANOVA with post-hoc analysis. A p-value of $<0.05$ was considered statistically significant. In the figure legends, p-values are presented as follows: $*<0.05, * *<0.01$. $* * *<0.001, * * * *<0.0001$ (unless otherwise stated).

\subsection{Ethics}

Ethics approval was obtained from the Research Ethics Board of the Hospital for Sick Children, Toronto, Ontario and the study was performed in accordance to the regulations of the Declaration of Helsinki. Written informed consent was obtained from all patients whose samples were used in this study. 


\section{Chapter 3}

\section{Results}

\section{Results}

\subsection{Cyclosporine treatment led to dose and time dependent endothelial cell cytotoxicity}

We first tested whether cyclosporine (CsA) exposure caused endothelial cell (EC) cytotoxicity with a lactate dehydrogenase (LDH) cytotoxicity assay. We found that exposure of ECs to CsA led to a dose- and duration-dependent endothelial cell cytotoxicity (Figure 3.1). An optimal balance of EC survival and CsA effect was obtained with CsA $10 \mu \mathrm{g} / \mathrm{ml}$ exposure for up to 24 hours.

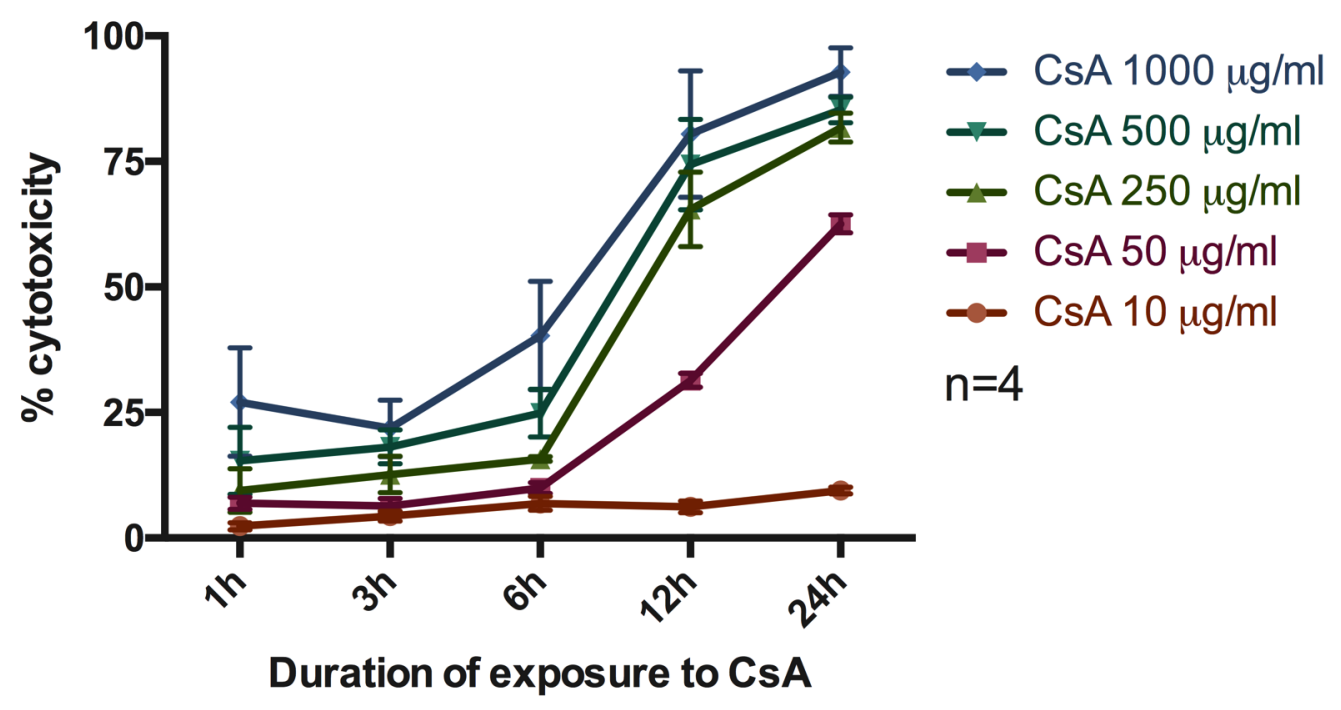

Figure 3.1: Cyclosporine treatment led to dose and time dependent endothelial cell cytotoxicity. EC cytotoxicity detected using LDH assay. Increasing CsA dose and duration of exposure resulted in increased EC cytotoxicity. 


\subsection{Cyclosporine treatment led to increased complement deposition on endothelial cell}

\subsubsection{Cyclosporine treatment led to an increase in C3c deposition on endothelial cell surfaces}

We adapted a previously established in-vitro model for complement-mediated thrombotic microangiopathy using blood outgrowth endothelial cells (BOEC) to examine the consequences of CsA-induced complement activation on EC.(Noone et al., 2016) Unless specified, CsA was reconstituted with media/10\% FBS for all experiments. Confluent monolayers of ECs were incubated in various concentrations of CsA in media/10\% FBS for 24 hours and subsequently exposed to $50 \%$ normal human serum (NHS) in serum-free media (SFM). We found that CsA 50 $\mu \mathrm{g} / \mathrm{ml}$ led to increased complement C3 deposition on EC (Figure 3.2).

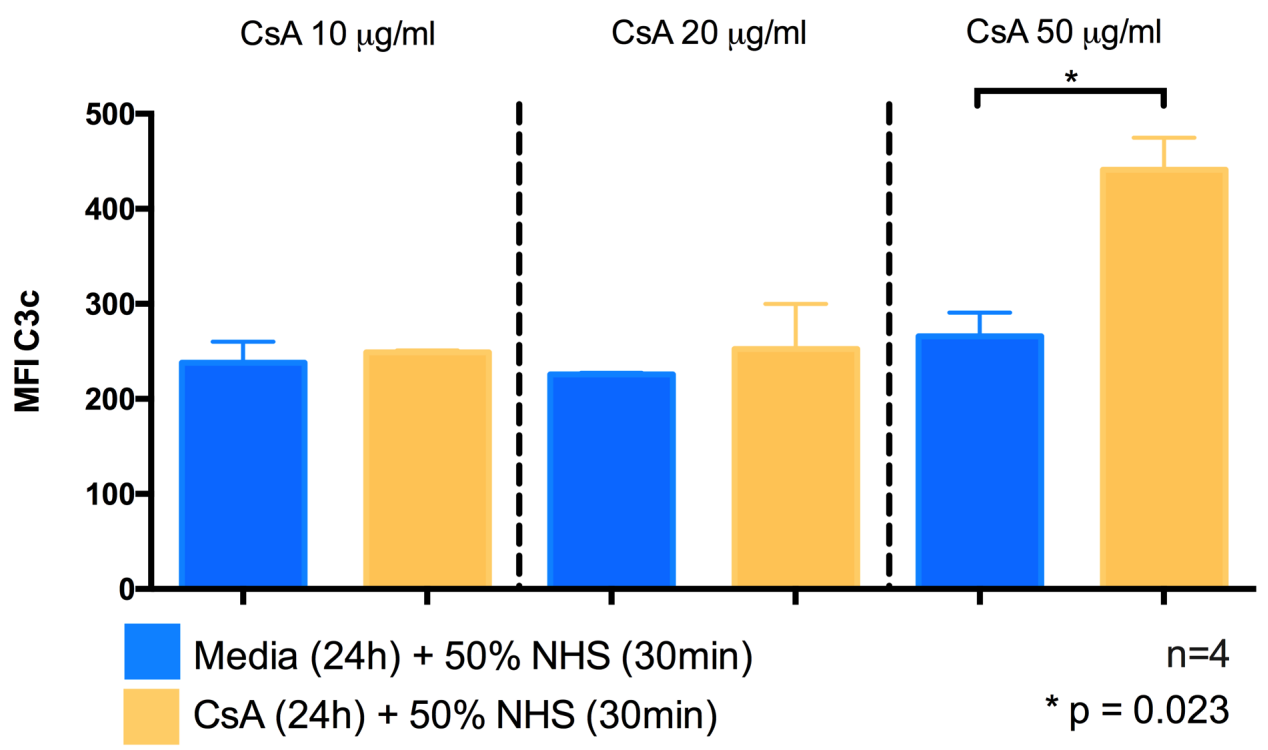

Figure 3.2: CsA led to an increase in complement deposition on EC surfaces. C3c deposition on EC surface by flow cytometry. Non-viable cells excluded from analysis with Fixable Viability Dye eFluor 780. Incubating EC with CsA $50 \mu \mathrm{g} / \mathrm{ml}$ resulted in significantly higher C3c deposition ( $\mathrm{n}=4, \mathrm{p}=0.023$, paired, two-tailed t-test $)$ 


\subsubsection{Serum deprivation enhanced cyclosporine-induced C3 deposition on endothelial cell surfaces}

Next, we incubated ECs for 24 hours with CsA $10 \mu \mathrm{g} / \mathrm{ml}$ reconstituted in media with varying concentrations of fetal bovine serum (FBS) (0-10\%), before adding 50\% NHS for $30 \mathrm{~min}$. Serum starvation resulted in a significantly higher $\mathrm{C} 3 \mathrm{c}$ deposition (Figure 3.3).

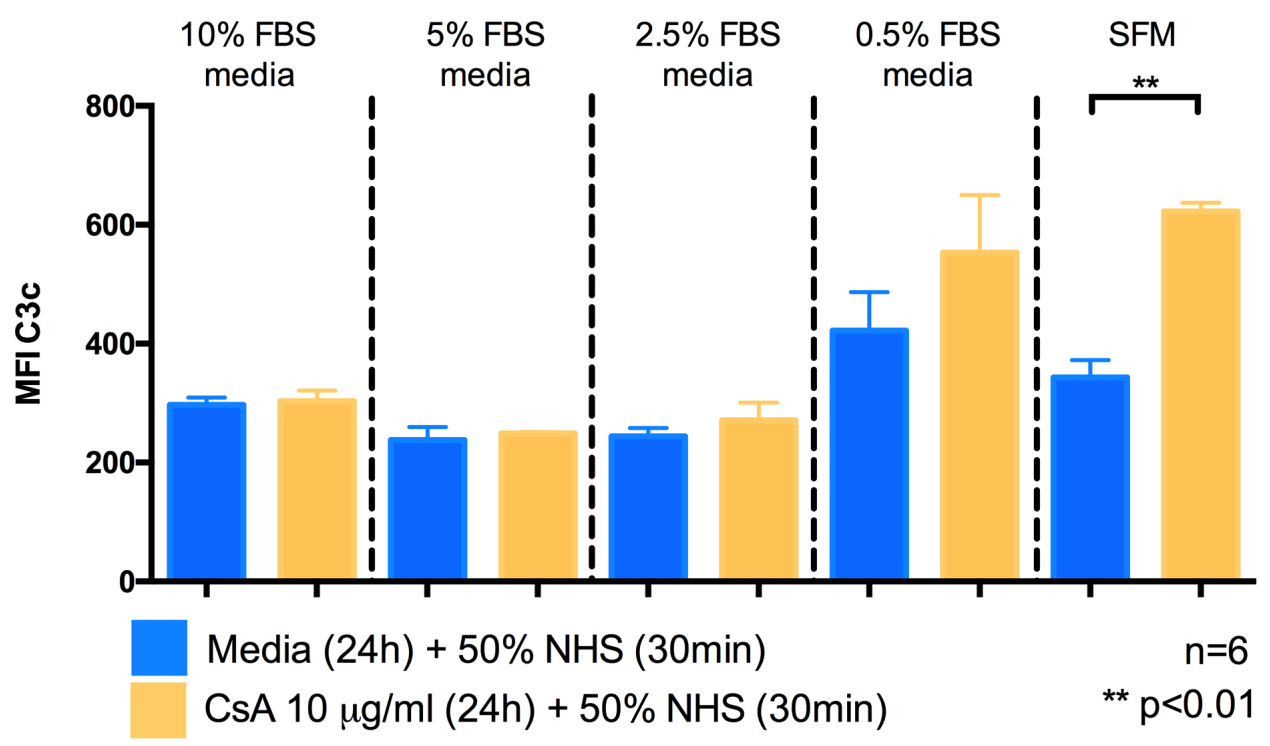

Figure 3.3: Serum deprivation enhanced CsA-induced complement deposition on EC

surfaces. C3c deposition on EC surface by flow cytometry. Non-viable cells excluded from analysis with Fixable Viability Dye eFluor 780. Incubating ECs with CsA reconstituted in media supplemented with decreasing amounts of fetal bovine serum (FBS) resulted in significantly higher $\mathrm{C} 3 \mathrm{c}$ deposition $(\mathrm{n}=6, \mathrm{p}<0.01$, paired, two-tailed $\mathrm{t}$-test $)$

\subsubsection{Antibody sensitization with anti-CD59 enhanced cyclosporine-induced C3 deposition on endothelial cell surfaces}

From previous work, we know that sensitization of ECs with a (blocking) antibody specific to the membrane-anchored complement regulator CD59 results in C3c deposition on EC surfaces. This previously established method combines the effects of complement induction via sensitization (via the classical pathway) and complement amplification (via the alternative pathway).(Barilla-LaBarca et al., 2002; Liszewski and Atkinson, 1996; Noone et al., 2016; Triantafilou et al., 2013) We were interested to examine if incubation with CsA would further increase $\mathrm{C} 3 \mathrm{c}$ deposition. We found that CsA pre-incubation further increased $\mathrm{C} 3 \mathrm{c}$ deposition on 
ECs treated with anti-CD59 antibody (Figure 3.4). To further assess C5b-9 deposition on ECs, we deployed flow cytometry using an anti-C9 antibody. We found that C5b-9 deposition was also increased when ECs were pre-treated with CsA and anti-CD59 (Figure 3.5). Of note, in keeping with previous data, no increase in C5b-9 deposition was detected when ECs were just incubated with media or CsA $10 \mu \mathrm{g} / \mathrm{ml}$.

Taken together, exposure of ECs to CsA resulted in a dose-dependent complement deposition, that can be enhanced by serum starvation or sensitization with a classical pathway activating antibody.

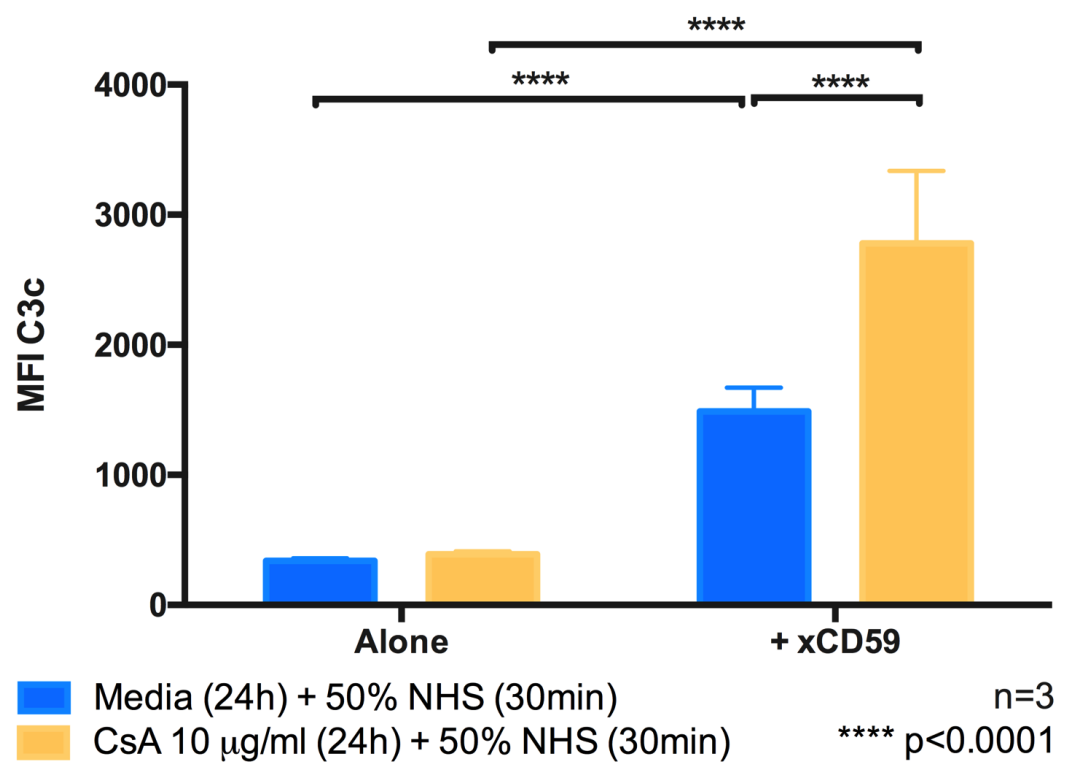

Figure 3.4: Anti-CD59 antibody sensitization enhanced CsA-induced complement deposition on EC surfaces. C3c deposition on EC surface by flow cytometry. Non-viable cells excluded from analysis with Fixable Viability Dye eFluor 780. Addition of anti-CD59 antibody enhanced CsA-induced C3c deposition ( $n=3, p<0.0001$, two-way ANOVA, Sidak's multiple comparisons test) 


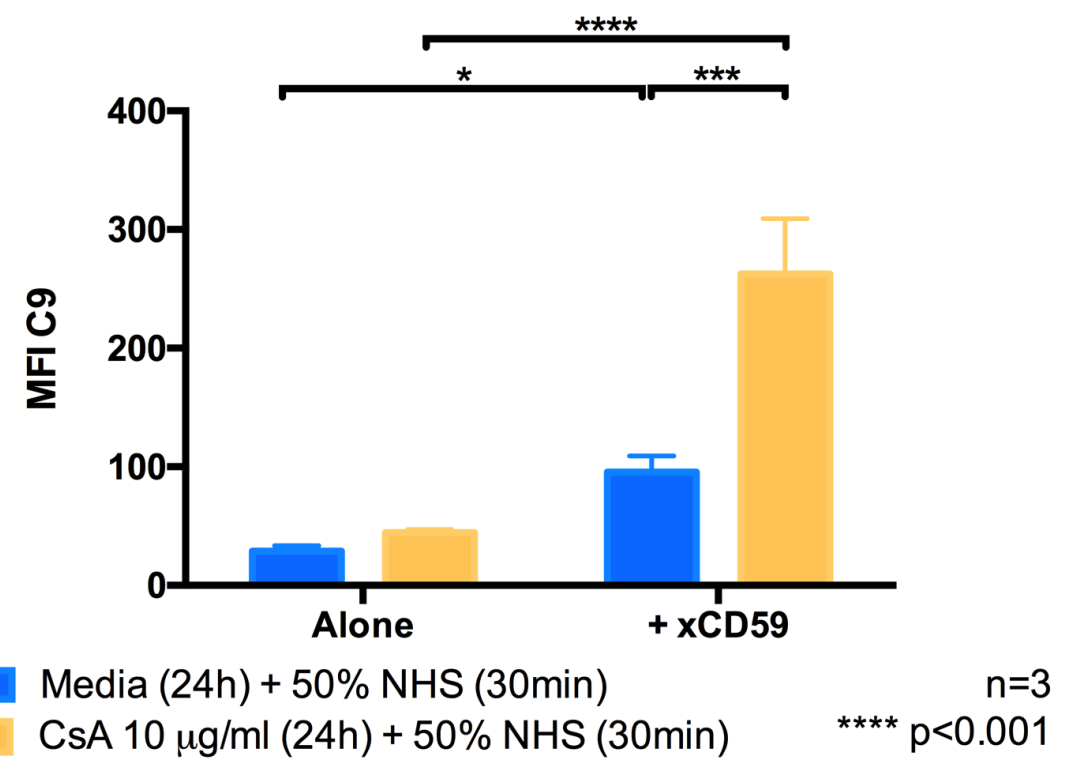

Figure 3.5: Anti-CD59 antibody sensitization enhanced CsA-induced terminal complement deposition on EC surfaces. C9 deposition on EC surface by flow cytometry. Non-viable cells excluded from analysis with Fixable Viability Dye eFluor 780. Addition of anti-CD59 antibody enhanced CsA-induced C9 deposition ( $n=3, p<0.0001$, two-way ANOVA, Sidak's multiple comparisons test)

\subsection{Cyclosporine treatment led to increased expression of surface membrane-bound complement regulators}

\subsubsection{Cyclosporine treatment led to an increased expression of MCP/CD46,} DAF/CD55 and CD59 on endothelial cell surfaces

Endothelial cell surfaces are protected against complement attack by specific membrane-bound regulators, membrane cofactor protein (MCP/CD46), decay accelerating factor (DAF/CD55), and protectin (CD59). (Teoh et al., 2016) We assessed the expression of MCP/CD46, DAF/CD55 and CD59 after exposure to CsA on BOEC surfaces by flow cytometry, and total cell expression of these regulators by western blot of BOEC lysates. The sequence of incubation with CsA $10 \mu \mathrm{g} / \mathrm{ml}$ for 24 hours resulted in an increased total and cell surface expression of $\mathrm{MCP} / \mathrm{CD} 46, \mathrm{DAF} / \mathrm{CD} 55$ and CD59 (Figure 3.6 \& 3.7) 
Figures 3.6 \& 3.7 (overleaf): CsA led to increased expression of membrane-bound complement regulators MCP/CD46, DAF/CD55 and CD59 on endothelial cell surfaces. Figure 3.6) EC surface membrane-bound complement regulators by flow cytometry. Nonviable cells excluded from analysis with Fixable Viability Dye eFluor 780. Figure 3.7) EC membrane-bound complement regulators in cell lysates by Western blot. Compared to media, incubating EC in CsA $10 \mu \mathrm{g} / \mathrm{ml}$ for 24 hours resulted in increased expression of membrane-bound complement regulators: A \& B) MCP/CD46, C \& D) DAF/CD55, and E \& F) protectin/CD59. 
A

CD46

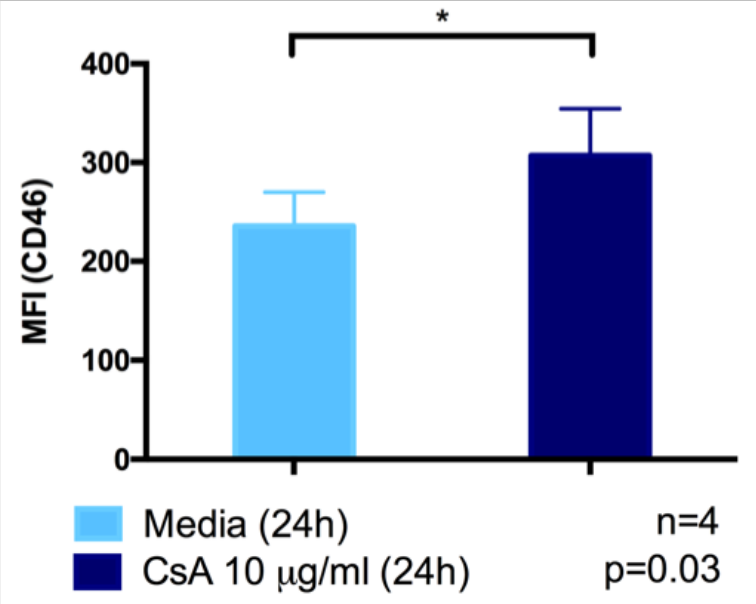

C

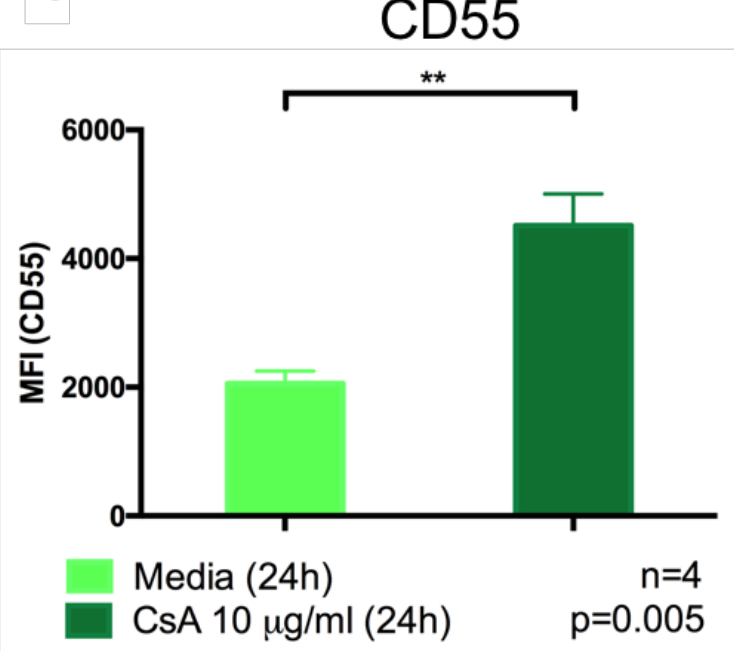

E

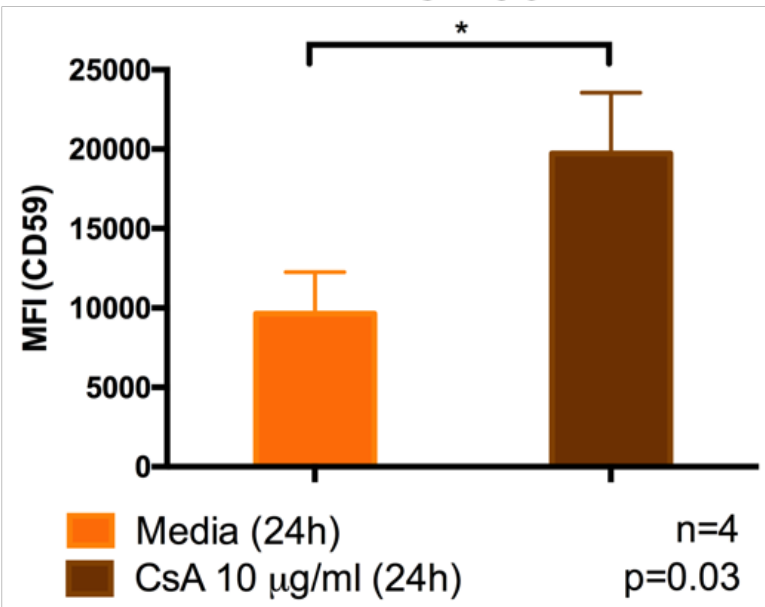

B

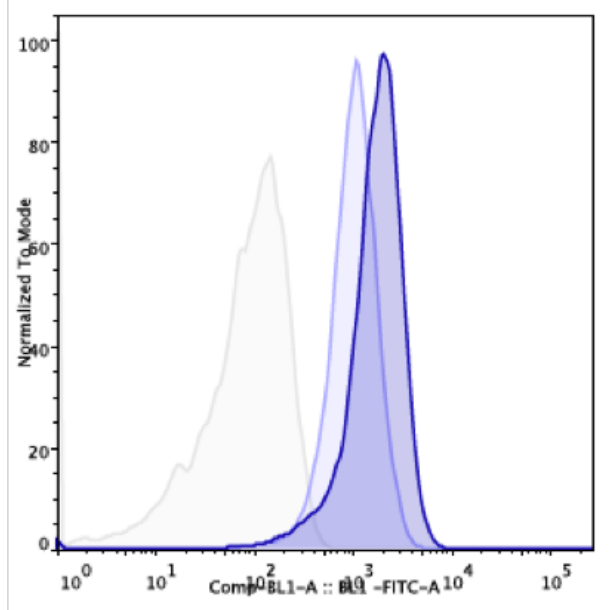

D

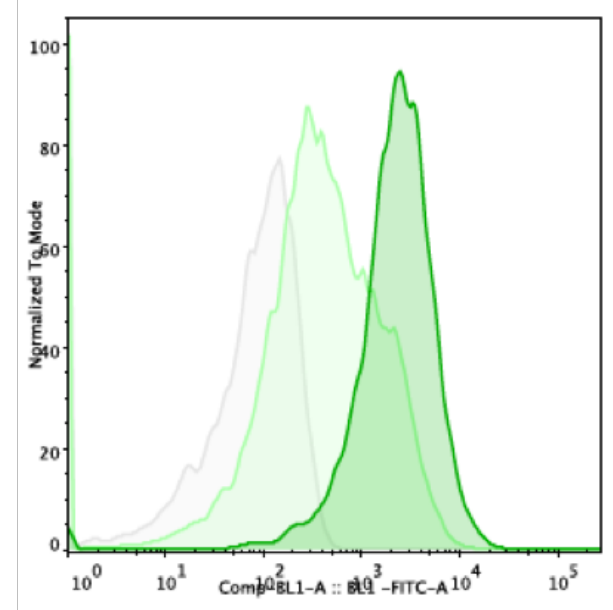

F

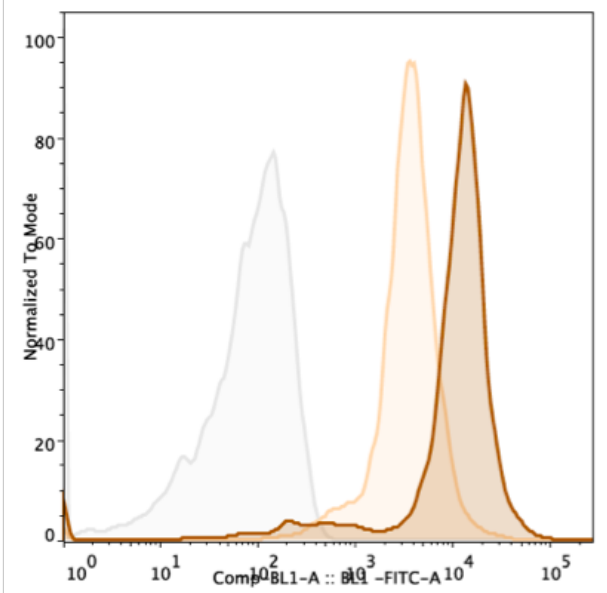


Figure 3.6 (previous page): CsA led to increased expression of membrane-bound complement regulators MCP/CD46, DAF/CD55 and CD59 on endothelial cell surfaces. EC surface membrane-bound complement regulators MCP/CD46, DAF/CD55 and CD59 by

flow cytometry. Non-viable cells excluded from analysis with Fixable Viability Dye eFluor 780. Graphical summary of median fluorescence intensity (MFI) from separate experiments (A, C \& E) with representative histograms (B, D \& F). Compared to media, incubating EC in CsA 10 $\mu \mathrm{g} / \mathrm{ml}$ for 24 hours resulted in increased expression of membrane-bound complement regulators: A \& B) MCP/CD46 (n=4, p=0.03, paired, two-tailed t-test), C \& D) DAF/CD55 (n=4, p=0.005, paired, two-tailed t-test), and $\mathbf{E} \boldsymbol{\&} \mathbf{F})$ protectin/CD59 ( $\mathrm{n}=4, \mathrm{p}=0.03$, paired, two-tailed t-test). 
A

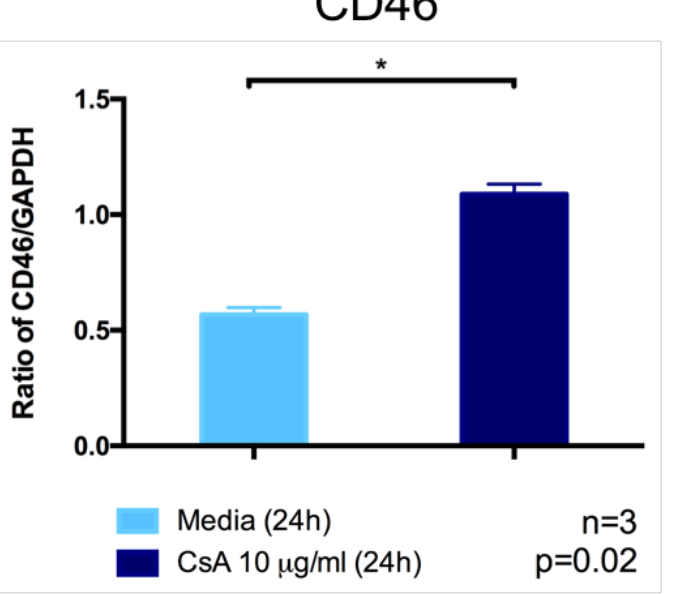

C

CD55

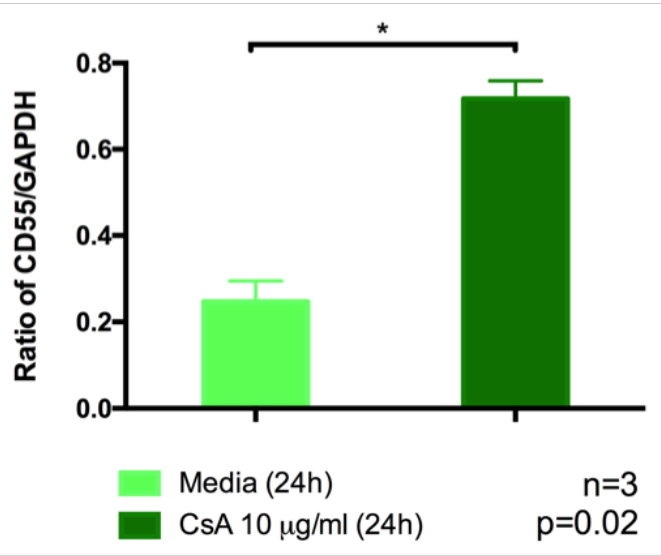

E

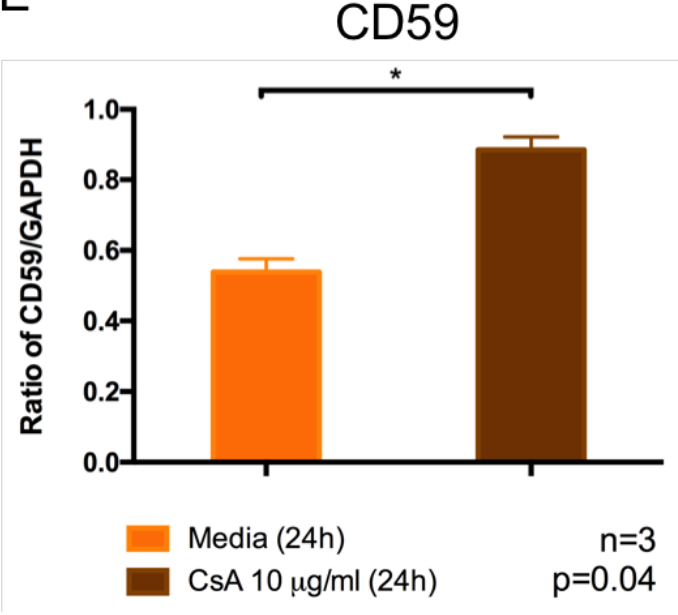

B

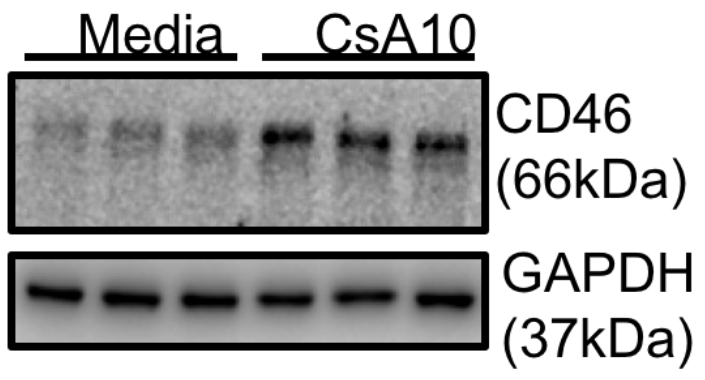

D

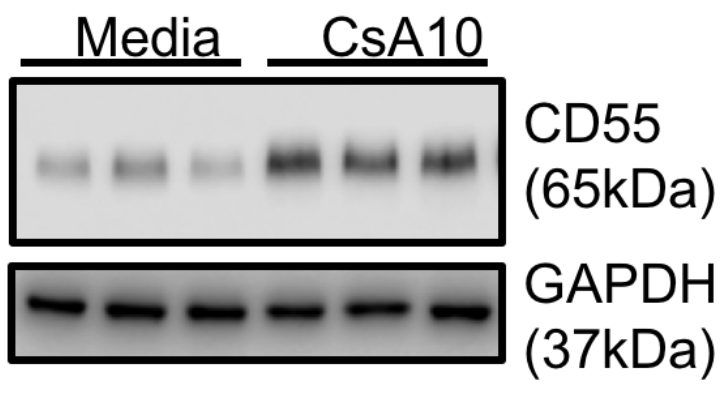

F

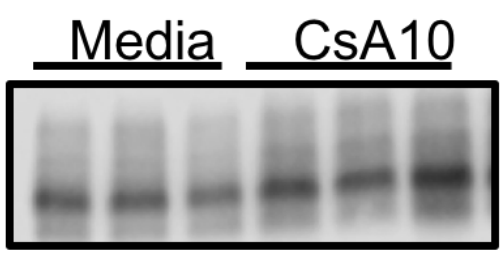

CD59

(14kDa)

GAPDH

(37kDa) 
Figure 3.7 (previous page): CsA led to increased expression of membrane-bound complement regulators MCP/CD46, DAF/CD55 and CD59 on endothelial cells. Membranebound complement regulators $\mathrm{MCP} / \mathrm{CD} 46, \mathrm{DAF} / \mathrm{CD55}$ and CD59 in cell lysates by Western

blot. Graphical summary of mean gray area of specified protein band normalized to loading control from separate experiments (A, C \& E) and Western blots (B, D \& F). Western blot images in B, D \& F were taken from the same piece of nitrocellulose membrane that were cut and incubated with respective primary and secondary antibodies separately. Blots for CD46 and CD55 were incubated with respective primary and secondary antibodies sequentially after stripping. Compared to media, incubating EC in CsA $10 \mu \mathrm{g} / \mathrm{ml}$ for 24 hours resulted in increased expression of membrane-bound complement regulators: A \& B) MCP/CD46 ( $n=3, p=0.02$, paired, two-tailed t-test), C \& D) DAF/CD55 (n=3, p=0.02, paired, two-tailed t-test), and $\mathbf{E} \& \mathbf{F})$ protectin/CD59 ( $\mathrm{n}=3, \mathrm{p}=0.04$, paired, two-tailed $\mathrm{t}$-test). 


\subsection{Cyclosporine treatment led to impaired complement factor $\mathrm{H}$ regulation on surfaces of endothelial cells}

\subsubsection{Cyclosporine treatment led to a reduction in complement factor $\mathrm{H}$ binding on surfaces of endothelial cells}

Complement factor $\mathrm{H}(\mathrm{CFH})$ is an important circulating inhibitor of the alternative pathway which inhibits $\mathrm{C} 3 \mathrm{~b}$ amplification on self-surfaces. $\mathrm{CFH}$ also acts as cofactor to complement factor I (CFI) and membrane cofactor protein (MCP/CD46) to cleave surface-bound C3b, promote disintegration of $\mathrm{C} 3 \mathrm{bBb}$ and competitively prevents $\mathrm{C} 3 \mathrm{~b}$ deposition on cell surfaces.(Makou et al., 2013; Rodriguez de Cordoba et al., 2004; Schmidt et al., 2008a) This surface regulatory effect of $\mathrm{CFH}$ requires its binding to EC surfaces via glycosaminoglycans or sialic acid clusters.(Clark et al., 2010; Clark et al., 2013; Kazatchkine et al., 1979; Schmidt et al., 2008b; Zaferani et al., 2012) We assessed the effect of CsA exposure on CFH binding on endothelial surfaces by flow cytometry. To do so, we fluorescently labelled CFH with Alexa Fluor 488 and confirmed its functional activity via a hemolysis assay. Alexa Fluor 488conjugated CFH was added for 1 minute to live cells before analysis with flow cytometry. Treatment with neuraminidase $500 \mathrm{mU} / \mathrm{ml}$, which cleaves sialic acid groups from glycoproteins was used as a positive control. The functionality of neuraminidase in cleaving sialic acid was confirmed by live imaging with wheat germ agglutin (Figure 3.11). We found that incubation of endothelial cells in CsA $10 \mu \mathrm{g} / \mathrm{ml}$ for 24 hours led to reduced CFH binding (Figure 3.8). 


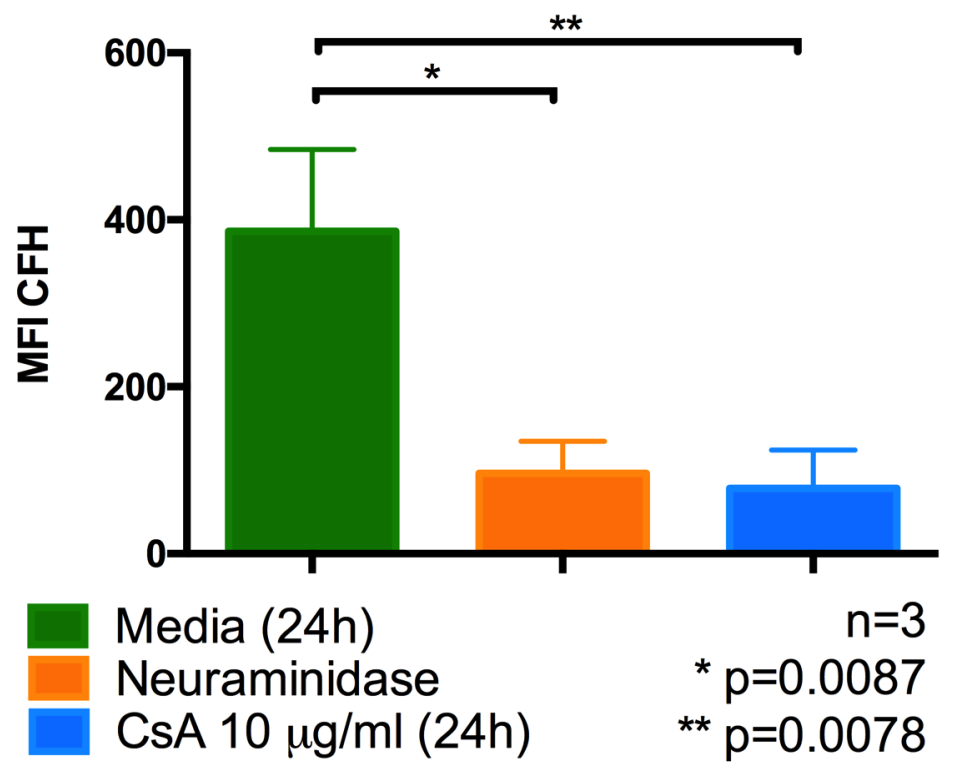

Figure 3.8: CsA led to reduced CFH binding on EC surface. Alexa Fluor 488-conjugated CFH binding on EC surface by flow cytometry. Non-viable cells excluded from analysis with Fixable Viability Dye eFluor 780. Exposure of BOECs to CsA $10 \mu \mathrm{g} / \mathrm{ml}$ for 24 hours led to reduced CFH binding on BOEC surface $(n=3, * * p=0.0078$, paired, two-tailed t-test). Treatment with neuraminidase $500 \mathrm{mU} / \mathrm{ml}$, which cleaves sialic acid groups from glycoproteins, led to reduced CFH binding on BOEC surface $\left(n=3,{ }^{*} p=0.0087\right.$, paired, two-tailed t-test). 


\subsubsection{Cyclosporine treatment led to impaired complement factor $\mathrm{H}$ surface cofactor activity}

We first assessed the endogenous cofactor activity of the EC surface-bound complement regulators (CD46). In this assay, BOECs were incubated with $\mathrm{C} 3 \mathrm{~b}$ and complement factor I (CFI), without $\mathrm{CFH}$, and the appearance of its degradation products ( $\boldsymbol{\alpha}^{\prime} 68, \boldsymbol{\alpha}^{\prime} 46$ and $\boldsymbol{\alpha}^{\prime} 43 \mathrm{kDa}$ fragments of the $\mathrm{C} 3 \mathrm{~b} \boldsymbol{\alpha}^{\prime}$ chain) were assessed on western blot. Degradation products were detectable after 90 minutes and increased with time (Figure 3.9A). When BOECs were preincubated with $\mathrm{CFH}$, prior to incubation with $\mathrm{C} 3 \mathrm{~b}$ and $\mathrm{CFI}, \mathrm{C} 3$ degradation products were detectable after 15 minutes (Figure 3.9B), demonstrating the cofactor activity of CFH on BOEC surfaces. Surface cofactor activity of CFH requires its binding to EC surfaces via glycosaminoglycans or sialic acid clusters.(Clark et al., 2010; Clark et al., 2013; Kazatchkine et al., 1979; Schmidt et al., 2008b; Zaferani et al., 2012) We tested this by pre-treating BOECs to neuraminidase which cleaves sialic acid groups from the glycocalyx of endothelial cells.(Libby et al., 1986) When BOECs were pre-incubated with neuraminidase $500 \mathrm{mU} / \mathrm{mL}$ for 1 hour followed by $\mathrm{CFH}$ for 1 hour, prior to being thoroughly washed and incubated with $\mathrm{C} 3 \mathrm{~b}$ and $\mathrm{CFI}$ at 37 degrees Celsius, degradation products were detectable only after 60 minutes (Figure 3.9C).

We then assessed the effect of CsA exposure on the cofactor activity of CFH on BOEC surfaces. BOECs exposed to various doses of CsA $10 \mu \mathrm{g} / \mathrm{ml}$, CsA $50 \mu \mathrm{g} / \mathrm{ml}$ and CsA $100 \mu \mathrm{g} / \mathrm{ml}$ for 24 hours demonstrated less cofactor activity of $\mathrm{CFH}$ on BOEC surfaces as evidenced by later appearance and less prominent appearance of $\mathrm{C} 3 \mathrm{~b}$ degradation products (Figure 3.9D-F and Figure 3.10). For statistical analysis, we formulated a ratio of the mean gray value of the $\boldsymbol{\alpha}$ '2 46 $\mathrm{kDa}$ band with the mean gray value of the $\boldsymbol{\alpha}^{\prime} 110 \mathrm{kDa}$ band. An increased ratio indicates that the $\boldsymbol{\alpha}^{\prime}$ chain was cleaved into its split products, indicative of $\mathrm{C} 3 \mathrm{~b}$ inactivation. 
A) Endogenous - Media

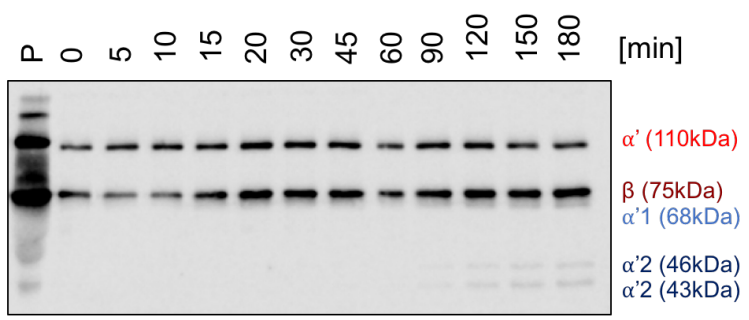

C) Endogenous - Neuraminidase $500 \mathrm{mU} / \mathrm{ml}$

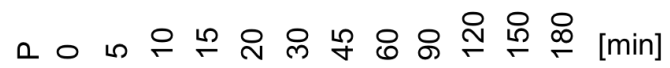

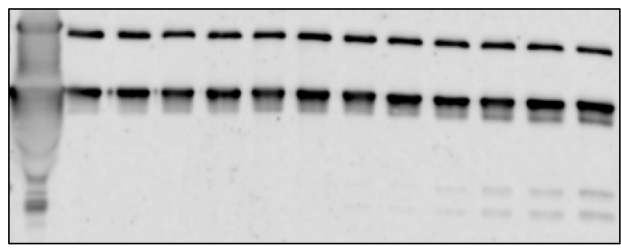

$\alpha^{\prime}(110 \mathrm{kDa})$

$\beta(75 \mathrm{kDa})$

$\alpha^{\prime} 1(68 \mathrm{kDa})$

$\alpha^{\prime 2} 2(46 \mathrm{kDa})$ $\alpha^{\prime} 2(43 \mathrm{kDa})$

E) Endogenous - Cyclosporine $10 \mu \mathrm{g} / \mathrm{ml}$

ㅇ o

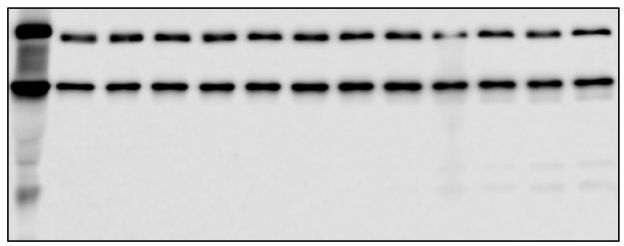

$\alpha^{\prime}(110 \mathrm{kDa})$

$\beta(75 \mathrm{kDa})$

''1 (68kDa)

$\alpha^{\prime} 2(46 \mathrm{kDa})$ '2 $2(43 \mathrm{kDa})$

G) Endogenous - Cyclosporine $50 \mu \mathrm{g} / \mathrm{ml}$

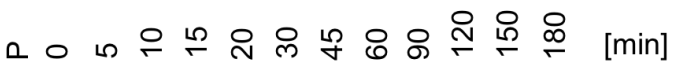

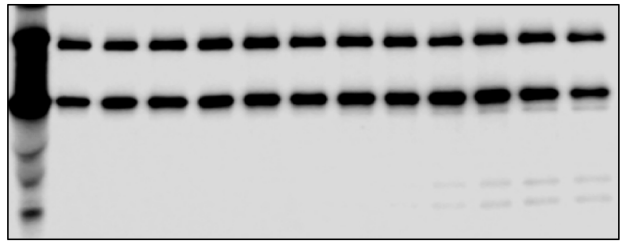

$\alpha^{\prime}(110 \mathrm{kDa})$

$\beta$ (75kDa)

$\alpha^{\prime} 1(68 \mathrm{kDa})$

$\alpha^{\prime} 2(46 \mathrm{kDa})$ $\alpha^{\prime} 2(43 \mathrm{kDa})$

I) Endogenous - Cyclosporine $100 \mu \mathrm{g} / \mathrm{ml}$

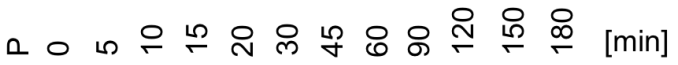

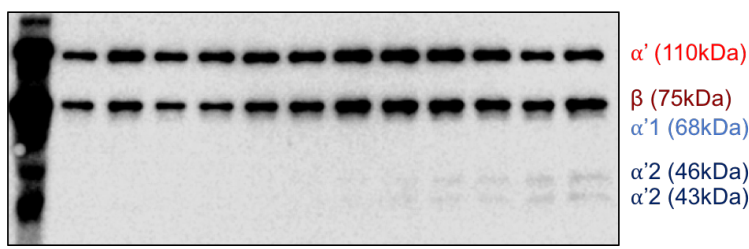

B) Complete - Media (Control)

ㅇ 난 유 은

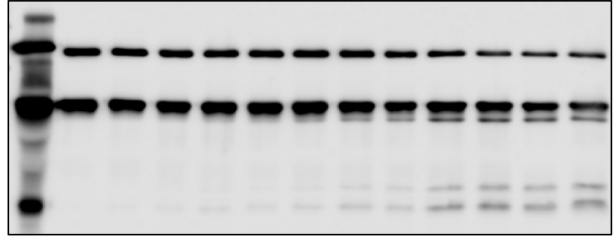

$\alpha^{\prime}(110 \mathrm{kDa})$

$\beta$ (75kDa)

$\alpha^{\prime} 1$ (68kDa)

$\alpha^{\prime 2}(46 \mathrm{kDa})$ $\alpha^{\prime} 2(43 \mathrm{kDa})$

D) Complete - Neuraminidase $500 \mathrm{mU} / \mathrm{ml}$ (Negative control)

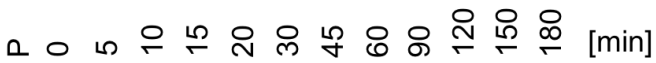

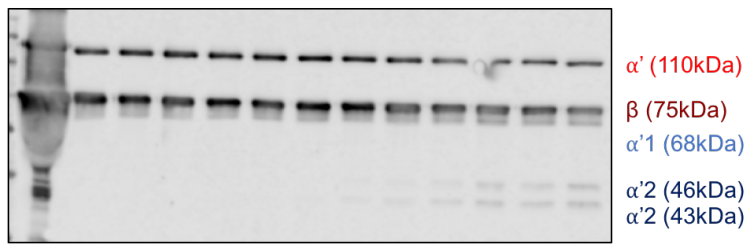

F) Complete - Cyclosporine $10 \mu \mathrm{g} / \mathrm{ml}$

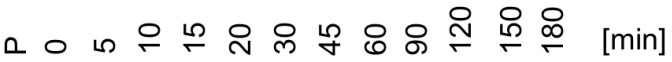

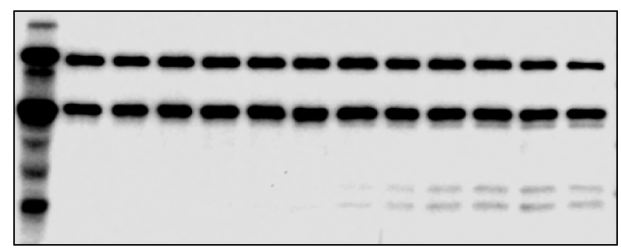

$\alpha^{\prime}(110 \mathrm{kDa})$

$\beta(75 \mathrm{kDa})$

$\alpha^{\prime} 1(68 \mathrm{kDa})$

$\alpha^{\prime} 2(46 \mathrm{kDa})$ $\alpha^{\prime} 2(43 \mathrm{kDa})$

H) Complete - Cyclosporine $50 \mu \mathrm{g} / \mathrm{ml}$

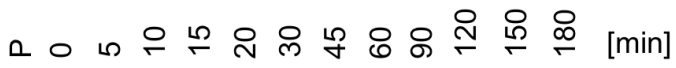

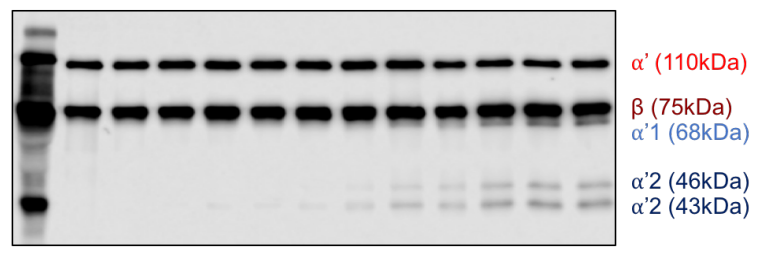

J) Complete - Cyclosporine $100 \mu \mathrm{g} / \mathrm{ml}$

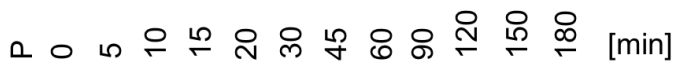

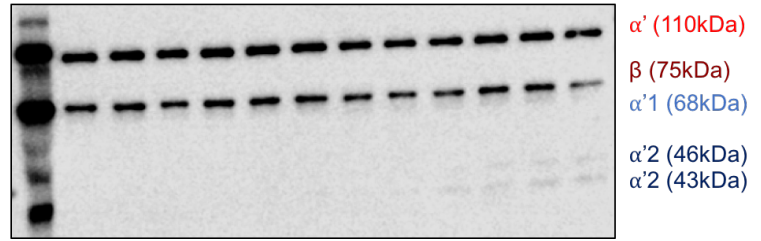


Figure 3.9 (previous page): CsA led to impaired CFH surface cofactor activity. CFH surface cofactor activity assay. BOECs were incubated with C3b $3.3 \mu \mathrm{g} / \mathrm{ml}$ and CFI $10 \mu \mathrm{g} / \mathrm{ml}$ at 37 degrees Celsius, with or without pre-incubation with CFH $10 \mu \mathrm{g} / \mathrm{ml}$ at 37 degrees Celcius. After the various time points, the supernatant was inactivated in sample buffer and separated by SDSPAGE and transferred onto a nitrocellulose membrane, and the appearance of C3b degradation fragments were analysed by Western blotting (representative Western blots are shown in figures). A) Endogenous cofactor activity on BOEC without CFH. BOECs were incubated with C3b and CFI at 37 degrees Celsius. Degradation products ( $\boldsymbol{\alpha}^{\prime} 68, \boldsymbol{\alpha}^{\prime} 46$ and $\boldsymbol{\alpha}^{\prime} 43 \mathrm{kDa}$ fragments of the $\mathrm{C} 3 \mathrm{~b} \boldsymbol{\alpha}^{\prime}$ chain) were detectable after 90 minutes and increased with time. There were no significant differences between the endogenous cofactor activity on BOEC without CFH whether they were exposed to A) media, C) Neuraminidase, E) CsA $10 \mu \mathrm{g} / \mathrm{ml}$, G) CsA $50 \mu \mathrm{g} / \mathrm{ml}$, or I) CsA $100 \mu \mathrm{g} / \mathrm{ml}$. B) Cofactor activity of CFH on surface of BOEC. BOECs were preincubated with CFH for 1 hour at 37 degrees Celcius and thoroughly washed, prior to incubation with $\mathrm{C} 3 \mathrm{~b}$ and CFI at 37 degrees Celsius. Degradation products were detectable after 15 minutes. D) Cofactor activity of CFH on surface of neuraminidase-treated BOEC. Neuraminidase cleaves sialic acid groups from cell surfaces. BOECs were pre-incubated with neuraminidase 500 $\mathrm{mU} / \mathrm{ml}$ for 1 hour followed by CFH $10 \mu \mathrm{g} / \mathrm{ml}$ for 1 hour at 37 degrees Celcius, prior to being thoroughly washed and incubated with C3b $3.3 \mu \mathrm{g} / \mathrm{ml}$ and CFI $10 \mu \mathrm{g} / \mathrm{ml}$ at 37 degrees Celsius. Degradation products were detectable after 60 minutes. F, H, J) Cofactor activity of CFH on surface of CsA-treated BOEC. BOECs were pre-incubated with CsA $10 \mu \mathrm{g} / \mathrm{ml}$, CsA $50 \mu \mathrm{g} / \mathrm{ml}$ or CsA $100 \mu \mathrm{g} / \mathrm{ml}$ for 24 hours. They were then incubated with CFH 10 for 1 hour at 37 degrees Celcius, washed thoroughly, and then incubated with C3b and CFI at 37 degrees Celsius. After the various time points, the supernatant was inactivated in sample buffer and separated by SDSPAGE and transferred onto a nitrocellulose membrane, and the appearance of C3 fragments was analysed by Western blotting. Degradation products were detectable: F) CsA $10 \mu \mathrm{g} / \mathrm{ml}$ after 45 minutes, H) CsA $50 \mu \mathrm{g} / \mathrm{ml}$ after 45 minutes, and J) CsA $100 \mu \mathrm{g} / \mathrm{ml}$ after 90 minutes. 


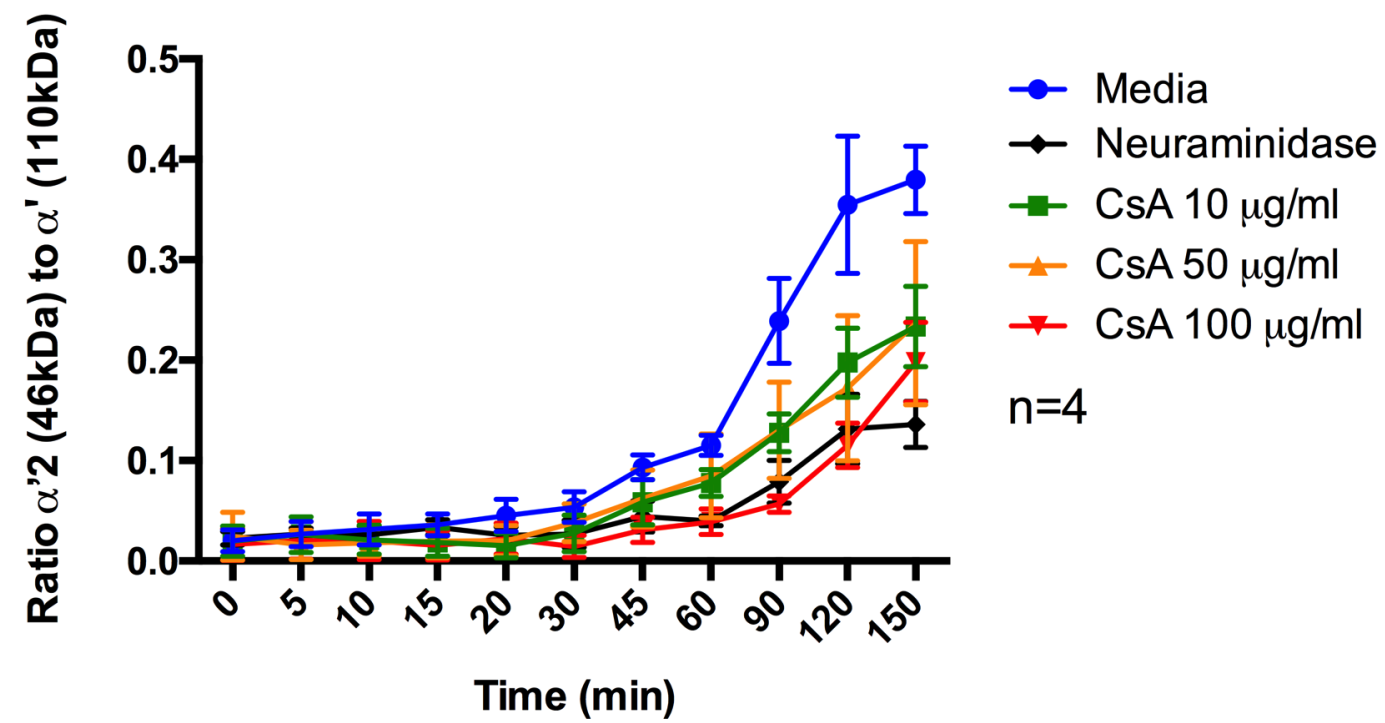

Figure 3.10: CsA led to impaired CFH surface cofactor activity. Graphical presentation of CFH surface cofactor activity assay experiments. There was significant reduction in $\mathrm{CFH}$ cofactor activity on the surfaces of BOECs treated with CsA when compared with control $(\mathrm{n}=4$, $\mathrm{p}<0.005$ for control vs CsA $10 \mu \mathrm{g} / \mathrm{ml}$ from 90 minutes onwards; $\mathrm{p}<0.04$ for control vs CsA 50 $\mu \mathrm{g} / \mathrm{ml}$ from 90 minutes onwards; $\mathrm{p}<0.03$ for control vs CsA $100 \mu \mathrm{g} / \mathrm{ml}$ from 45 minutes onwards; $\mathrm{p}<0.001$ for control vs neuraminidase $500 \mathrm{mU} / \mathrm{ml}$ from 60 minutes onwards; paired, two-tailed t-test) 


\subsection{Cyclosporine treatment led to diminished endothelial cell glycocalyx}

\subsubsection{Cyclosporine treatment led to diminished endothelial cell glycocalyx}

The surface regulatory function of $\mathrm{CFH}$ requires its binding to EC surfaces via glycosaminoglycans or sialic acid clusters.(Clark et al., 2010; Clark et al., 2013; Kazatchkine et al., 1979; Schmidt et al., 2008b; Zaferani et al., 2012) We found that CsA treatment led to reduction of $\mathrm{CFH}$ binding to the surface of endothelial cells and impaired $\mathrm{CFH}$ surface cofactor activity. We therefore assessed whether CsA treatment affected the endothelial cell glycocalyx (consisting of glycosaminoglycans and sialic acid residues) by staining with an Alexa Fluor 594conjugated wheat germ agglutinin (Thermo Fischer Scientific, W11262, dilution 1:500) which binds to sialic acid and $\mathrm{N}$-acetylglucosaminyl residues, and live cell imaging. We imaged cells live as fixation resulted in decreased overall fluorescence. To prevent endocytosis, incubation with WGA was performed in the cold. Our results show that endothelial cells treated with neuraminidase, which cleaves sialic acid groups from the glycocalyx of endothelial cells,(Libby et al., 1986) stained less intensely with WGA when compared to control cells treated with media (Figure 3.11 A \& B). Furthermore, treatment with CsA $10 \mu \mathrm{g} / \mathrm{ml}$ and CsA $50 \mu \mathrm{g} / \mathrm{ml}$ also resulted in less intense staining with WGA when compared to control (Figure 3.11 C \& D). Taken together, our findings suggest that CsA treatment resulted in a decrease of sialic acid and/or glycosaminoglycans in endothelial cell glycocalyx (Figure 3.12). 


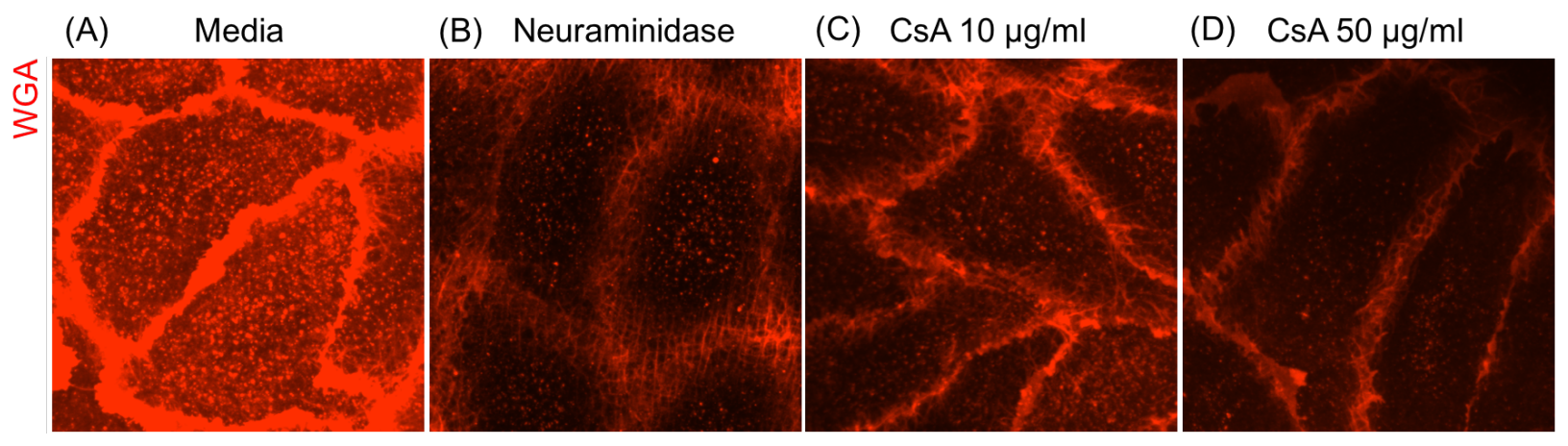

Figure 3.11: CsA led to diminished endothelial cell glycocalyx. Live cell imaging of endothelial cell glycocalyx with Alexa Fluor 594-conjugated wheat germ agglutinin (WGA). When compared to EC treated with A) media for 24 hours (control), EC treated with B) neuraminidase $500 \mathrm{mU} / \mathrm{mL}$ for 1 hour, C) CsA $10 \mu \mathrm{g} / \mathrm{ml}$ for 24 hours, and D) CsA $50 \mu \mathrm{g} / \mathrm{ml}$ for 24 hours were less intensely stained with WGA.

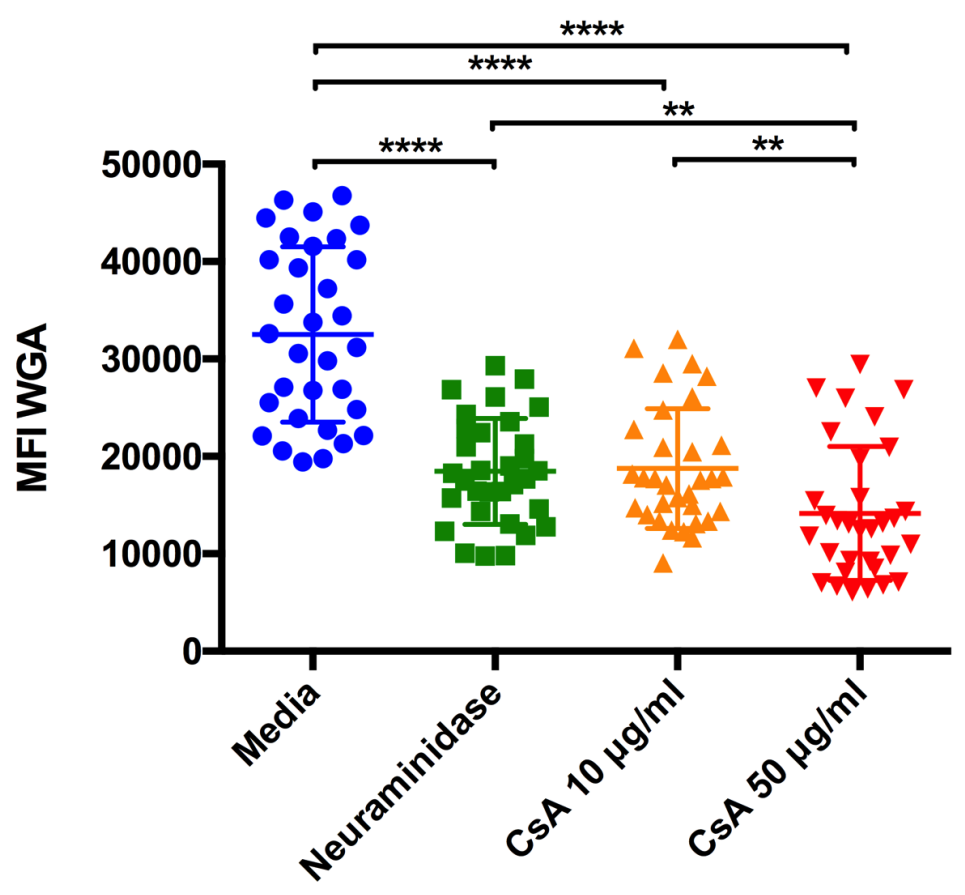

Figure 3.12: CsA led to diminished endothelial cell glycocalyx. Graphical presentation of live cell imaging of endothelial cell glycocalyx with Alexa Fluor 594-conjugated wheat germ agglutinin (WGA). Mean fluorescence intensity was measured with ImageJ. Total of 3 sets of experiments with 10 representative images taken per condition (each dot represents 1 image). There was significant reduction in mean fluorescence intensity of WGA staining on ECs treated with CsA $(\mathrm{n}=3, * * \mathrm{p}=0.0063, * * * * \mathrm{p}<0.0001$, two-tailed t-test $)$ 


\subsection{Membrane cofactor protein (MCP/CD46) deficiency increased the susceptibility to cyclosporine-induced complement activation on endothelial cell surfaces}

\subsubsection{MCP BOEC possess endothelial cell characteristics and are deficient in MCP/CD46}

Blood outgrowth endothelial cells (BOEC) isolated from a patient with atypical hemolytic uremic syndrome secondary to a frameshift variant in the membrane cofactor protein (MCP/CD46) gene [c.747dupA (p.Ala250Serfs*6)] were characterised and their endothelial cell phenotype were confirmed by immunofluorescence and flow cytometry (Figure 3.13A-C). Using flow cytometry, we determined that the expression level of the membrane-anchored complement regulator, $\mathrm{MCP} / \mathrm{CD} 46$, were lower in $\mathrm{BOECs}$ isolated from this patient when compared to control BOECs isolated from healthy donors (Figure 3.13D).

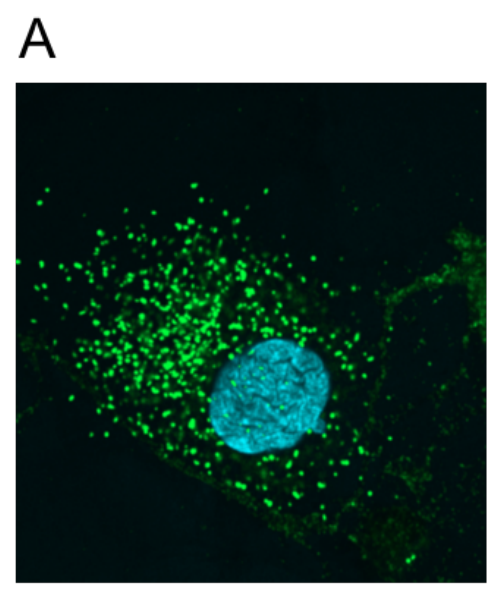

VWF

\section{C}

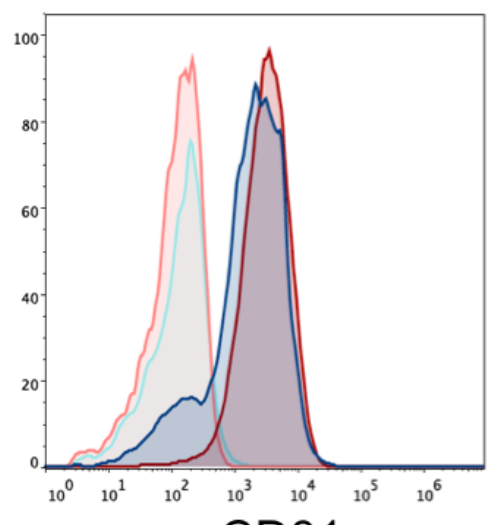

CD31

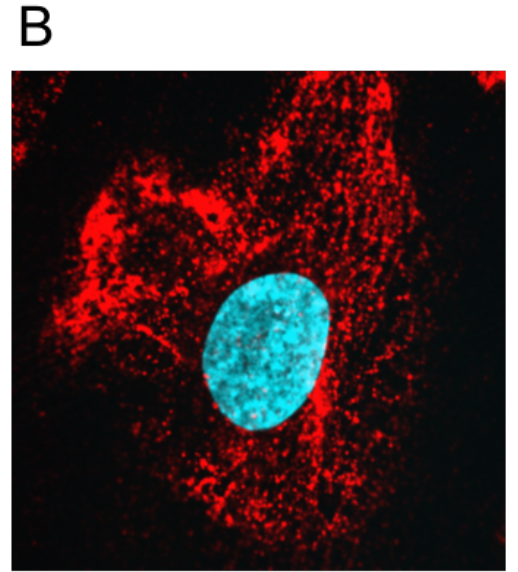

Caveolin
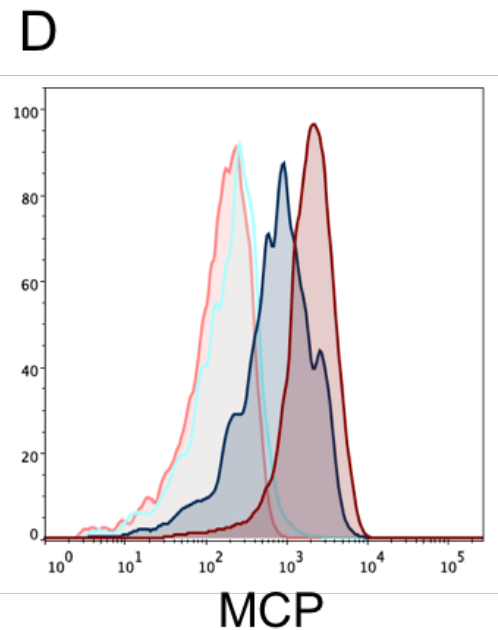

CTRL BOEC MCP deficient BOEC 
Figure 3.13 (previous page): MCP BOECs demonstrate endothelial cell phenotype and have decreased surface expression of membrane-bound MCP/CD46. Characterisation of MCP BOEC. A, B, C) An endothelial cell phenotype was confirmed by demonstrating the presence of Weibel-Palade bodies containing fluorescently-labelled von Willebrand factor (VWF, Alexa Fluor 488, green), caveolin (caveolin, Alexa Fluor 555, red) and PECAM1/CD31 positivity. D) Flow cytometry confirmed that BOECs isolated from the patient with a frameshift variant in the membrane cofactor protein (MCP/CD46) gene [c.747dupA (p.Ala250Serfs*6)] had reduced expression of the membrane-anchored complement regulator MCP/CD46.

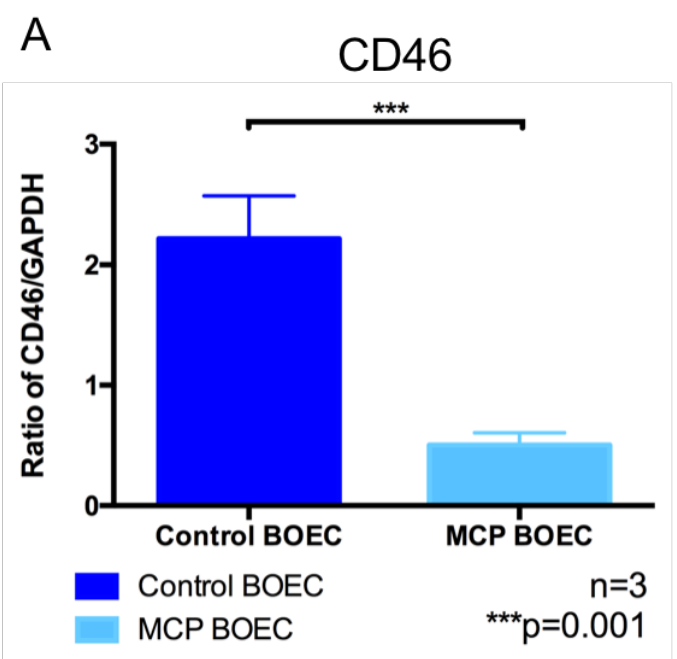

B

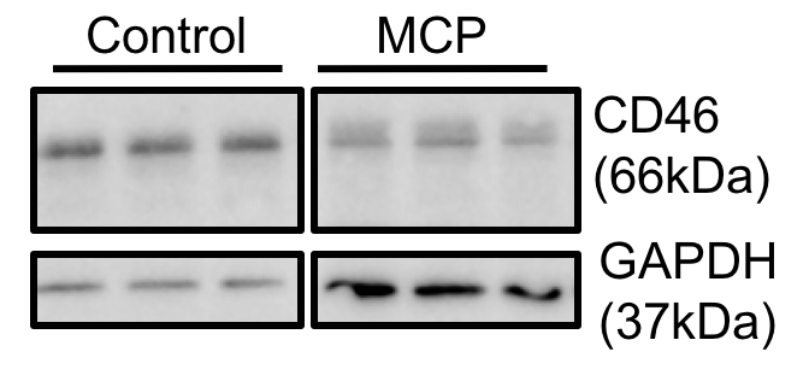

Figure 3.14: MCP BOECs are deficient in membrane-bound MCP/CD46. Comparison of membrane-bound MCP/CD46 in BOEC from healthy donor (control) and donor with MCP gene variant in cell lysates by Western blot. Western blot images in B were taken from the same piece of nitrocellulose membrane that were cut and incubated with respective primary and secondary antibodies separately. Western blot images in B were from experiments comparing CD46 expression in control and MCP BOECs treated with media (Control BOECs lane 3-5, MCP BOECs lane 9-11) and with CsA $10 \mu \mathrm{g} / \mathrm{ml}$ (Control BOECs lane 6-8, MCP BOECs lane 12-14; data not shown). BOECs isolated from patient with a frameshift variant in the membrane cofactor protein (MCP/CD46) gene [c.747dupA (p.Ala250Serfs*6)] had reduced expression of the membrane-anchored complement regulator $\mathrm{MCP} / \mathrm{CD} 46$. 


\subsubsection{MCP-deficient BOEC were more susceptible to cyclosporine-induced complement deposition on endothelial cell surfaces}

Next, we wanted to assess if the BOECs derived from the patient with a pathogenic variant in $\mathrm{MCP} / \mathrm{CD} 46$ were more susceptible to CsA-induced complement deposition. The sequence of incubating MCP-deficient BOECs with CsA $10 \mu \mathrm{g} / \mathrm{ml}$ for 24 hours, followed by 50\% NHS led to increased $\mathrm{C} 3$ deposition. The same sequence of incubation on BOECs from healthy controls did not lead to an increase in $\mathrm{C} 3 \mathrm{c}$ deposition. Taken together, we found that MCP-deficiency rendered an increased susceptibility to CsA-induced complement C3 deposition on surfaces of endothelial cells (Figure 3.15).

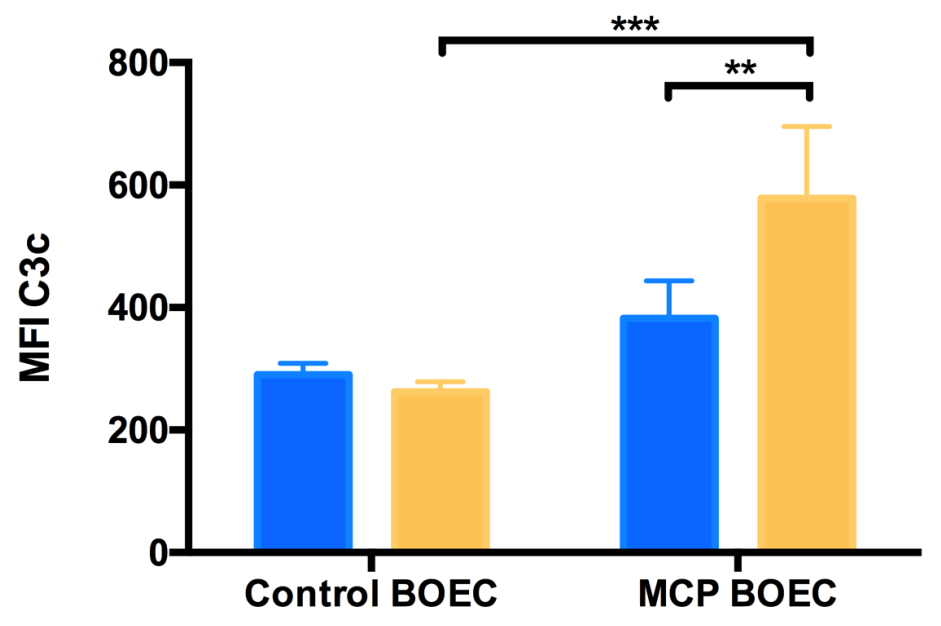

$$
\begin{array}{lr}
\text { Media }(24 \mathrm{~h})+50 \% \text { NHS }(30 \mathrm{~min}) & \mathrm{n}=3 \\
\text { CsA } 10 \mu \mathrm{g} / \mathrm{ml}(24 \mathrm{~h})+50 \% \text { NHS }(30 \mathrm{~min}) & { }^{* *} \mathrm{p}<0.001
\end{array}
$$

Figure 3.15: MCP-deficient BOECs were more susceptible to CsA-induced complement deposition on endothelial cell surfaces. C3c deposition on EC surface by flow cytometry. Nonviable cells were excluded from analysis with Fixable Viability Dye eFluor 780. Incubating MCP-deficient BOEC with CsA $10 \mu \mathrm{g} / \mathrm{ml}$ for 24 hours resulted in significantly higher C3c deposition when compared to control BOEC ( $n=3, p<0.001$, two-way ANOVA, Sidak's multiple comparisons test). 


\section{Chapter 4 \\ Unifying Discussion, Conclusions and Future Directions}

\section{$4 \quad$ Unifying Discussion, Conclusions and Future Directions}

\subsection{Unifying Discussion}

Calcineurin inhibitors (CNI) are widely used immunosuppressive medications. They are most commonly used in the field of transplantation medicine (solid organ and hematopoietic stem cell transplantation) to prevent allograft rejection. However, their use is not confined to patients who have received solid organ and/or hematopoietic stem cell transplants; but are also used to treat a variety of autoimmune disorders, vasculitides and glomerulonephritides. Since CNIs came to clinical prominence in the early 1980s, CNI-based immunosuppression regimens have become the mainstay of maintenance immunosuppression in the care of post-transplant patients. CNIs have revolutionized the care of post-transplant patients, significantly reducing early rejection and improving early transplant allograft and patient survival. However, its use has been complicated by its nephro- and vascular toxicity. CNI use is associated with acute and chronic injury to the kidney tubulo-interstitium, arterioles and glomerulus. A relatively uncommon, but potentially devastating consequence of its effect on the glomerular endothelium is the development of thrombotic microangiopathy (TMA).

The adverse effects of CNI use is thought to contribute to the development of chronic allograft injury which poses a major challenge to transplantation medicine. Despite the improvement in early allograft and patient outcomes, CNI use has not brought about significant improvements in longer-term allograft survival. More than half of kidney transplant allografts are still lost by 10 years post-transplant, and allograft half-life has stagnated over the last 3 decades. Compounding this issue is the rising global rate of end-stage organ failure, leading to increasing waiting-list times, which are associated with increased morbidity and mortality. There is an urgent need to further our understanding of the underlying pathomechanisms related to CNI-induced toxicity which could inform future development of potential therapeutic strategies.

The nuclear factor for activated T cells (NFAT) pathway are a family of transcription factors that upregulate the expression of multiple genes involved in full activation of T cells (cytokines, co- 
stimulatory molecules) which in turn enhances the inflammatory process that contributes to allograft rejection. However, in endothelial cells, the NFAT pathway is involved in regulating the expression of genes involved in important homeostatic function to maintain endothelial cell health i.e. angiogenesis. Thus, inhibiting this pathway with CNIs mitigate the ability of the immune system to reject a transplant allograft, but at a potential cost of injury to the endothelium. Possible causes of CNI-induced endothelial injury have been attributed to vasoconstriction-associated ischemia, increased platelet aggregation, activation of prothrombotic factors and disruption of VEGF-VEGFR mediated angiogenesis.(Yang et al., 2012b)

Evolving evidence suggest a central role for complement dysregulation in the pathogenesis of microvascular endothelial injury which is crucial for the development of TMA. Complement C3 deposition in areas of endothelial injury in human kidney biopsy specimens affected by CNI nephrotoxicity hint at the involvement of the complement system. In an animal model of CNI toxicity, Kim et.al. showed evidence of increased expression of C3, C4d and the membrane attack complex in injured mice kidney tissue.(Kim et al., 2007) In another animal model, Renner et.al. implicated a role for complement involvement in CNI-induced endothelial injury.(Renner et al., 2013) Factor B deficient (fB-/-) mice were spared of cyclosporine-induced complementmediated nephro-, vascular- and glomerular injury that affected their wild-type littermates. Murine endothelial cells exposed to cyclosporine in vitro also showed increased C3 deposition, C3a generation and cell lysis. The study also implicated cyclosporine-induced endothelial cell release of alternative pathway-activating microparticles as a possible mechanism for propagating further bystander endothelial cell injury.(Renner et al., 2013) However, the exact mechanism by which CNIs induce complement activation remain poorly understood.

In our present study, we aimed to clarify the mechanism of CNI-induced complement activation on endothelial cell surfaces and to test the hypothesis that additional 'hits' i.e. a functionally relevant mutation that leads to a complement regulatory defect, increase the susceptibility to CNI-induced complement-mediated endothelial cell injury. 


\subsubsection{Relevant in vitro model to study calcineurin inhibitor-induced complement activation on endothelial cells}

We adapted a previously established in vitro endothelial cell model that allows us to study the effect of complement activation on endothelial cells and the pathogenesis of TMA.(Bowman et al., 2017; Martin-Ramirez et al., 2012; Noone et al., 2016) Blood outgrowth endothelial cells (BOEC) were utilised as they maintain a robust and stable endothelial cell phenotype over multiple passages, have great regenerative capacity, and phenotypically resemble microvascular endothelial cells. Unlike other endothelial cell lines i.e. human umbilical vein endothelial cells (HUVEC) or glomerular endothelial cells (GEC), BOECs have the distinct advantage of being isolated from patients' peripheral blood, reflecting the specific genetic characteristics of the individual patient, therefore allowing us to study the specific patient susceptibility factors i.e. the effect of a functionally relevant $\mathrm{MCP} / \mathrm{CD} 46$ mutation. We used cyclosporine as the prototypical calcineurin inhibitor in our current study as it is widely used in the published literature to study the effect of calcineurin inhibitors. It is within our future plans to use this model to study the effects of other relevant drugs i.e. tacrolimus.

Utilising this model, we first established that increasing doses and duration of exposure of cyclosporine lead to increased endothelial cell injury (Figure 3.1). In the clinical setting, the therapeutic target range for cyclosporine is maintained at a trough level between 100-400 ng/ml. Target steady-state trough concentrations vary depending on the indication of its use, the type of transplant, the use of concomitant immunosuppression, varying clinical and/or institutional protocols and time post-transplant. Suggested target 2-hour post-dose levels could be as high as $2000 \mathrm{ng} / \mathrm{ml}$.(Schiff et al., 2007) Various published in vitro experimental studies on the effect of cyclosporine on various endothelial cell lines used a wide range of drug concentration ranging from $0.1 \mu \mathrm{g} / \mathrm{ml}$ to $4000 \mu \mathrm{g} / \mathrm{ml}$ over varying durations of exposure (up to 72 hours).(Basu et al., 2010; Bouvier et al., 2009; Farivar et al., 2005; Gooch et al., 2017; Grupper et al., 2013; Ikezoe et al., 2012; Illsinger et al., 2011; Renner et al., 2013; Rodrigues-Diez et al., 2016) Although the levels of cyclosporine maintained clinically is lower than those used in experimental in vitro studies, they are not directly comparable. It is one of the limitations of in vitro models of disease. The differences likely reflect the different susceptibility of various different endothelial cell lines, and also inter-species differences. The duration of exposure used in in vitro models are also limited to within 24-72 hours, whereas many patients are on life-long immunosuppression. 
To our knowledge, we are first to study the effect of cyclosporine utilising BOEC. Within our model, an optimal balance of endothelial cell survival and CNI effect was obtained with cyclosporine dose between $10-100 \mu \mathrm{g} / \mathrm{ml}$ for up to 24 hours.

The sequence of cyclosporine incubation followed by $50 \%$ normal human serum (NHS) resulted in a dose-dependent increase in complement $\mathrm{C} 3$ deposition and cell death (Figure 3.2). BOECs from healthy controls only showed increased surface C3 deposition with cyclosporine $50 \mu \mathrm{g} / \mathrm{ml}$ or higher. Cyclosporine was reconstituted in standard endothelial cell growth medium [cEGM-2: Endothelial Basal Medium 2 (EBM-2) supplemented with growth factors (EGM-2 BulletKit), $1 \%$ antibiotic-antimycotic and 10\% fetal bovine serum]. However, 'serum-starved' BOECs were more susceptible to cyclosporine-induced complement C3 deposition. Exposure of BOECs to cyclosporine $10 \mu \mathrm{g} / \mathrm{ml}$ (reconstituted in serum-free media) resulted in increased C3 deposition when compared to control conditions (BOEC exposed to cyclosporine $10 \mu \mathrm{g} / \mathrm{ml}$ reconstituted in media/10\% FBS) (Figure 3.3). Fetal bovine serum (FBS) is supplemented in endothelial cell growth medium to provide a wide variety of macromolecular proteins, low molecular weight nutrients, and growth promoting factors necessary for maintenance of a healthy in vitro endothelial cell culture. Our findings suggest that deprivation of these vital growth factors render an increased susceptibility to cyclosporine-induced complement activation on endothelial cell surfaces.

Incubating cells with an anti-CD59 blocking antibody is an established model to induce enhanced complement deposition on endothelial cell surfaces to allow for studying the effects of complement activation on endothelial cells.(Barilla-LaBarca et al., 2002; Liszewski and Atkinson, 1996; Noone et al., 2016; Triantafilou et al., 2013) This strategy combines the effect of complement induction via sensitization (via the classical pathway) and complement amplification (via the alternative pathway). Interestingly, we found that incubating cells with anti-CD59 led to an enhancement of cyclosporine-induced complement deposition (C3 and C5b9) on endothelial cell surfaces (Figure 3.4 and 3.5). Given the $\sim 2$ fold increase in surface expression of CD59 after exposure to cyclosporine (confirmed by flow cytometry and Western blot) (Figure 3.6E-F and 3.7E-F), the fact that the anti-CD59 is a monoclonal IgG2b antibody an isotype that is known to activate complement via the classical pathway - and the fact that anti-CD59 inhibits the action of the surface-bound complement regulator CD59, the increased 
complement deposition on endothelial cell surfaces induced by cyclosporine is likely due to antiCD59 antibody-initiated activation of the classical pathway, exacerbated by a reduced capacity to regulate the amplification propagated via the alternative pathway.(Noone et al., 2016; Seino et al., 1993) This finding may be considered an in vitro correlate to describe how the increased "antibody load" deposited on microvascular endothelium that occur in antibody-mediated rejection could increase the susceptibility of the endothelium to complement-mediated injury.

\subsubsection{Cyclosporine treatment impaired the regulation of the alternative pathway of complement}

The alternative pathway of complement is constitutively active and efficiently amplifies the activation of the complement system within a short period of time. Protection of host cells from complement-mediated injury is achieved with an equally efficient regulatory mechanism that is provided by a combination of fluid-phase and surface membrane-bound complement regulators. Complement factor $\mathrm{H}(\mathrm{CFH})$ is a key component in preventing $\mathrm{C} 3 \mathrm{~b}$ amplification on surfaces of endothelial cells. CFH acts as cofactor to complement factor I (CFI)-catalyzed cleavage of C3b and inhibits the initiation and accelerates the decay of the $\mathrm{C} 3$ convertase $(\mathrm{C} 3 \mathrm{bBb})$. Utilising a previously established method of assessing surface cofactor activity (Heinen et al., 2007), we

found that cyclosporine treatment led to impairment of CFH surface cofactor activity (Figure 3.9 and 3.10). In the assay, we also included BOEC that were treated with neuraminidase to test whether the absence of sialic acid on the glycocalyx of endothelial cells affected the surface cofactor activity of $\mathrm{CFH}$. The neuraminidase used (derived from Clostridium perfringens) primarily targets sialic acids in $\alpha 2,3$ (to a lesser extent $\alpha 2,6$ and $\alpha 2,8$ ) configuration, and can cleave terminal sialic acid from O-linked glycans, N-linked glycans and glycolipids. Of particular interest, we found that neuraminidase treatment led to a similar impairment of CFH surface cofactor activity (Figure 3.9 and 3.10), suggesting the possibility that cyclosporine affects $\mathrm{CFH}$ binding to endothelial cell surfaces by reduction of sialic acid residues within the glycocalyx.

For CFH, a 'fluid-phase' plasma protein to exert its effect as cofactor to CFI-catalyzed cleavage of $\mathrm{C} 3 \mathrm{~b}$, it must recognize and be recruited to host endothelial cell surfaces. To do so, CFH must bind to glycans harboring terminal sialic acid residues via CFH SCR 6-8 and SCR 19-20 (Figure 1.16 and 1.17). Because we found that cyclosporine treatment led to impaired CFH surface 
cofactor activity, we tested whether it does so by impairing the binding of $\mathrm{CFH}$ to endothelial cell surfaces. Utilising a previously described flow cytometry protocol of quantifying the binding of CFH (Hyvarinen et al., 2016), we showed that cyclosporine treatment did indeed lead to decreased binding of CFH to surfaces of endothelial cells (Figure 3.8). Treatment with neuraminidase also resulted in decreased CFH binding to surfaces of endothelial cells. Taken together, these findings suggest that cyclosporine treatment leads to impaired CFH recognition of and binding to host endothelial cell surfaces which ultimately impairs its surface regulation of the alternative pathway. The inability of $\mathrm{CFH}$ to inactivate $\mathrm{C} 3 \mathrm{~b}$ covalently bound on endothelial cell surfaces would result in an uninhibited amplification loop that allows the full activation of the complement cascade.

We believe that our finding of increased expression of the surface membrane-bound complement regulators $\mathrm{MCP} / \mathrm{CD} 46, \mathrm{DAF} / \mathrm{CD} 55$ and CD59 (Figure 3.6 and 3.7) is a compensatory cellular response to cyclosporine treatment and possibly the impaired $\mathrm{CFH}$ regulation of the alternative pathway. As previously discussed, CFH plays a key role in the regulation of the alternative pathway on surfaces of host endothelial cells: 1) cofactor to CFI-catalyzed inactivation of C3b, 2) competitively inhibits $\mathrm{C} 3 \mathrm{~b}$ deposition, and 3) promotes the disintegration of the $\mathrm{C} 3$ convertase. $\mathrm{MCP} / \mathrm{CD} 46$ aids in the inactivation of $\mathrm{C} 3 \mathrm{~b}$ as a cofactor in the CFI-catalyzed cleavage of $\mathrm{C} 3 \mathrm{~b}$. DAF/CD55 accelerates the disintegration of the $\mathrm{C} 3$ and $\mathrm{C} 5$ convertases and CD59 prevents the formation of the membrane attack complex (C5b-9) by binding to C8. The failure of $\mathrm{CFH}$ to bind to endothelial cell surfaces and exert its function that is induced in our model by cyclosporine, would lead to an increased C3b 'load', which when not tightly regulated, will be amplified with the formation of the $\mathrm{C} 3$ convertases and even more $\mathrm{C} 3 \mathrm{~b}$, eventually leading to the activation of the terminal pathway. In this context, we speculate that increasing the expression of the other complement regulatory armamentarium would be in the host endothelial cells' best 'survival' interest. 


\subsubsection{Cyclosporine-induced abolishment of the endothelial cell glycocalyx - a mechanism for impaired surface $\mathrm{CFH}$ regulation}

As discussed above, $\mathrm{CFH}$ is an important regulator of the alternative pathway. It is found in circulating plasma, and must be recruited to host endothelial cell surfaces to exert its surface regulatory function. To do so, CFH must bind to glycans harboring terminal sialic acid residues via CFH SCR 6-8 and SCR 19-20 (Figure 1.16 and 1.17). We found impaired binding of CFH, leading to impaired surface cofactor activity on endothelial cell surfaces treated with cyclosporine (Figures 3.8, 3.9 and 3.10). A similar impairment of CFH binding and function was observed in neuraminidase treated endothelial cells. The neuraminidase used (derived from Clostridium perfringens) primarily targets sialic acids in $\alpha 2,3$ (to a lesser extent $\alpha 2,6$ and $\alpha 2,8$ ) configuration, and can cleave terminal sialic acid from O-linked glycans, N-linked glycans and glycolipids. We tested the hypothesis that cyclosporine-induced impairment of $\mathrm{CFH}$ surface binding and regulation is mediated through abolishment of the endothelial cell glycocalyx, where glycosaminoglycans and sialic acid residues are abundantly found. Utilising a live cell imaging technique with endothelial cells stained with wheat germ agglutinin, we found that cyclosporine and neuraminidase treatment significantly diminished the endothelial cell glycocalyx (Figures 3.11 and 3.12). The wheat germ agglutinin used is not specific to sialic acid or glycosaminoglycans. It binds to sialic acid and $\mathrm{N}$-acetylglucosaminyl residues within the endothelial cell glycocalyx. Our current finding suggest that cyclosporine treatment negatively affects the endothelial cell glycocalyx which contains molecules that are key to $\mathrm{CFH}$ recognition and binding. Thus, we speculate that this cyclosporine-induced abolishment of the endothelial cell glycocalyx could be the possible pathomechanism to impaired CFH surface regulation, leading to complement activation. However, it remains controversial whether sialic acid or glycosaminoglycans is more important for binding $\mathrm{CFH}$ to endothelial surfaces. Our current findings do not specifically implicate glycosaminoglycans or sialic acid residues. It is within our plans to test the contribution of these specific components individually. 


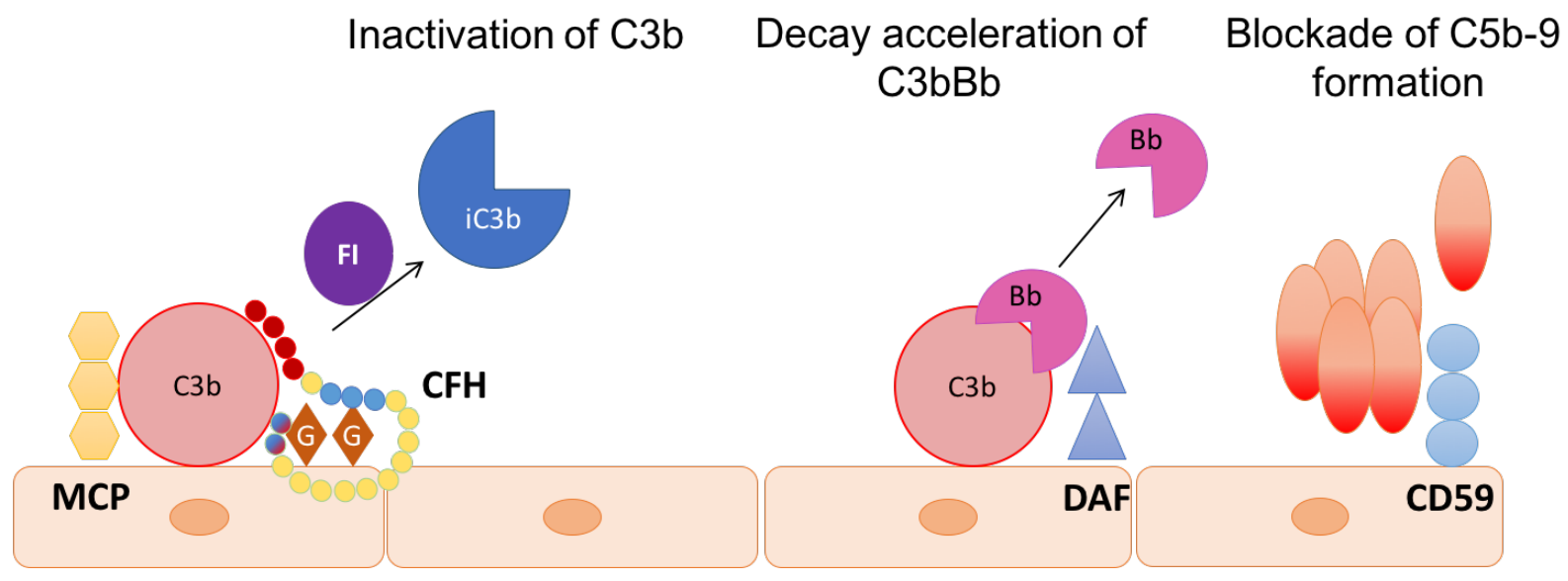

Figure 4.1: Complement regulation on endothelial cells in health. Surface complement regulation follows three main principles: (I) inactivation of $\mathrm{C} 3 \mathrm{~b}$ via the serine protease complement factor I (CFI), a step that requires the presence of cofactors, soluble complement factor $\mathrm{H}(\mathrm{CFH})$ and the membrane-bound membrane cofactor protein (MCP/CD46). (ii) acceleration of the physiological decay of the $\mathrm{C} 3$ convertase $(\mathrm{C} 3 \mathrm{bBb})$ via soluble $\mathrm{CFH}$ and the membrane-bound decay accelerating factor (DAF/CD55); and (iii) blockade of the formation of the membrane attack complex (MAC/C5b-9) via CD59. Adapted with permission from (Teoh et al., 2016). 


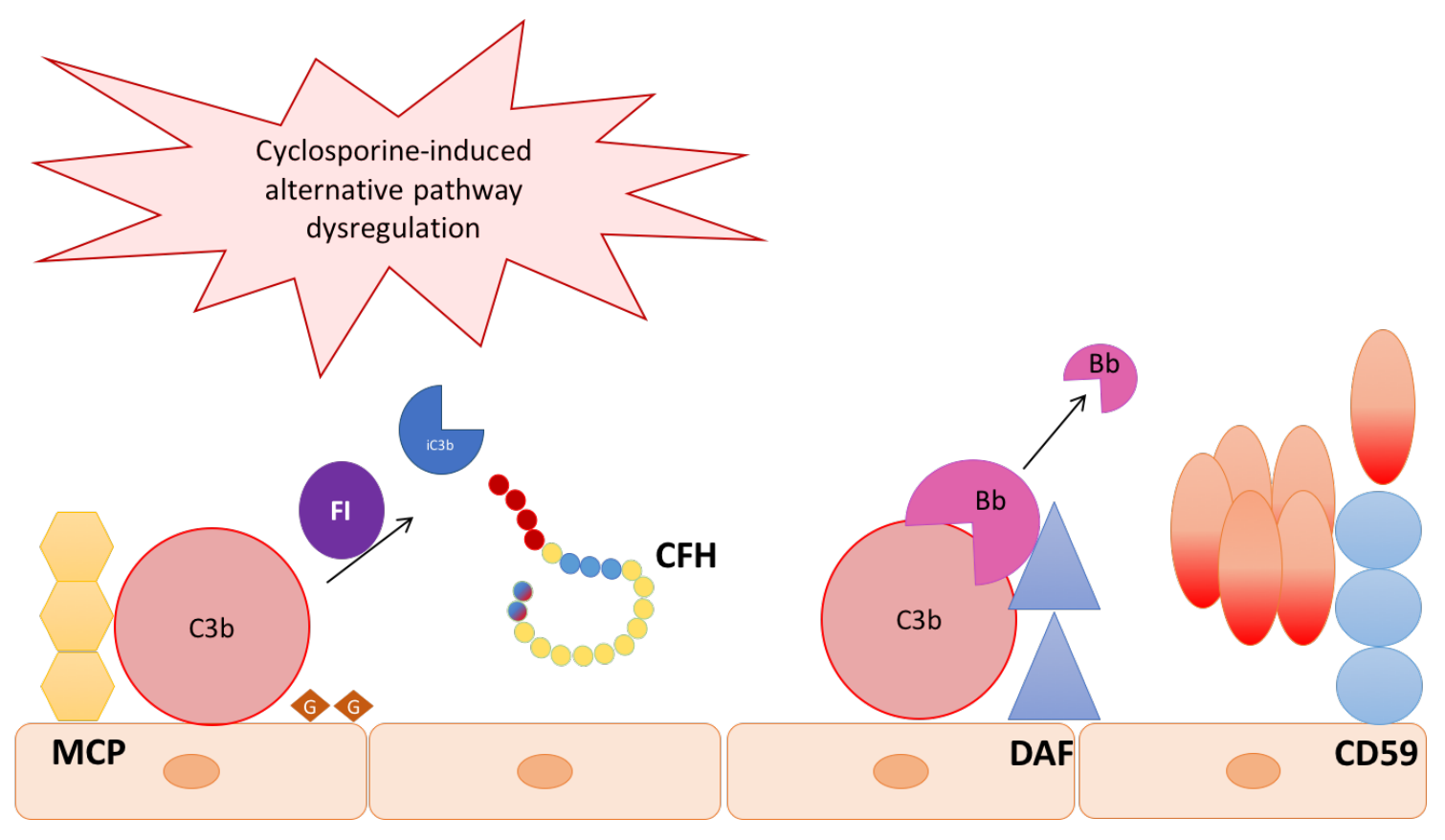

Figure 4.2: Proposed model of surface complement dysregulation due to cyclosporine.

Cyclosporine treatment leads to a diminished endothelial cell glycocalyx $(\mathrm{G})$, which in turn impairs the binding and complement regulatory function of $\mathrm{CFH}$ on endothelial cell surfaces. This leads to impaired regulation of the alternative pathway which amplifies $\mathrm{C} 3$ cleavage to form more $\mathrm{C} 3 \mathrm{~b}$ and formation of $\mathrm{C} 3$ convertase $(\mathrm{C} 3 \mathrm{bBb})$, which in turn leads to more $\mathrm{C} 3 \mathrm{~b}$ formation and deposition on endothelial cell surfaces. This dysregulation also leads to further progression of the complement cascasde leading to terminal pathway activation and formation of the membrane attack complex (C5b-9). To compensate for this increased 'complement load', endothelial cells upregulate the expression of the other surface membrane-bound complement regulators $\mathrm{MCP} / \mathrm{CD} 46, \mathrm{DAF} / \mathrm{CD} 55$ and $\mathrm{CD} 59$. 


\subsubsection{MCP/CD46 deficiency increased susceptibility to cyclosporine- induced complement activation}

Our model system utilizing blood outgrowth endothelial cells (BOEC) derived from human donors offered the distinct advantage of studying the effects of cyclosporine-induced complement activation in close resemblance to specific individual patients' genotype and phenotypic response. It allows the study of specific patient susceptibility factors that may influence how they respond to a particular insult.

This system was used to study the effect of an underlying genetic mutation (MCP/CD46 mutation) had on the susceptibility to complement-mediated endothelial cell injury induced by cyclosporine. BOECs were isolated from a patient with atypical hemolytic uremic syndrome with a frameshift variant in the MCP/CD46 gene that is known to lead to loss of function and disease. These BOECs showed stable endothelial cell phenotype (Figure 3.13A-C) and were deficient in the surface membrane-bound regulator MCP/CD46 (Figure 3.13D and 3.14). The BOECs isolated from this patient with the pathogenic variant in MCP/CD46 had increased surface C3 deposition at baseline. When exposed to cyclosporine, they had significantly higher amounts of surface $\mathrm{C} 3$ deposition when compared to control BOECs (Figure 3.15). Taken together, our findings suggest the MCP/CD46 mutation leading to deficient expression of $\mathrm{MCP} / \mathrm{CD} 46$ increased the susceptibility to cyclosporine-induced complement activation on endothelial cell surfaces, supporting the hypothesis that additional (genetic) aberrancies increase the susceptibility of an individual to the effects of cyclosporine-induced complement-mediated endothelial cell injury (Figure 1.18). This also highlights one of the strengths of our model which utilizes BOECs, allowing us to study the specific patient susceptibility factors and their individual response to injury. 


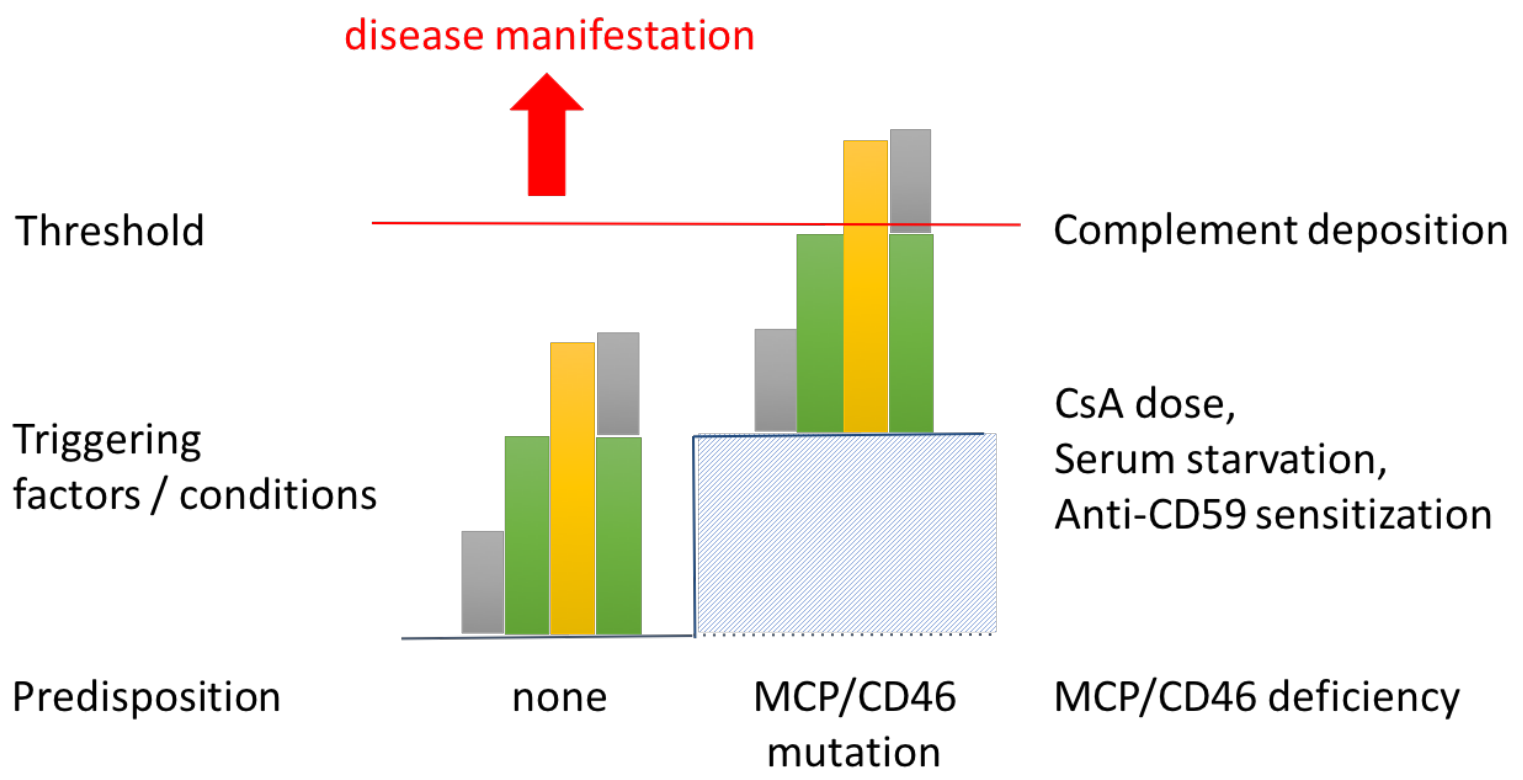

Figure 4.3: Multiple hit hypothesis for CNI-induced complement activation. CNI-induced complement-mediated endothelial cell injury is the consequence of the combination of genetic predisposition and triggering factors/conditions. Findings from our model suggest that $\mathrm{MCP} / \mathrm{CD} 46$ mutation (leading to $\mathrm{MCP} / \mathrm{CD} 46$ deficiency) genetically predisposes to increased susceptibility to CNI-induced complement activation. Modifiable triggering factors within the model are increased CsA dose, serum starvation and sensitization with an anti-CD59 antibody. Figure adapted with permission from (Riedl et al., 2014a). 


\subsection{Conclusion}

Calcineurin inhibitors (CNI) are widely used immunosuppressive medications and are the current gold standard in post-transplant immunosuppression since its introduction into clinical transplant medicine in the early 1980s. Despite significantly reduced the rate of acute rejection and significantly improved early allograft and patient outcomes, its use is associated with significant long-term nephrotoxicity and vascular toxicity, which contributes to chronic allograft injury. Consequently, improvements in longer term outcomes post-transplant have not been realized. More than half of transplant allografts are still lost by 10 years post-transplant. In this era when the global rate of end-stage organ failure is rapidly rising and shortage of organs for transplantation, the challenge facing the transplant community is the improvement of long-term transplant allograft survival.

CNI use is associated with acute and chronic tubulo-interstitial, arteriolar and glomerular injury. While possible mechanisms of injury relate to vasoconstriction associated ischemia, increased platelet aggregation, activation of prothrombotic factors and disruption of VEGF regulation of angiogenesis, evolving evidence also suggest the involvement of the complement system. The association of CNI use and development of thrombotic microangiopathy in patients and complement deposition in areas of endothelial injury in kidney biopsy specimens affected with CNI nephrotoxicity offer hints to the involvement of complement. Animal models of CNI toxicity implicate the complement system and offer explanations of how further complementmediated injury can be propagated. However, the exact mechanism by which CNIs induce complement activation was lacking.

Our study findings shed light on the issue and offers a possible explanation of how CNIs induce complement activation. Our findings suggest a role for complement-mediated endothelial cell injury induced by cyclosporine and implicate CFH surface dysregulation in cyclosporine-induced complement activation on endothelial cell surfaces. Cyclosporine-induced injury and abolishment of the endothelial cell glycocalyx, which contain key components (glycosaminoglycans and sialic acid) that bind CFH to endothelial cell surfaces, may be the key mechanism leading to alternative pathway dysregulation.

In addition, we found that a pathogenic $\mathrm{MCP} / \mathrm{CD} 46$ variant leading to deficient expression of $\mathrm{MCP} / \mathrm{CD} 46$ increased the susceptibility to cyclosporine-induced complement activation on 
endothelial cell surfaces, supporting the multiple hit hypothesis. We believe that this finding confirms the contribution of an underlying genetic predisposition to the pathogenesis of medication-related toxicity. Finally, we believe that by utilizing BOECs isolated from healthy donors and donors with known genetic variants, our model offers a unique method to study the functional effects of a genetic predisposition on medication-induced endothelial cell toxicity. 


\subsection{Future Directions}

\subsubsection{Introduction}

Our current study established a model to study the pathogenesis of CNI-induced complement activation utilizing blood outgrowth endothelial cells (BOEC) which offer the distinct advantage of being isolated from patients' peripheral blood, reflecting the specific genetic characteristics of the individual patient, therefore allowing us to study the specific patient susceptibility factors. Utilizing this model, we established a role for complement-mediated injury as another possible mechanism by which CNIs lead to endothelial injury. Our findings implicate the dysregulation of the alternative pathway rendered by impaired $\mathrm{CFH}$ surface binding and cofactor activity as a possible mechanism of CNI-induced complement activation. Key to this finding may be the injury and abolishment of the endothelial cell glycocalyx caused by CNI. In addition to postulating a possible pathogenic mechanism for CNI toxicity, this exciting finding opens a 'Pandora's box' in the understanding of CNI-induced endothelial cell injury: the maintenance of a healthy endothelial cell glycocalyx is essential to endothelial cell function and homeostasis, and hence damage to the glycocalyx may have detrimental consequences to the overall health and function of the endothelium.

While we utilized BOEC isolated from a patient with a known pathogenic variant in the $\mathrm{MCP} / \mathrm{CD} 46$ gene that led to a deficiency in expression of $\mathrm{MCP} / \mathrm{CD} 46$ on endothelial cell surfaces within our model to address the issue of genetic predisposition to susceptibility of CNIinduced complement-mediated injury, we have established a model that enables us to study the specific genetic characteristics and susceptibility of the individual patient. It is our aim to extend the utility of our model to study the contribution of specific genetic predispositions to toxicity related to CNIs (cyclosporine and tacrolimus) and other medications. Combining them with serum/plasma and other cellular components of blood (neutrophils, macrophages and platelets) would allow us the opportunity to study the interactions between patient-specific endothelial cells and these various components, mimicking the 'real-life' in vivo response.

Moving on from this, we aim to employ our model to further unravel the mechanism of CsAinduced glycocalyx injury. We also aim to examine whether the MCP/CD46 deficient BOECs can mount a dynamic response to cyclosporine-induced complement stress by increasing the expression of the other surface membrane-bound complement regulators like control BOECs. 


\subsubsection{Does cyclosporine-induced complement-mediated endothelial cell injury lead to endothelial cell dysfunction?}

\subsubsection{Rationale, hypothesis and aims}

CNI use is associated with development of thrombotic microangiopathy (TMA) that contributes to nephrotoxicity. Crucial to the development of TMA is injury to the microvascular endothelium. Endothelial cell injury and activation leads to platelet and neutrophil recruitment which eventually leads to thrombus formation, inflammation and subsequent organ failure. Having established our model system utilizing BOECs to study cyclosporine-induced complement activation on endothelial cell surface, we are now poised to study the effect of this complement activation on endothelial dysfunction. We hypothesize that cyclosporine-induced complement activation lead to endothelial cell injury and dysfunction with the development of a pro-inflammatory and pro-thrombotic phenotype, disruption of endothelial cell integrity, impairment of endothelial cell migration and proliferation.

\subsubsection{Proposed methods}

Employing our model of cyclosporine-induced complement activation on BOEC surfaces, we will:

\section{Determine cellular necrosis and apoptosis as a consequence of cyclosporine-induced} complement activation

We will stain BOECs exposed to cyclosporine and 50\% NHS with Annexin V and propridium iodide to assess for apoptosis and necrosis by flow cytometry.

Determine the pro-thrombotic (platelet adhesion) and pro-inflammatory (neutrophil adhesion) consequences following cyclosporine-induced complement activation

We will isolate platelets and neutrophils from peripheral blood of control subjects and stain them with calcein-dye in order to be visualized in the microfluidic chamber.(Cote et al., 2014; Patel et al., 2012) Adhering cells will be measured by fluorescence intensity using the BioFlux software.(Chaturvedi et al., 2013) Experiments will be performed in fluidic conditions at shear rates of 5-10 dyne $/ \mathrm{cm}^{2}$ mimicking blood flow in the kidney microvasculature.(Bevan et al., 2011) 


\section{$\underline{\text { Assess endothelial cell integrity }}$}

We will assess endothelial cell integrity by measuring the trans-endothelial electrical resistance.

\section{Assess endothelial cell migration}

We will assess EC migration with a scratch wound-healing assay in static and microfluidic conditions by measuring wound closure.(Rodriguez et al., 2005; van der Meer et al., 2010) Experiments in fluidic conditions will be performed at shear rates of 5-10 dyne $/ \mathrm{cm}^{2}$ mimicking blood flow in the kidney microvasculature.(Bevan et al., 2011)

\section{$\underline{\text { Assess endothelial cell proliferation }}$}

We will assess EC proliferation with a 5-bromo-2'-deoxyuridine (BrDU) assay.

\subsubsection{Preliminary Results}

We first examined whether cyclosporine treatment followed by exposure to $50 \%$ normal human serum (NHS) led to increased cell death via necrosis or apoptosis. We found that exposure to the higher dose of cyclosporine $50 \mu \mathrm{g} / \mathrm{ml}$ for 24 hours followed by 30 minutes of $50 \%$ NHS led to more cell necrosis over apoptosis (Figure 4.4).

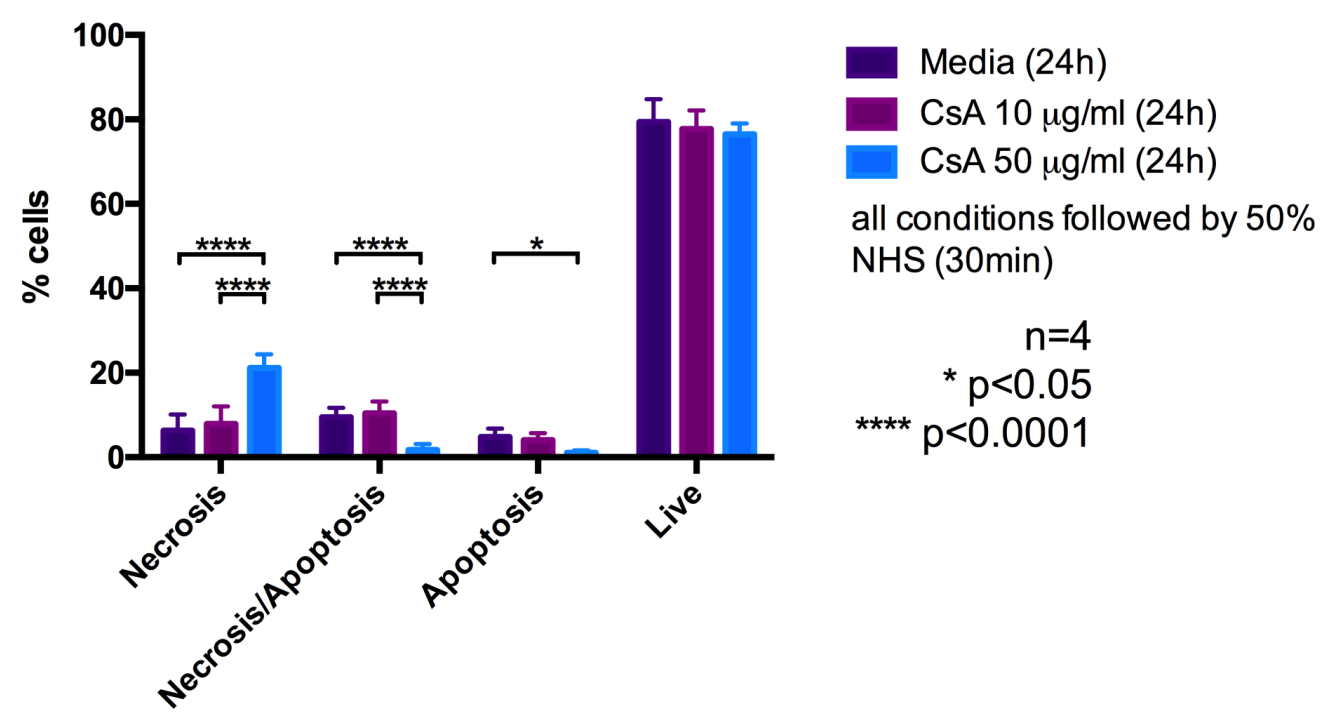

Figure 4.4: Cyclosporine-induced complement-mediated cell cytotoxicity by flow cytometry. Cells were stained with Annexin V (apoptosis) and propridium iodide (necrosis). CsA $50 \mu \mathrm{g} / \mathrm{ml}$ (24 hours) followed by $50 \%$ NHS (30 min) led to more cell necrosis over apoptosis. 
We then found that scratch wound-healing was impaired when endothelial cells were treated with CsA $10 \mu \mathrm{g} / \mathrm{ml}$ for 24 hours (Figures 4.5 and 4.6).

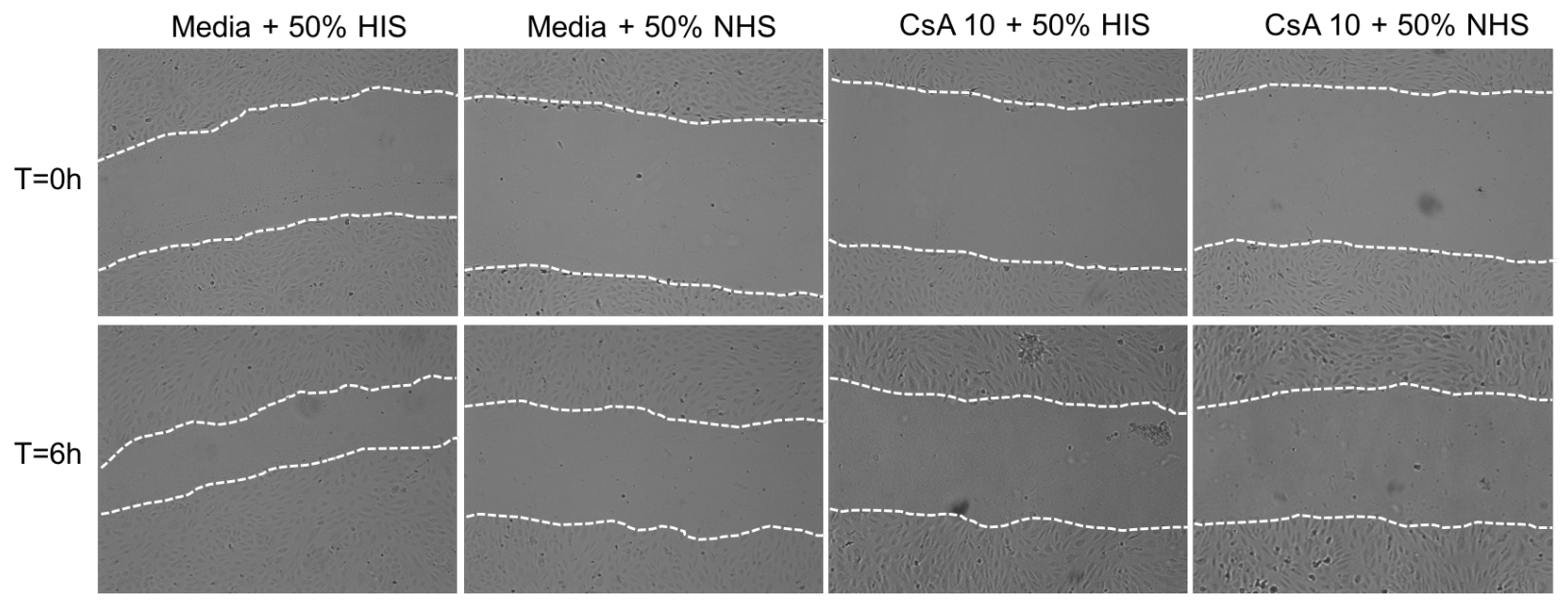

Figure 4.5: Cyclosporine impaired scratch wound healing. Scratch wound-healing assay. Confluent monolayers of BOEC were treated with media or cyclosporine $10 \mu \mathrm{g} / \mathrm{ml}$ for 24 hours. A scratch wound was made and cells were allowed to heal over 6 hours with either $50 \%$ heatinactivated serum (HIS, complement inactive) or 50\% normal human serum (NHS, complement active).

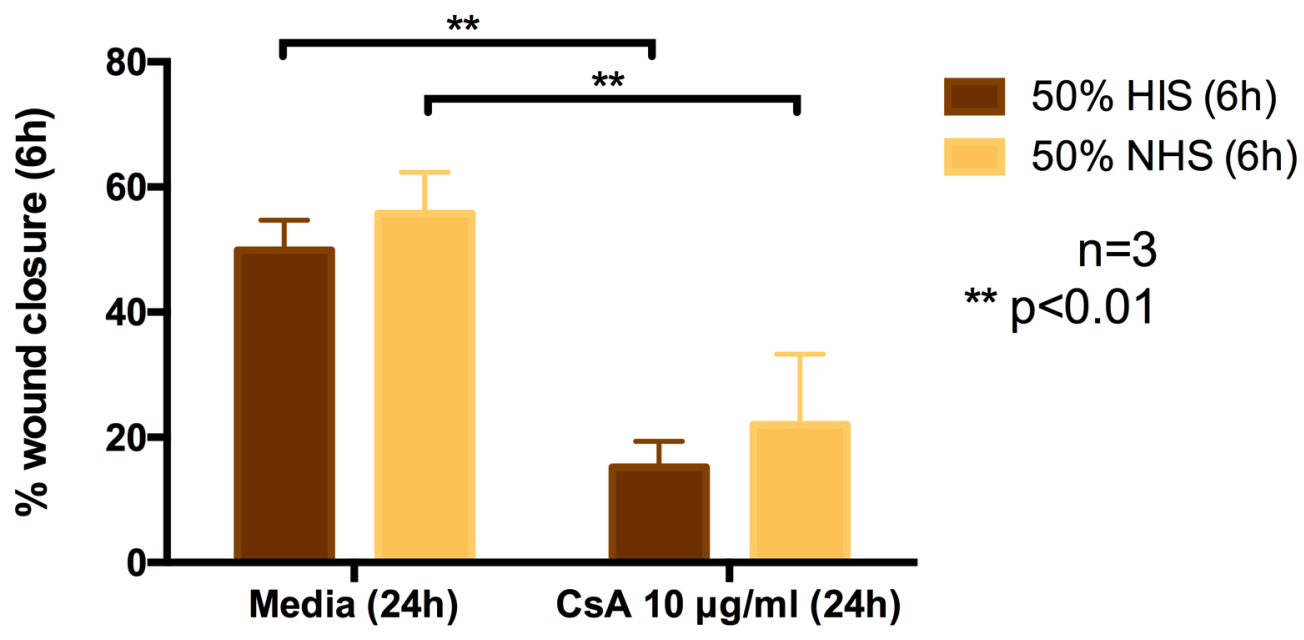

Figure 4.6: Cyclosporine impaired scratch wound healing. Summary of scratch woundhealing assay. Treatment with cyclosporine $10 \mu \mathrm{g} / \mathrm{ml}$ for 24 hours significantly impaired scratch wound-healing over 6 hours. There were no differences in scratch wound-healing whether the healing occurred in a complement active (50\% NHS) or inactive (50\% HIS) environment. 


\subsubsection{Discussion}

These preliminary results confirm that cyclosporine treatment led to endothelial cell injury and dysfunction. The higher dose of cyclosporine $50 \mu \mathrm{g} / \mathrm{ml}$ led to an increased proportion of necrotic cells (over apoptotic cells) despite a similar overall cell survival. Cyclosporine treatment also led to impaired scratch wound-healing, although we found no significant complement-mediated effect on scratch wound-healing.

We will next assess if this impairment in scratch wound-healing is secondary to impaired endothelial cell migration or reduced proliferation. We will complete this part of our work by assessing the effect of cyclosporine-induced complement-mediated endothelial cell injury on endothelial cell integrity, neutrophil and platelet adhesion.

\subsubsection{Does Tacrolimus induce a similar complement dysregulation and complement-mediated endothelial cell injury and dysfunction?}

Clinically, tacrolimus (a newer calcineurin inhibitor) is associated with less nephro- and vascular toxicity. We plan to employ our model system to assess if there is differential effect of tacrolimus in causing injury to endothelial cells, leading to CFH surface dysregulation and subsequent complement-mediated endothelial cell injury and dysfunction.

\subsubsection{Is cyclosporine-induced endothelial cell glycocalyx injury mediated by angiopoietin-2?}

As previously discussed, $\mathrm{CFH}$ is an important regulator of the alternative pathway. It is found in circulating plasma, and must be recruited to host endothelial cells surfaces to exert its surface regulatory function. To do so, $\mathrm{CFH}$ must bind to glycans harboring terminal sialic acid residues via CFH SCR 6-8 and SCR 19-20 (Figure 1.16 and 1.17). Futhermore, CFH has binding sites for heparan sulfate (linear sulfated polysaccharides found within glycosaminoglycans) found within SCR 6-8 and SCR 19-20.(Schmidt et al., 2008b) Heparan sulfate are only present in the glycocalyx of host cells and are absent on pathogens, allowing CFH to differentiate between host and pathogenic surfaces.(Pangburn, 2000; Sarrazin et al., 2011) A recent study suggested that the 
breakdown of endothelial cell glycocalyx is due to the loss of heparan sulfate secondary to secretion of heparan sulfate-specific heparanase from lysosomal stores, mediated by the release of angiopoietin-2.(Lukasz et al., 2017) Angiopoietin-2 is released from within its store in endothelial Weibel Palades bodies by inflammatory stimulation and disrupts the constitutive Angiopoietin-1 and Tie-2 signalling which is crucial for developmental angiogenesis.(Fiedler et al., 2004; Sato et al., 1995)

In our study, we found that cyclosporine treatment led to abolishment of the endothelial cell glycocalyx (Figures 3.11 and 3.12). We plan to determine if this cyclosporine-induced glycocalyx injury is due to the loss of heparan sulfate that is mediated by angiopoietin- 2 . We first plan to assess if cyclosporine treatment negatively affects heparan sulfate content within the endothelial cell glycocalyx by immunofluorescence imaging. We will interrogate the role of secreted heparanases by using a heparanase inhibitor (i.e. heparin). We will then assess if cyclosporine treatment leads to endothelial release of von Willebrand factor (vWF) and angiopoietin-2 by immunofluorescence, and assess if they co-localize within Weibel Palade bodies on imaging. We will then utilize BOECs isolated from type 3 von Willebrand disease patients (which lack vWF and Weibel Palade bodies) to interrogate the role of angiopoietin-2 in mediating cyclosporine-induced glycocalyx injury.

\subsubsection{Do calcineurin inhibitors induce endothelial glycocalyx injury in vivo?}

Findings from our in vitro model highlight cyclosporine-induced endothelial glycocalyx injury as a possible cause of impaired regulation of the alternative pathway, leading to complement activation and injury on endothelial cells. While kidney biopsies from patients with CNI toxicity are known to have increased complement deposition in areas of arteriolar injury, a diminished endothelial glycocalyx has never been assessed. We intend to obtain research ethics board approval to assess if kidney biopsy specimens with evidence of CNI toxicity also have diminished endothelial glycocalyx by immunohistochemistry using anti-heparan sulfate proteoglycan antibody. 


\subsubsection{Are MCP/CD46 deficient BOECs derived from a patient with MCP/CD46 mutation capable of mounting a dynamic response to cyclosporine-induced complement activation?}

We showed that BOECs derived from a patient with MCP/CD46 mutation are deficient in the surface membrane-bound MCP/CD46 (Figures 3.13D and 3.14), and are more susceptible to cyslosporine-induced complement C3 deposition (Figure 3.15). We plan to further study whether these $\mathrm{MCP} / \mathrm{CD} 46$ deficient BOECs are also capable of increasing the expression of the surface membrane-bound complement regulators MCP/CD46, DAF/CD55 and CD59 in response to complement challenge induced by cyclosporine.

\subsubsection{Does the MCP/CD46 mutation render a worse response to complement-mediated injury induced by cyclosporine?}

We plan to study if the increased susceptibility of the MCP BOECs to cyclosporine-induced complement deposition also translate to a more severe endothelial cell injury and dysfunction phenotype. We plan to repeat experiments as outlined in Section 4.3.2 with MCP BOECs to test this hypothesis that MCP BOECs are more susceptible to worse cyclosporine-induced complement-mediated endothelial cell injury and dysfunction.

\subsubsection{Will BOEC isolated from patients with CNI toxicity further our understanding of $\mathrm{CNI}$-induced complement-mediated endothelial cell toxicity?}

We plan to study specific patient susceptibility factors that may have predisposed them to developing CNI toxicity. Briefly, BOEC isolated from patients with biopsy-proven CNI toxicity can be incorporated within our model system to study if they are more susceptible to CNIinduced complement-mediated endothelial cell injury and dysfunction. Patient specific serum, neutrophils and platelets could also be incorporated into the model to assess the contribution of each of these components to their individual susceptibility to CNI toxicity. 


\subsubsection{Establishing a role for biomarkers of endothelial glycocalyx injury for early detection of $\mathrm{CNI}$-induced endothelial injury}

We found cyclosporine treatment to have a negative impact on the endothelial glycocalyx. We intend to apply this knowledge to establish the use of serum/plasma biomarkers of endothelial glycocalyx injury in monitoring of patients treated with CNIs. Shedding of several endothelial glycocalyx components i.e. syndecan-1, heparan sulfate and hyaluronan have been shown to be elevated in plasma of patients in the context of several conditions associated with endothelial cell injury i.e. cardiovascular injury, ischemia and hemorrhagic shock.(Chappell et al., 2007; Haywood-Watson et al., 2011; Rabelink et al., 2010; Rehm et al., 2007) Currently, the definitive diagnosis of CNI toxicity is made through kidney biopsy. Repeated kidney biopsies for monitoring and early detection of CNI toxicity is associated with the inherent risks of biopsies i.e. bleeding. We intend to obtain research ethics board approval for a prospective clinical study to assess the utility of these plasma biomarkers of endothelial glycocalyx injury for ongoing monitoring of patients on CNI treatment. Briefly, we will collect blood samples from patients prior to initiation with treatment of CNI, and after commencing on CNI treatment (24 hours, 1 week, and monthly thereafter to coincide with therapeutic drug monitoring) for quantification of circulating endothelial glycocalyx components (syndecan-1, heparan sulfate, hyaluronan) and circulating markers of endothelial dysfunction (angiopoietin-2, soluble vascular cell adhesion molecule-1 and von Willebrand factor)(Cofiell et al., 2015; Rabelink et al., 2010). We will correlate the levels of these markers with serum creatinine and therapeutic drug monitoring levels of CNI. Patients on treatment with CNIs in our institution undergo surveillance kidney biopsies at pre-determined time-points: 1) post-kidney transplant patients have surveillance kidney biopsies performed at 6 weeks, 3 months, 1 year post-transplant and yearly thereafter), and 2) nephrotic syndrome patients on CNI treatment have surveillance kidney biopsies performed at baseline prior to initiation of CNI treatment and at 2 years post-CNI treatment (and every 18-24 months thereafter if they remain on CNI treatment). In addition, indication biopsies are performed when necessary. We will correlate the levels of circulating endothelial glycocalyx components and circulating markers of endothelial dysfunction with these kidney biopsy findings and attempt to establish an association with the development of CNI toxicity. It is our aim to assess the feasibility of using these circulating biomarkers of endothelial glycocalyx injury and dysfunction as a non-invasive monitoring tool for early detection of CNI toxicity. 


\section{References}

Abbott, K.L., Robida, A.M., Davis, M.E., Pavlath, G.K., Camden, J.M., Turner, J.T., and Murphy, T.J. (2000). Differential regulation of vascular smooth muscle nuclear factor kappa-B by G alpha q-coupled and cytokine receptors. J Mol Cell Cardiol 32, 391-403.

Ahmann, K.A., Johnson, S.L., Hebbel, R.P., and Tranquillo, R.T. (2011). Shear stress responses of adult blood outgrowth endothelial cells seeded on bioartificial tissue. Tissue engineering Part A $17,2511-2521$.

Ahsan, N., Johnson, C., Gonwa, T., Halloran, P., Stegall, M., Hardy, M., Metzger, R., Shield, C.I., Rocher, L., Scandling, J., et al. (2001). Randomized trial of tacrolimus plus mycophenolate mofetil or azathioprine versus cyclosporine oral solution (modified) plus mycophenolate mofetil after cadaveric kidney transplantation: Results at 2 years. Transplantation 72, 245-250.

Al-Massarani, G., Vacher-Coponat, H., Paul, P., Widemann, A., Arnaud, L., Loundou, A., Robert, S., Berland, Y., Dignat-George, F., and Camoin-Jau, L. (2008). Impact of immunosuppressive treatment on endothelial biomarkers after kidney transplantation. Am J Transplant 8, 2360-2367.

Al-Nouri, Z.L., Reese, J.A., Terrell, D.R., Vesely, S.K., and George, J.N. (2015). Drug-induced thrombotic microangiopathy: a systematic review of published reports. Blood 125, 616-618.

Ali, M.N., Syed, A., and Bhandari, S. (2013). Case series: hemolytic uremic syndrome--another cause of transplant dysfunction. Transplant Proc 45, 3284-3288.

Amara, U., Rittirsch, D., Flierl, M., Bruckner, U., Klos, A., Gebhard, F., Lambris, J.D., and Huber-Lang, M. (2008). Interaction between the coagulation and complement system. Adv Exp Med Biol 632, 71-79.

Amberg, G.C., Rossow, C.F., Navedo, M.F., and Santana, L.F. (2004). NFATc3 regulates Kv2.1 expression in arterial smooth muscle. J Biol Chem 279, 47326-47334.

Armesilla, A.L., Lorenzo, E., Gomez del Arco, P., Martinez-Martinez, S., Alfranca, A., and Redondo, J.M. (1999). Vascular endothelial growth factor activates nuclear factor of activated T cells in human endothelial cells: a role for tissue factor gene expression. Mol Cell Biol 19, 20322043.

Azzi, J.R., Sayegh, M.H., and Mallat, S.G. (2013). Calcineurin inhibitors: 40 years later, can't live without. J Immunol 191, 5785-5791.

Barbour, T.D., Ruseva, M.M., and Pickering, M.C. (2016). Update on C3 glomerulopathy. Nephrol Dial Transplant 31, 717-725.

Barilla-LaBarca, M.L., Liszewski, M.K., Lambris, J.D., Hourcade, D., and Atkinson, J.P. (2002). Role of membrane cofactor protein (CD46) in regulation of $\mathrm{C} 4 \mathrm{~b}$ and $\mathrm{C} 3 \mathrm{~b}$ deposited on cells. J Immunol 168, 6298-6304. 
Basu, A., Datta, D., Zurakowski, D., and Pal, S. (2010). Altered VEGF mRNA stability following treatments with immunosuppressive agents: implications for cancer development. J Biol Chem 285, 25196-25202.

Benz, K., Amann, K., Dittrich, K., and Dötsch, J. (2007). Thrombotic microangiopathy as a complication in a patient with focal segmental glomerulosclerosis. Pediatric Nephrology 22, 2125-2128.

Bevan, H.S., Slater, S.C., Clarke, H., Cahill, P.A., Mathieson, P.W., Welsh, G.I., and Satchell, S.C. (2011). Acute laminar shear stress reversibly increases human glomerular endothelial cell permeability via activation of endothelial nitric oxide synthase. Am J Physiol Renal Physiol 301, F733-742.

Blaum, B.S., Hannan, J.P., Herbert, A.P., Kavanagh, D., Uhrin, D., and Stehle, T. (2015). Structural basis for sialic acid-mediated self-recognition by complement factor $\mathrm{H}$. Nat Chem Biol 11, 77-82.

Blom, A.M., Hallstrom, T., and Riesbeck, K. (2009). Complement evasion strategies of pathogens-acquisition of inhibitors and beyond. Mol Immunol 46, 2808-2817.

Bochkov, V.N. (2002). Oxidized phospholipids stimulate tissue factor expression in human endothelial cells via activation of ERK/EGR-1 and Ca++/NFAT. Blood 99, 199-206.

Bokenkamp, A., Hoyer, P.F., Offner, G., Helmchen, U., and Brodehl, J. (1992). Recurrent haemolytic uraemic syndrome in a boy with focal and segmental glomerulosclerosis. European Journal of Pediatrics 151, 791-792.

Bonnet, S., Rochefort, G., Sutendra, G., Archer, S.L., Haromy, A., Webster, L., Hashimoto, K., Bonnet, S.N., and Michelakis, E.D. (2007). The nuclear factor of activated T cells in pulmonary arterial hypertension can be therapeutically targeted. Proc Natl Acad Sci U S A 104, 1141811423.

Borel, J., Feurer, C., Gubler, H., and Stahelin, H. (1976). Biological effects of cyclosporin A: a new antilymphocytic agent. Agents Actions 6, 468-475.

Bouts, A.H., Roofthooft, M.T.R., Salomons, G.S., and Davin, J.C. (2010). CD46-associated atypical hemolytic uremic syndrome with uncommon course caused by cblC deficiency. Pediatric Nephrology 25, 2547-2548.

Bouvier, N., Flinois, J.P., Gilleron, J., Sauvage, F.L., Legendre, C., Beaune, P., Thervet, E., Anglicheau, D., and Pallet, N. (2009). Cyclosporine triggers endoplasmic reticulum stress in endothelial cells: a role for endothelial phenotypic changes and death. Am J Physiol Renal Physiol 296, F160-169.

Bowman, M.L., Pluthero, F.G., Tuttle, A., Casey, L., Li, L., Christensen, H., Robinson, K.S., Lillicrap, D., Kahr, W.H.A., and James, P. (2017). Discrepant platelet and plasma von Willebrand factor in von Willebrand disease patients with p.Pro2808Leufs*24. J Thromb Haemost ePublication ahead of print, 1-9. 
Bram, R.J., Hung, D.T., Martin, P.K., Schreiber, S.L., and Crabtree, G.R. (1993). Identification of the immunophilins capable of mediating inhibition of signal transduction by cyclosporin A and FK506: roles of calcineurin binding and cellular location. Mol Cell Biol 13, 4760-4769.

Bren, A., Pajek, J., Grego, K., Buturovic, J., Ponikvar, R., Lindic, J., Knap, B., Vizjak, A., Ferluga, D., and Kandus, A. (2005). Follow-up of kidney graft recipients with cyclosporineassociated hemolytic-uremic syndrome and thrombotic microangiopathy. Transplant Proc 37, 1889-1891.

Bresin, E., Rurali, E., Caprioli, J., Sanchez-corral, P., Fremeaux-, V., Cordoba, S.R.D., Pinto, S., Goodship, T.H.J., Alberti, M., Ribes, D., et al. (2013). Combined Complement Gene Mutations in Atypical Hemolytic Uremic Syndrome In fl uence Clinical Phenotype. J Am Soc Nephrol 24, 475-486.

Caires, R.a., Marques, I.D.B., Repizo, L.P., Sato, V.a.H., Carmo, L.P.F., Machado, D.J.B., de Paula, F.J., Nahas, W.C., and David-Neto, E. (2012). De Novo Thrombotic Microangiopathy After Kidney Transplantation: Clinical Features, Treatment, and Long-Term Patient and Graft Survival. Transplantation Proceedings 44, 2388-2390.

Calne, R.Y. (1987). Cyclosporin in cadaveric renal transplantation: 5-year follow-up of a multicentre trial. Lancet 2, 506-507.

Calne, R.Y., Rolles, K., Thiru, S., McMaster, P., Craddock, G.N., Aziz, S., White, D.J.G., Evans, D.B., Dunn, D.C., Henderson, R.G., et al. (1979). Cyclosporin A Initially as the Only Immunosuppressant in 34 Recipients of Cadaveric Organs: 32 Kidneys, 2 Pancreases, and 2 Livers. Lancet 314, 1033-1036.

Calne, R.Y., Thiru, S., McMaster, P., Craddock, G.N., White, D.J.G., Evans, D.B., Dunn, D.C., Pentlow, B.D., and Rolles, K. (1978). Cyclosporin A in Patients Receiving Renal Allografts from Cadaver Donors. Lancet 312, 1323-1327.

Camous, L., Roumenina, L., Bigot, S., Brachemi, S., Fremeaux-Bacchi, V., Lesavre, P., and Halbwachs-Mecarelli, L. (2011). Complement alternative pathway acts as a positive feedback amplification of neutrophil activation. Blood 117, 1340-1349.

Campbell, W.D., Lazoura, E., Okada, N., and Okada, H. (2002). Inactivation of C3a and C5a Octapeptides by Carboxypeptidase R and Carboxypeptidase N. Microbiology and Immunology $46,131-134$.

Campistol, J.M., Arias, M., Ariceta, G., Blasco, M., Espinosa, M., Grinyo, J.M., Praga, M., Torra, R., Vilalta, R., and Rodriguez de Cordoba, S. (2013). An update for atypical haemolytic uraemic syndrome: diagnosis and treatment. A consensus document. Nefrologia 33, 27-45.

Canadian Multicentre Transplant Study Group (1983). A randomized clinical trial of cyclosporine in cadaveric renal transplantation. N Engl J Med 309, 809-815.

Canadian Multicentre Transplant Study Group (1986). A randomized clinical trial of cyclosporine in cadaveric renal transplantation. Analysis at three years. N Engl J Med 314, 1219-1225. 
Cataland, S.R., and Wu, H.M. (2014). Diagnosis and management of complement mediated thrombotic microangiopathies. Blood Reviews 28, 67-74.

Cattran, D.C., Appel, G.B., Hebert, L.A., Hunsicker, L.G., Pohl, M.A., Hoy, W.E., Maxwell, D.R., Kunis, C.L., and North America Nephrotic Syndrome Study, G. (2001). Cyclosporine in patients with steroid-resistant membranous nephropathy: a randomized trial. Kidney Int 59, 1484-1490.

Chang, C.P., Neilson, J.R., Bayle, J.H., Gestwicki, J.E., Kuo, A., Stankunas, K., Graef, I.A., and Crabtree, G.R. (2004). A field of myocardial-endocardial NFAT signaling underlies heart valve morphogenesis. Cell 118, 649-663.

Chang Milbauer, L., Wei, P., Enenstein, J., Jiang, A., Hillery, C.A., Scott, J.P., Nelson, S.C., Bodempudi, V., Topper, J.N., Yang, R.B., et al. (2008). Genetic endothelial systems biology of sickle stroke risk. Blood 111, 3872-3879.

Chapin, J., Eyler, S., Smith, R., Tsai, H.M., and Laurence, J. (2013). Complement factor H mutations are present in ADAMTS13-deficient, ticlopidine-associated thrombotic microangiopathies. Blood 121, 4012-4013.

Chappell, D., Jacob, M., Hofmann-Kiefer, K., Bruegger, D., Rehm, M., Conzen, P., Welsch, U., and Becker, B.F. (2007). Hydrocortisone preserves the vascular barrier by protecting the endothelial glycocalyx. Anesthesiology 107, 776-784.

Chaturvedi, S., Yuen, D.a., Bajwa, A., Huang, Y.-W., Sokollik, C., Huang, L., Lam, G.Y., Tole, S., Liu, G.-Y., Pan, J., et al. (2013). Slit2 prevents neutrophil recruitment and renal ischemiareperfusion injury. J Am Soc Nephrol 24, 1274-1287.

Chen, M., Forrester, J.V., and Xu, H. (2007). Synthesis of complement factor H by retinal pigment epithelial cells is down-regulated by oxidized photoreceptor outer segments. Exp Eye Res $84,635-645$.

Chen, M.-H., Chen, M.-H., Chen, W.-S., Mu-Hsin Chang, P., Lee, H.-T., Lin, H.-Y., and Huang, D.-F. (2011). Thrombotic microangiopathy in systemic lupus erythematosus: a cohort study in North Taiwan. Rheumatology (Oxford, England) 50, 768-775.

Chiou, Y.Y., Lee, Y.C., and Chen, M.J. (2017). Cyclosporine-based immunosuppressive therapy for patients with steroid-resistant focal segmental glomerulosclerosis: a meta-analysis. Curr Med Res Opin, 1-11.

Clark, S.J., Bishop, P.N., and Day, A.J. (2010). Complement factor H and age-related macular degeneration: the role of glycosaminoglycan recognition in disease pathology. Biochem Soc Trans 38, 1342-1348.

Clark, S.J., Ridge, L.A., Herbert, A.P., Hakobyan, S., Mulloy, B., Lennon, R., Wurzner, R., Morgan, B.P., Uhrin, D., Bishop, P.N., et al. (2013). Tissue-specific host recognition by complement factor $\mathrm{H}$ is mediated by differential activities of its glycosaminoglycan-binding regions. J Immunol 190, 2049-2057. 
Coats, M.T., Murphy, T., Paton, J.C., Gray, B., and Briles, D.E. (2011). Exposure of ThomsenFriedenreich antigen in Streptococcus pneumoniae infection is dependent on pneumococcal neuraminidase A. Microb Pathog 50, 343-349.

Cockerill, G.W., Bert, A.G., Ryan, G.R., Gamble, J.R., Vadas, M.A., and Cockerill, P.N. (1995). Regulation of granulocyte-macrophage colony-stimulating factor and E-selectin expression in endothelial cells by cyclosporin A and the T-cell transcription factor NFAT. Blood 86, 26892698.

Cofiell, R., Kukreja, A., Bedard, K., Yan, Y., Mickle, A., Ogawa, M., Bedrosian, C., and Faas, S. (2015). Eculizumab reduces complement activation, inflammation, endothelial damage, thrombosis, and renal injury markers in aHUS. Blood 125, 3253-3262.

Coppens, V., Heremans, Y., Leuckx, G., Suenens, K., Jacobs-Tulleneers-Thevissen, D., Verdonck, K., Lahoutte, T., Luttun, a., Heimberg, H., and De Leu, N. (2013). Human blood outgrowth endothelial cells improve islet survival and function when co-transplanted in a mouse model of diabetes. Diabetologia 56, 382-390.

Cortina, G., Trojer, R., Waldegger, S., Schneeberger, S., Gut, N., and Hofer, J. (2015). De novo tacrolimus-induced thrombotic microangiopathy in the early stage after renal transplantation successfully treated with conversion to everolimus. Pediatr Nephrol 30, 693-697.

Cote, O., Clark, M.E., Viel, L., Labbe, G., Seah, S.Y., Khan, M.A., Douda, D.N., Palaniyar, N., and Bienzle, D. (2014). Secretoglobin 1A1 and 1A1A differentially regulate neutrophil reactive oxygen species production, phagocytosis and extracellular trap formation. PLoS One 9, e96217.

Dauwe, D., Pelacho, B., Wibowo, A., Walravens, A.S., Verdonck, K., Gillijns, H., Caluwe, E., Pokreisz, P., van Gastel, N., Carmeliet, G., et al. (2016). Neovascularization Potential of Blood Outgrowth Endothelial Cells From Patients With Stable Ischemic Heart Failure Is Preserved. J Am Heart Assoc 5, e002288.

de Frutos, S., Duling, L., Alo, D., Berry, T., Jackson-Weaver, O., Walker, M., Kanagy, N., and Gonzalez Bosc, L. (2008). NFATc3 is required for intermittent hypoxia-induced hypertension. Am J Physiol Heart Circ Physiol 294, H2382-2390.

de Frutos, S., Spangler, R., Alo, D., and Bosc, L.V. (2007). NFATc3 mediates chronic hypoxiainduced pulmonary arterial remodeling with alpha-actin up-regulation. J Biol Chem 282, 1508115089.

de la Pompa, J.L., Timmerman, L.A., Takimoto, H., Yoshida, H., Elia, A.J., Samper, E., Potter, J., Wakeham, A., Marengere, L., Langille, B.L., et al. (1998). Role of the NF-ATc transcription factor in morphogenesis of cardiac valves and septum. Nature 392, 182-186.

Degn, S.E., and Thiel, S. (2013). Humoral pattern recognition and the complement system. Scand J Immunol 78, 181-193.

Delvaeye, M., Noris, M., De Vriese, A., Esmon, C.T., Esmon, N.L., Ferrell, G., Del-Favero, J., Plaisance, S., Claes, B., Lambrechts, D., et al. (2009). Thrombomodulin mutations in atypical hemolytic-uremic syndrome. N Engl J Med 361, 345-357. 
Dieterle, A., Gratwohl, A., Nizze, H., Huser, B., Mihatsch, M.J., Thiel, G., Tichelli, A., Signer, E., Nissen, C., and Speck, B. (1990). Chronic cyclosporine-associated nephrotoxicity in bone marrow transplant patients. Transplantation 49, 1093-1100.

Dragon-Durey, M.-A., Loirat, C., Cloarec, S., Macher, M.-A., Blouin, J., Nivet, H., Weiss, L., Fridman, W.H., and Frémeaux-Bacchi, V. (2005). Anti-Factor H autoantibodies associated with atypical hemolytic uremic syndrome. J Am Soc Nephrol 16, 555-563.

Ekberg, H., Bernasconi, C., Tedesco-Silva, H., Vitko, S., Hugo, C., Demirbas, A., Acevedo, R.R., Grinyo, J., Frei, U., Vanrenterghem, Y., et al. (2009). Calcineurin inhibitor minimization in the Symphony study: observational results 3 years after transplantation. Am J Transplant 9 , 1876-1885.

Ekberg, H., Tedesco-Silva, H., Demirbas, A., Vitko, S., Nashan, B.B., Gurkan, A., Margreiter, R., Hugo, C., Grinyo, J.M., Frei, U., et al. (2007). Reduced exposure to calcineurin inhibitors in renal transplantation. N Engl J Med 357, 2562-2575.

El Karoui, K., Hill, G.S., Karras, A., Jacquot, C., Moulonguet, L., Kourilsky, O., FrémeauxBacchi, V., Delahousse, M., Duong Van Huyen, J.-P., Loupy, A., et al. (2012). A clinicopathologic study of thrombotic microangiopathy in IgA nephropathy. J Am Soc Nephrol 23, 137-148.

Ellis, C.N., Fradin, M.S., Messana, J.M., Brown, M.D., Siegel, M.T., Hartley, A.H., Rocher, L.L., Wheeler, S., Hamilton, T.A., Parish, T.G., et al. (1991). Cyclosporine for plaque-type psoriasis. Results of a multidose, double-blind trial. N Engl J Med 324, 277-284.

Enenstein, J., Milbauer, L., Domingo, E., Wells, A., Roney, M., Kiley, J., Wei, P., and Hebbel, R.P. (2010). Proinflammatory phenotype with imbalance of KLF2 and RelA: risk of childhood stroke with sickle cell anemia. Am J Hematol 85, 18-23.

Ensley, A.E., Nerem, R.M., Anderson, D.E., Hanson, S.R., and Hinds, M.T. (2012). Fluid shear stress alters the hemostatic properties of endothelial outgrowth cells. Tissue Eng Part A 18, 127136.

Esparza-Gordillo, J., Soria, J.M., Buil, A., Almasy, L., Blangero, J., Fontcuberta, J., and Rodriguez de Cordoba, S. (2004). Genetic and environmental factors influencing the human factor $\mathrm{H}$ plasma levels. Immunogenetics $56,77-82$.

European Multicentre Trial Group (1982). Cyclosporin A as Sole Immunosuppressive Agent in Recipients of Kidney Allografts from Cadaver Donors. Lancet 320, 57-60.

European Multicentre Trial Group (1983). Cyclosporin in cadaveric renal transplantation: oneyear follow-up of a multicentre trial. Lancet 2, 986-989.

Eurotransplant International Foundation (2015). Eurotransplant Annual Report 2015.

Fakhouri, F., Roumenina, L., Provot, F., Sallee, M., Caillard, S., Couzi, L., Essig, M., Ribes, D., Dragon-Durey, M.A., Bridoux, F., et al. (2010). Pregnancy-associated hemolytic uremic syndrome revisited in the era of complement gene mutations. J Am Soc Nephrol 21, 859-867. 
Farivar, A.S., Mackinnon-Patterson, B.C., Barnes, A.D., McCourtie, A.S., and Mulligan, M.S. (2005). Cyclosporine modulates the response to hypoxia-reoxygenation in pulmonary artery endothelial cells. Annals of Thoracic Surgery 79, 1010-1016.

Fathman, C.G., and Myers, B.D. (1992). Cyclosporine therapy for autoimmune disease. N Engl J Med 326, 1693-1695.

Fearon, D.T. (1978). Regulation by membrane sialic acid of beta1H-dependent decaydissociation of amplification C3 convertase of the alternative complement pathway. Proc Natl Acad Sci U S A 75, 1971-1975.

Fernandez, L.A., Sanz-Rodriguez, F., Zarrabeitia, R., Perez-Molino, A., Hebbel, R.P., Nguyen, J., Bernabeu, C., and Botella, L.M. (2005). Blood outgrowth endothelial cells from Hereditary Haemorrhagic Telangiectasia patients reveal abnormalities compatible with vascular lesions. Cardiovasc Res 68, 235-248.

Ferreira, V.P., Herbert, A.P., Cortes, C., McKee, K.A., Blaum, B.S., Esswein, S.T., Uhrin, D., Barlow, P.N., Pangburn, M.K., and Kavanagh, D. (2009). The binding of factor H to a complex of physiological polyanions and $\mathrm{C} 3 \mathrm{~b}$ on cells is impaired in atypical hemolytic uremic syndrome. J Immunol 182, 7009-7018.

Fiedler, U., Scharpfenecker, M., Koidl, S., Hegen, A., and Augustin, H.G. (2004). The Tie2Ligand Angiopoietin-2 Is Stored in and Rapidly Released Upon Stimulation from Endothelial Cell Weibel-Palade Bodies. Cardiovascular Pathology 13.

Foreman, K.E., Vaporciyan, A.A., Bonish, B.K., Jones, M.L., Johnson, K.J., Glovsky, M.M., Eddy, S.M., and Ward, P.A. (1994). C5a-induced expression of P-selectin in endothelial cells. Journal of Clinical Investigation 94, 1147-1155.

Fremeaux-Bacchi, V., Fakhouri, F., Garnier, A., Bienaimé, F., Dragon-Durey, M.A., Ngo, S., Moulin, B., Servais, A., Provot, F., Rostaing, L., et al. (2013). Genetics and outcome of atypical hemolytic uremic syndrome: A nationwide french series comparing children and adults. Clin J Am Soc Nephrol 8, 554-562.

Frimat, M., Roumenina, L., Camous, L., Bigot, S., Lesavre, P., Satchell, S.C., Mathieson, P.W., Fremeaux-Bacchi, V., and Halbwachs-Mecarelli, L. (2009). Complement activation by endothelial cells treated with inflammatory cytokines or heme, in the context of atypical hemolytic uremic syndrome. Molecular Immunology 46, 2849.

Frimat, M., Tabarin, F., Dimitrov, J.D., Poitou, C., Halbwachs-Mecarelli, L., Fremeaux-Bacchi, V., and Roumenina, L.T. (2013). Complement activation by heme as a secondary hit for atypical hemolytic uremic syndrome. Blood 122, 282-292.

Fuchs, S., Dohle, E., Kolbe, M., and Kirkpatrick, C.J. (2010). Outgrowth endothelial cells: sources, characteristics and potential applications in tissue engineering and regenerative medicine. Adv Biochem Eng Biotechnol 123, 201-217. 
Fuchs, S., Hermanns, M.I., and Kirkpatrick, C.J. (2006). Retention of a differentiated endothelial phenotype by outgrowth endothelial cells isolated from human peripheral blood and expanded in long-term cultures. Cell Tissue Res 326, 79-92.

Furmanczyk, A., Komuda-Leszek, E., and Durlik, M. (2009). Atypical calcineurin inhibitorinduced haemolytic uremic syndrome after liver transplantation. Ann Transplant 14, 47-51.

Furuta, S., and Jayne, D.R. (2013). Antineutrophil cytoplasm antibody-associated vasculitis: recent developments. Kidney Int 84, 244-249.

Gasser, C., Gautier, E., Steck, A., Siebenmann, R.E., and Oechslin, R. (1955). Hemolytic-uremic syndrome: bilateral necrosis of the renal cortex in acute acquired hemolytic anemia.

Schweizerische medizinische Wochenschrift 85, 905-909.

George, J.N., and Nester, C.M. (2014). Syndromes of Thrombotic Microangiopathy. N Engl J Med 371, 654-666.

Geraghty, M.T., Perlman, E.J., Martin, L.S., Hayflick, S.J., Casella, J.F., Rosenblatt, D.S., and Valle, D. (1992). Cobalamin C defect associated with hemolytic-uremic syndrome. The Journal of Pediatrics 120, 934-937.

Gilbert, R.D., Stanley, L.K., Fowler, D.J., Angus, E.M., Hardy, S.A., and Goodship, T.H. (2013). Cisplatin-induced haemolytic uraemic syndrome associated with a novel intronic mutation of CD46 treated with eculizumab. Clinical Kidney Journal 6, 421-425.

Goldstein, D.J., Zuech, N., Sehgal, V., Weinberg, A.D., Drusin, R., and Cohen, D. (1997). Cyclosporine-associated end-stage nephropathy after cardiac transplantation: incidence and progression. Transplantation 63, 664-668.

Golo, T., Kino, T., Hatanaka, H., Nishiyama, M., Okuhara, M., Kohsaka, M., Aoki, H., and Imanaka, H. (1987). Discovery of FK-506, a novel immunosuppressant isolated from Streptomyces tsukubaensis. Transplant Proc 19, 4-8.

Gooch, J.L., King, C., Francis, C.E., Garcia, P.S., and Bai, Y. (2017). Cyclosporine A alters expression of renal microRNAs: New insights into calcineurin inhibitor nephrotoxicity. PLoS One 12 , e0175242.

Gordon, D.L., Kaufman, R.M., Blackmore, T.K., Kwong, J., and Lublin, D.M. (1995). Identification of complement regulatory domains in human factor H. J Immunol 155, 348-356.

Graef, I.A., Chen, F., Chen, L., Kuo, A., and Crabtree, G.R. (2001). Signals Transduced by $\mathrm{Ca} 2+/$ Calcineurin and NFATc3/c4 Pattern the Developing Vasculature. Cell 105, 863-875.

Gray, J.M., and Ameduri, R.K. (2016). Tacrolimus-associated hemolytic uremic syndrome in a pediatric heart transplant recipient. Pediatr Transplant 20, 866-867.

Gremmels, H., Fledderus, J.O., van Balkom, B.W., and Verhaar, M.C. (2011). Transcriptome analysis in endothelial progenitor cell biology. Antioxid Redox Signal 15, 1029-1042. 
Groeneveld, D.J., van Bekkum, T., Dirven, R.J., Wang, J.W., Voorberg, J., Reitsma, P.H., and Eikenboom, J. (2015). Angiogenic characteristics of blood outgrowth endothelial cells from patients with von Willebrand disease. J Thromb Haemost 13, 1854-1866.

Grupper, A., Shashar, M., Bahry, D., Pri-Paz, Y., Ben Tur, O., Levi, S., Chernichovski, T., Chernin, G., and Schwartz, I.F. (2013). Cyclosporine attenuates arginine transport, in human endothelial cells, through modulation of cationic amino acid transporter-1. Am J Nephrol 37, 613-619.

Halbwachs, L., and Lesavre, P. (2012). Endothelium-neutrophil interactions in ANCA-associated diseases. J Am Soc Nephrol 23, 1449-1461.

Hammerschmidt, D.E., Harris, P.D., Wayland, J.H., Craddock, P.R., and Jacob, H.S. (1981). Complement-induced granulocyte aggregation in vivo. Am J Pathol 102, 146-150.

Hanifin, J.M., Ling, M.R., Langley, R., Breneman, D., and Rafal, E. (2001). Tacrolimus ointment for the treatment of atopic dermatitis in adult patients: part I, efficacy. J Am Acad Dermatol 44, S28-38.

Hart, A., Smith, J.M., Skeans, M.A., Gustafson, S.K., Stewart, D.E., Cherikh, W.S., Wainright, J.L., Kucheryavaya, A., Woodbury, M., Snyder, J.J., et al. (2017). OPTN/SRTR 2015 Annual Data Report: Kidney. Am J Transplant 17 Suppl 1, 21-116.

Hassenpflug, W.A., Budde, U., Schneppenheim, S., and Schneppenheim, R. (2014). Inherited thrombotic thrombocytopenic purpura in children. Seminars in Thrombosis and Hemostasis 40, 487-492.

Haywood-Watson, R.J., Holcomb, J.B., Gonzalez, E.A., Peng, Z., Pati, S., Park, P.W., Wang, W., Zaske, A.M., Menge, T., and Kozar, R.A. (2011). Modulation of syndecan-1 shedding after hemorrhagic shock and resuscitation. PLoS One 6, e23530.

Hebbel, R.P. (2017). Blood endothelial cells: utility from ambiguity. J Clin Invest 127, 16131615.

Heinen, S., Jozsi, M., Hartmann, A., Noris, M., Remuzzi, G., Skerka, C., and Zipfel, P.F. (2007). Hemolytic uremic syndrome: a factor $\mathrm{H}$ mutation (E1172Stop) causes defective complement control at the surface of endothelial cells. J Am Soc Nephrol 18, 506-514.

Herbert, A.P., Kavanagh, D., Johansson, C., Morgan, H.P., Blaum, B.S., Hannan, J.P., Barlow, P.N., and Uhrin, D. (2012). Structural and functional characterization of the product of diseaserelated factor $\mathrm{H}$ gene conversion. Biochemistry 51, 1874-1884.

Hernández, G.L., Volpert, O.V., Íñiguez, M.A., Lorenzo, E., Martínez-Martínez, S., Grau, R., Fresno, M., and Redondo, J.M. (2001). Selective Inhibition of Vascular Endothelial Growth Factor-Mediated Angiogenesis by Cyclosporin A. The Journal of Experimental Medicine 193, 607-620.

Hesser, B.A., Liang, X.H., Camenisch, G., Yang, S., Lewin, D.A., Scheller, R., Ferrara, N., and Gerber, H.P. (2004). Down syndrome critical region protein 1 (DSCR1), a novel VEGF target 
gene that regulates expression of inflammatory markers on activated endothelial cells. Blood $104,149-158$.

Hirschberg, R., Wang, S., and Mitu, G.M. (2008). Functional symbiosis between endothelium and epithelial cells in glomeruli. Cell and Tissue Research 331, 485-493.

Hofer, J., Janecke, A.R., Zimmerhackl, L.B., Riedl, M., Rosales, A., Giner, T., Cortina, G., Haindl, C.J., Petzelberger, B., Pawlik, M., et al. (2013). Complement factor H-related protein 1 deficiency and factor $\mathrm{H}$ antibodies in pediatric patients with atypical hemolytic uremic syndrome. Clin J Am Soc Nephrol 8, 407-415.

Horslen, S., Barr, M.L., Christensen, L.L., Ettenger, R., and Magee, J.C. (2007). Pediatric transplantation in the United States, 1996-2005. Am J Transplant 7, 1339-1358.

Hricik, D.E., Formica, R.N., Nickerson, P., Rush, D., Fairchild, R.L., Poggio, E.D., Gibson, I.W., Wiebe, C., Tinckam, K., Bunnapradist, S., et al. (2015). Adverse Outcomes of Tacrolimus Withdrawal in Immune-Quiescent Kidney Transplant Recipients. J Am Soc Nephrol 26, 31143122 .

Huber-Lang, M., Sarma, J.V., Zetoune, F.S., Rittirsch, D., Neff, T.A., McGuire, S.R., Lambris, J.D., Warner, R.L., Flierl, M.A., Hoesel, L.M., et al. (2006). Generation of C5a in the absence of C3: a new complement activation pathway. Nat Med 12, 682-687.

Hughes, D., Fu, A.a., Puggioni, A., Glockner, J.F., Anwer, B., McGuire, A.M., Mukhopadhyay, D., and Misra, S. (2009). Adventitial transplantation of blood outgrowth endothelial cells in porcine haemodialysis grafts alleviates hypoxia and decreases neointimal proliferation through a matrix metalloproteinase-9-mediated pathway - A pilot study. Nephrol Dial Transplant 24, 8596.

Hurwitz, M.Y., Putkey, J.A., Klee, C.B., and Means, A.R. (1988). Domain II of calmodulin is involved in activation of calcineurin. FEBS Lett 238, 82-86.

Hyvarinen, S., Meri, S., and Jokiranta, T.S. (2016). Disturbed sialic acid recognition on endothelial cells and platelets in complement attack causes atypical hemolytic uremic syndrome. Blood 127, 2701-2710.

Ikezoe, T., Yang, J., Nishioka, C., Honda, G., Furihata, M., and Yokoyama, A. (2012).

Thrombomodulin protects endothelial cells from a calcineurin inhibitor-induced cytotoxicity by upregulation of extracellular signal-regulated kinase/myeloid leukemia cell-1 signaling. Arterioscler Thromb Vasc Biol 32, 2259-2270.

Illsinger, S., Janzen, N., Lucke, T., Bednarczyk, J., Schmidt, K.H., Hoy, L., Sander, J., and Das, A.M. (2011). Cyclosporine A: impact on mitochondrial function in endothelial cells. Clin Transplant 25, 584-593.

Jayne, D.R.W., Bruchfeld, A.N., Harper, L., Schaier, M., Venning, M.C., Hamilton, P., Burst, V., Grundmann, F., Jadoul, M., Szombati, I., et al. (2017). Randomized Trial of C5a Receptor Inhibitor Avacopan in ANCA-Associated Vasculitis. J Am Soc Nephrol ePublication ahead of print, 1-12. 
Jiang, A., Pan, W.E.I., Milbauer, L.C., Shyr, Y.U., and Hebbel, R.P. (2007). A Practical Question Based on Cross-Platform Microarray Data Normalization: Are Boec More Like Large Vessel or Microvascular Endothelial Cells or Neither of Them? Journal of Bioinformatics and Computational Biology 05, 875-893.

Jiang, X., Sung, Y.K., Tian, W., Qian, J., Semenza, G.L., and Nicolls, M.R. (2014). Graft microvascular disease in solid organ transplantation. J Mol Med (Berl) 92, 797-810.

Jodele, S., Fukuda, T., Vinks, A., Mizuno, K., Laskin, B.L., Goebel, J., Dixon, B.P., Teusink, A., Pluthero, F.G., Lu, L., et al. (2014). Eculizumab therapy in children with severe hematopoietic stem cell transplantation-associated thrombotic microangiopathy. Biology of blood and marrow transplantation : journal of the American Society for Blood and Marrow Transplantation 20, 518525 .

Jodele, S., Licht, C., Goebel, J., Dixon, B.P., Zhang, K., Sivakumaran, T.A., Davies, S.M., Pluthero, F.G., Lu, L., and Laskin, B.L. (2013). Abnormalities in the alternative pathway of complement in children with hematopoietic stem cell transplant-associated thrombotic microangiopathy. Blood 122, 2003-2007.

Jodele, S., Zhang, K., Zou, F., Laskin, B., Dandoy, C.E., Myers, K.C., Lane, A., Meller, J., Medvedovic, M., Chen, J., et al. (2016). The genetic fingerprint of susceptibility for transplantassociated thrombotic microangiopathy. Blood 127, 989-996.

Johnson, E.N., Lee, Y.M., Sander, T.L., Rabkin, E., Schoen, F.J., Kaushal, S., and Bischoff, J. (2003). NFATc1 mediates vascular endothelial growth factor-induced proliferation of human pulmonary valve endothelial cells. J Biol Chem 278, 1686-1692.

Jokiranta, T.S., Cheng, Z.-Z., Seeberger, H., Jòzsi, M., Heinen, S., Noris, M., Remuzzi, G., Ormsby, R., Gordon, D.L., Meri, S., et al. (2005). Binding of Complement Factor H to Endothelial Cells Is Mediated by the Carboxy-Terminal Glycosaminoglycan Binding Site. The American Journal of Pathology 167, 1173-1181.

Jozsi, M., Heinen, S., Hartmann, A., Ostrowicz, C.W., Halbich, S., Richter, H., Kunert, A., Licht, C., Saunders, R.E., Perkins, S.J., et al. (2006). Factor H and atypical hemolytic uremic syndrome: mutations in the $\mathrm{C}$-terminus cause structural changes and defective recognition functions. J Am Soc Nephrol 17, 170-177.

Kahlenberg, J.M., Thacker, S.G., Berthier, C.C., Cohen, C.D., Kretzler, M., and Kaplan, M.J. (2011). Inflammasome activation of IL-18 results in endothelial progenitor cell dysfunction in systemic lupus erythematosus. J Immunol 187, 6143-6156.

Kaneko, Y., Tajiri, N., Shinozuka, K., Glover, L.E., Weinbren, N.L., Cortes, L., and Borlongan, C.V. (2012). Cell therapy for stroke: emphasis on optimizing safety and efficacy profile of endothelial progenitor cells. Curr Pharm Des 18,3731-3734.

Kavanagh, D., Goodship, T.H., and Richards, A. (2013). Atypical hemolytic uremic syndrome. Seminars in Nephrology 33, 508-530. 
Kavanagh, D., Richards, A., and Atkinson, J. (2008). Complement regulatory genes and hemolytic uremic syndromes. Annu Rev Med 59, 293-309.

Kazatchkine, M.D., Fearon, D.T., and Austen, K.F. (1979). Human alternative complement pathway: membrane-associated sialic acid regulates the competition between $\mathrm{B}$ and $\beta 1 \mathrm{H}$ for cellbound C3b. J Immunol 122, 75-81.

Kettritz, R. (2014). With complements from ANCA mice. J Am Soc Nephrol 25, 207-209.

Kim, Y.O., Lim, S.W., Li, C., Kang, H.J., Ahn, K.O., Yang, H.J., Ghee, J.Y., Kim, S.H., Kim, J.Y., Choi, B.S., et al. (2007). Activation of intrarenal complement system in mouse model for chronic cyclosporine nephrotoxicity. Yonsei Medical Journal 48, 517-525.

Kino, T., Hatanaka, H., Miyata, S., Inamura, N., Nishiyama, M., Yajima, T., Goto, T., Okuhara, M., Kohsaka, M., Aoki, H., et al. (1987). FK-506, a novel immunosuppressant isolated from a Streptomyces. II. Immunosuppressive effect of FK-506 in vitro. J Antibiot (Tokyo) 40, 12561265.

Klee, C.B., Draetta, G., and Hubbard, M. (1988). Calcineurin. Adv Enzymol Relat Areas Mol Biol 61, 149-200.

Knobl, P. (2014). Inherited and acquired thrombotic thrombocytopenic purpura (TTP) in adults. Seminars in Thrombosis and Hemostasis 40, 493-502.

Kolata, G. (1983). Drug transforms transplant medicine. Science 221, 40-42.

Komhoff, M., Roofthooft, M.T., Teertstra, T., Westra, D., Losito, A., van de Kar, N., and Berger, R.M. (2013). Combined renal thrombotic microangiopathy and pulmonary arterial hypertension is caused by cobalamine C deficiency. Pediatric Nephrology 28, 1374.

Krisinger, M.J., Goebeler, V., Lu, Z., Meixner, S.C., Myles, T., Pryzdial, E.L., and Conway, E.M. (2012). Thrombin generates previously unidentified C5 products that support the terminal complement activation pathway. Blood 120, 1717-1725.

Kuhn, S., and Zipfel, P.F. (1996). Mapping of the domains required for decay acceleration activity of the human factor H-like protein 1 and factor H. Eur J Immunol 26, 2383-2387.

Lamb, K.E., Lodhi, S., and Meier-Kriesche, H.U. (2011). Long-term renal allograft survival in the United States: a critical reappraisal. Am J Transplant 11, 450-462.

Le Quintrec, M., Lionet, A., Kamar, N., Karras, A., Barbier, S., Buchler, M., Fakhouri, F., Provost, F., Fridman, W.H., Thervet, E., et al. (2008). Complement mutation-associated de novo thrombotic microangiopathy following kidney transplantation. Am J Transplant 8, 1694-1701.

Le Quintrec, M., Zuber, J., Moulin, B., Kamar, N., Jablonski, M., Lionet, A., Chatelet, V., Mousson, C., Mourad, G., Bridoux, F., et al. (2013). Complement genes strongly predict recurrence and graft outcome in adult renal transplant recipients with atypical hemolytic and uremic syndrome. Am J Transplant 13, 663-675. 
Libby, P., Alroy, J., and Pereira, M.E. (1986). A neuraminidase from Trypanosoma cruzi removes sialic acid from the surface of mammalian myocardial and endothelial cells. J Clin Invest 77, 127-135.

Lin, C.C., King, K.L., Chao, Y.W., Yang, A.H., Chang, C.F., and Yang, W.C. (2003). Tacrolimus-associated hemolytic uremic syndrome: a case analysis. J Nephrol 16, 580-585.

Lin, Y., Chang, L., Solovey, A., Healey, J.F., Lollar, P., and Hebbel, R.P. (2002). Use of blood outgrowth endothelial cells for gene therapy for hemophilia A. Blood 99, 457-462.

Lin, Y., Weisdorf, D.J., Solovey, A., and Hebbel, R.P. (2000). Origins of circulating endothelial cells and endothelial outgrowth from blood. [Miscellaneous Article] 39. J Clin Invest 105, 71-77.

Lipskaia, L., Pourci, M.L., Delomenie, C., Combettes, L., Goudouneche, D., Paul, J.L., Capiod, T., and Lompre, A.M. (2003). Phosphatidylinositol 3-kinase and calcium-activated transcription pathways are required for VLDL-induced smooth muscle cell proliferation. Circ Res 92, 11151122.

Liptak, P., and Ivanyi, B. (2006). Primer: Histopathology of calcineurin-inhibitor toxicity in renal allografts. Nature clinical practice Nephrology 2, 398-404; quiz following 404.

Liszewski, M.K., and Atkinson, J.P. (1996). Membrane cofactor protein (MCP; CD46). Isoforms differ in protection against the classical pathway of complement. Journal of Immunology 156, 4415-4421.

Liszewski, M.K., Post, T.W., and Atkinson, J.P. (1991). Membrane cofactor protein (MCP or CD46): newest member of the regulators of complement activation gene cluster. Annu Rev Immunol 9, 431-455.

Loirat, C. (2014). Anti-factor H autoantibody- associated hemolytic uremic syndrome : the earlier diagnosed and treated, the better. Kidney Int 85, 1019-1022.

Loirat, C., and Frémeaux-Bacchi, V. (2011). Atypical hemolytic uremic syndrome. Orphanet journal of rare diseases 6,60 .

Louise, C.B., and Obrig, T.G. (1994). Human renal microvascular endothelial cells as a potential target in the development of the hemolytic uremic syndrome as related to fibrinolysis factor expression, in vitro. Microvasc Res 47, 377-387.

Lukasz, A., Hillgruber, C., Oberleithner, H., Kusche-Vihrog, K., Pavenstädt, H., Rovas, A., Hesse, B., Goerge, T., and Kümpers, P. (2017). Endothelial glycocalyx breakdown is mediated by angiopoietin-2. Cardiovascular Research 113, 671-680.

Madariaga, H.M., and Riella, L.V. (2017). Chronic Allograft Injury: An Overview of Pathogenesis and Treatment Strategies. Contrib Nephrol 190, 168-180.

Maga, T.K., Nishimura, C.J., Weaver, A.E., Frees, K.L., and Smith, R.J.H. (2010). Mutations in alternative pathway complement proteins in American patients with atypical hemolytic uremic syndrome. Human mutation 31, E1445-1460. 
Makou, E., Herbert, A.P., and Barlow, P.N. (2013). Functional anatomy of complement factor H. Biochemistry 52, 3949-3962.

Mancini, M., and Toker, A. (2009). NFAT proteins: emerging roles in cancer progression. Nat Rev Cancer 9, 810-820.

Manenti, L., Signorini, L., Gnappi, E., Pilato, F.P., Vaglio, A., Allegri, L., and Buzio, C. (2013). Outcome of renal ANCA associated vasculitis (AAV) with complement hyperactivation signs: a retrospective study. Nephrol Dial Transplant 28, i1-i2.

Manenti, L., Vaglio, A., Gnappi, E., Maggiore, U., Allegri, L., Allinovi, M., Urban, M.L., Delsante, M., Galetti, M., Nicastro, M., et al. (2015). Association of Serum C3 Concentration and Histologic Signs of Thrombotic Microangiopathy with Outcomes among Patients with ANCA-Associated Renal Vasculitis. Clin J Am Soc Nephrol 10, 2143-2151.

Markiewski, M.M., Nilsson, B., Nilsson Ekdahl, K., Mollnes, T.E., and Lambris, J.D. (2007). Complement and coagulation: strangers or partners in crime? Trends in Immunology 28, 184192.

Martin-Ramirez, J., Hofman, M., van den Biggelaar, M., Hebbel, R.P., and Voorberg, J. (2012). Establishment of outgrowth endothelial cells from peripheral blood. Nature Protocols 7, 17091715.

Masuda, K., Nakajima, A., Urayama, A., Nakae, K., Kogure, M., and Inaba, G. (1989). Doublemasked trial of cyclosporin versus colchicine and long-term open study of cyclosporin in Behcet's disease. Lancet 1, 1093-1096.

Matsushita, M., Endo, Y., and Fujita, T. (2013). Structural and functional overview of the lectin complement pathway: its molecular basis and physiological implication. Arch Immunol Ther Exp (Warsz) 61, 273-283.

Mazzolai, L., Bouzourene, K., Hayoz, D., Dignat-George, F., Liu, J.W., Bounameaux, H., Dunoyer-Geindre, S., and Kruithof, E.K. (2011). Characterization of human late outgrowth endothelial progenitor-derived cells under various flow conditions. J Vasc Res 48, 443-451.

Medina, R.J., O'Neill, C.L., Sweeney, M., Guduric-Fuchs, J., Gardiner, T.A., Simpson, D.A., and Stitt, A.W. (2010). Molecular analysis of endothelial progenitor cell (EPC) subtypes reveals two distinct cell populations with different identities. BMC Med Genomics 3, 18.

Medjeral-Thomas, N.R., O'Shaughnessy, M.M., O'Regan, J.a., Traynor, C., Flanagan, M., Wong, L., Teoh, C.W., Awan, A., Waldron, M., Cairns, T., et al. (2013). C3 Glomerulopathy:

Clinicopathologic Features and Predictors of Outcome. Clin J Am Soc Nephrol 9, 46-53.

Meier-Kriesche, H.-U., Schold, J.D., Srinivas, T.R., and Kaplan, B. (2004). Lack of Improvement in Renal Allograft Survival Despite a Marked Decrease in Acute Rejection Rates Over the Most Recent Era. Am J Transplant 4, 378-383.

Mele, C., Remuzzi, G., and Noris, M. (2014). Hemolytic uremic syndrome. Seminars in immunopathology 36, 399-420. 
Meri, S. (2013). Complement activation in diseases presenting with thrombotic microangiopathy. European Journal of Internal Medicine 24, 496-502.

Meri, S., and Pangburn, M.K. (1990). Discrimination between activators and nonactivators of the alternative pathway of complement: regulation via a sialic acid/polyanion binding site on factor H. Proc Natl Acad Sci 87, 3982-3986.

Meri, S., and Pangburn, M.K. (1994). Regulation of alternative pathway complement activation by glycosaminoglycans: specificity of the polyanion binding site on factor H. Biochem Biophys Res Commun 198, 52-59.

Minami, T., Horiuchi, K., Miura, M., Abid, M.R., Takabe, W., Noguchi, N., Kohro, T., Ge, X., Aburatani, H., Hamakubo, T., et al. (2004). Vascular endothelial growth factor- and thrombininduced termination factor, Down syndrome critical region-1, attenuates endothelial cell proliferation and angiogenesis. J Biol Chem 279, 50537-50554.

Minami, T., Miura, M., Aird, W.C., and Kodama, T. (2006). Thrombin-induced autoinhibitory factor, Down syndrome critical region-1, attenuates NFAT-dependent vascular cell adhesion molecule-1 expression and inflammation in the endothelium. J Biol Chem 281, 20503-20520.

Moore, I., Strain, L., Pappworth, I., Kavanagh, D., Barlow, P.N., Herbert, A.P., Schmidt, C.Q., Staniforth, S.J., Holmes, L.V., Ward, R., et al. (2010). Association of factor H autoantibodies with deletions of CFHR1, CFHR3, CFHR4, and with mutations in CFH, CFI, CD46, and C3 in patients with atypical hemolytic uremic syndrome. Blood 115, 379-387.

Moschcowitz, E. (1952). An acute febrile pleiochromic anemia with hyaline thrombosis of the terminal arterioles and capillaries. An undescribed disease. American Journal of Medicine 13, 567-569.

Muller-Eberhard, H.J. (1988). Molecular organization and function of the complement system. Annu Rev Biochem 57, 321-347.

Naesens, M., Kuypers, D.R., and Sarwal, M. (2009). Calcineurin inhibitor nephrotoxicity. Clin J Am Soc Nephrol 4, 481-508.

Nagasawa, S., and Stroud, R.M. (1977). Mechanism of action of the C3b inactivator: requirement for a high molecular weight cofactor (C3b-C4bINA cofactor) and production of a new $\mathrm{C} 3 \mathrm{~b}$ derivative (C3b'). Immunochemistry 14, 749-756.

Nagy, J.A., Dvorak, A.M., and Dvorak, H.F. (2007). VEGF-A and the induction of pathological angiogenesis. Annu Rev Pathol 2, 251-275.

Nieves-Cintron, M., Amberg, G.C., Nichols, C.B., Molkentin, J.D., and Santana, L.F. (2007). Activation of NFATc3 down-regulates the beta 1 subunit of large conductance, calcium-activated $\mathrm{K}+$ channels in arterial smooth muscle and contributes to hypertension. J Biol Chem 282, 32313240 . 
Nilsson, L.M., Nilsson-Ohman, J., Zetterqvist, A.V., and Gomez, M.F. (2008). Nuclear factor of activated T-cells transcription factors in the vasculature: the good guys or the bad guys? Curr Opin Lipidol 19, 483-490.

Nilsson, L.M., Sun, Z.W., Nilsson, J., Nordstrom, I., Chen, Y.W., Molkentin, J.D., WideSwensson, D., Hellstrand, P., Lydrup, M.L., and Gomez, M.F. (2007). Novel blocker of NFAT activation inhibits IL-6 production in human myometrial arteries and reduces vascular smooth muscle cell proliferation. Am J Physiol Cell Physiol 292, C1167-1178.

Nishimura, T., Myles, T., Piliponsky, A.M., Kao, P.N., Berry, G.J., and Leung, L.L. (2007). Thrombin-activatable procarboxypeptidase B regulates activated complement C5a in vivo. Blood 109, 1992-1997.

Noone, D., Al-Matrafi, J., Tinckam, K., Zipfel, P.F., Herzenberg, A.M., Thorner, P.S., Pluthero, F.G., Kahr, W.H.A., Filler, G., Hebert, D., et al. (2012). Antibody mediated rejection associated with complement factor H-related protein 3/1 deficiency successfully treated with Eculizumab. Am J Transplant 12, 2546-2553.

Noone, D.G., Riedl, M., Pluthero, F.G., Bowman, M.L., Liszewski, M.K., Lu, L., Quan, Y., Balgobin, S., Schneppenheim, R., Schneppenheim, S., et al. (2016). Von Willebrand factor regulates complement on endothelial cells. Kidney Int 90, 123-134.

Noris, M., Caprioli, J., Bresin, E., Mossali, C., Pianetti, G., Gamba, S., Daina, E., Fenili, C., Castelletti, F., Sorosina, A., et al. (2010). Relative role of genetic complement abnormalities in sporadic and familial aHUS and their impact on clinical phenotype. Clin J Am Soc Nephrol 5, 1844-1859.

Noris, M., and Remuzzi, G. (2009). Atypical hemolytic-uremic syndrome. N Engl J Med 361, 1676-1687.

Noris, M., and Remuzzi, G. (2010). Thrombotic microangiopathy after kidney transplantation. Am J Transplant 10, 1517-1523.

Ojo, A.O., Held, P.J., Port, F.K., Wolfe, R.A., Leichtman, A.B., Young, E.W., Arndorfer, J., Christensen, L., and Merion, R.M. (2003). Chronic renal failure after transplantation of a nonrenal organ. N Engl J Med 349, 931-940.

Othman, M., Chirinian, Y., Brown, C., Notley, C., Hickson, N., Hampshire, D., Buckley, S., Waddington, S., Parker, A.L., Baker, A., et al. (2010). Functional characterization of a 13-bp deletion (c.-1522_-1510del13) in the promoter of the von Willebrand factor gene in type 1 von Willebrand disease. Blood 116, 3645-3652.

Pangburn, M.K. (2000). Host recognition and target differentiation by factor H, a regulator of the alternative pathway of complement. Immunopharmacology 49, 149-157.

Pangburn, M.K., Ferreira, V.P., and Cortes, C. (2008). Discrimination between host and pathogens by the complement system. Vaccine 26, I15-I21. 
Pangburn, M.K., and Muller-Eberhard, H.J. (1978). Complement C3 convertase: cell surface restriction of beta1 $\mathrm{H}$ control and generation of restriction on neuraminidase-treated cells. Proc Natl Acad Sci 75, 2416-2420.

Pangburn, M.K., and Muller-Eberhard, H.J. (1983). Kinetic and thermodynamic analysis of the control of $\mathrm{C} 3 \mathrm{~b}$ by the complement regulatory proteins factors $\mathrm{H}$ and I. Biochemistry 22, 178185.

Pangburn, M.K., Schreiber, R.D., and Muller-Eberhard, H.J. (1977). Human complement C3b inactivator: isolation, characterization, and demonstration of an absolute requirement for the serum protein beta1H for cleavage of $\mathrm{C} 3 \mathrm{~b}$ and $\mathrm{C} 4 \mathrm{~b}$ in solution. J Exp Med 146, 257-270.

Parissis, H., Gould, K., and Dark, J. (2010). Dangerous drug interactions leading to hemolytic uremic syndrome following lung transplantation. J Cardiothorac Surg 5, 70.

Patel, S., Huang, Y.W., Reheman, A., Pluthero, F.G., Chaturvedi, S., Mukovozov, I.M., Tole, S., Liu, G.Y., Li, L., Durocher, Y., et al. (2012). The cell motility modulator Slit2 is a potent inhibitor of platelet function. Circulation 126, 1385-1395.

Peitsch, M.C., and Tschopp, J. (1991). Assembly of macromolecular pores by immune defense systems. Curr Opin Cell Biol 3, 710-716.

Perkins, S.J., Fung, K.W., and Khan, S. (2014). Molecular Interactions between Complement Factor $\mathrm{H}$ and Its Heparin and Heparan Sulfate Ligands. Front Immunol 5, 126.

Pickering, M.C., D'Agati, V.D., Nester, C.M., Smith, R.J., Haas, M., Appel, G.B., Alpers, C.E., Bajema, I.M., Bedrosian, C., Braun, M., et al. (2013). C3 glomerulopathy: consensus report. Kidney Int 84, 1079-1089.

Ponticelli, C. (2007). De novo thrombotic microangiopathy. An underrated complication of renal transplantation. Clinical Nephrology 67, 335-340.

Ponticelli, C. (2014). Ischaemia-reperfusion injury: a major protagonist in kidney transplantation. Nephrol Dial Transplant 29, 1134-1140.

Praga, M., Barrio, V., Juarez, G.F., Luno, J., and Grupo Espanol de Estudio de la Nefropatia, M. (2007). Tacrolimus monotherapy in membranous nephropathy: a randomized controlled trial. Kidney Int 71, 924-930.

Rabelink, T.J., de Boer, H.C., and van Zonneveld, A.J. (2010). Endothelial activation and circulating markers of endothelial activation in kidney disease. Nat Rev Nephrol 6, 404-414.

Rafiee, P., Heidermann, J., Ogawa, H., Johnson, N.A., Fisher, P.J., Li, M.S., Otterson, M.F., Johnson, C.P., and Binion, D.G. (2004). Cyclosporin A differentially inhibits multiple steps in VEGF induced angiogenesis in human microvascular endothelial cells through altered intracellular signaling. Cell Communicationg and Signaling 2, 1-22. 
Ranger, A.M., Grusby, M.J., Hodge, M.R., Gravallese, E.M., de la Brousse, F.C., Hoey, T., Mickanin, C., Baldwin, H.S., and Glimcher, L.H. (1998). The transcription factor NF-ATc is essential for cardiac valve formation. Nature 392, 186-190.

Rao, A., Luo, C., and Hogan, P.G. (1997). Transcription factors of the NFAT family: regulation and function. Annu Rev Immunol 15, 707-747.

Ray, P.E., Tassi, E., Liu, X.H., and Wellstein, A. (2006). Role of fibroblast growth factorbinding protein in the pathogenesis of HIV-associated hemolytic uremic syndrome. Am J Physiol Regul Integr Comp Physiol 290, R105-113.

Rehm, M., Bruegger, D., Christ, F., Conzen, P., Thiel, M., Jacob, M., Chappell, D., Stoeckelhuber, M., Welsch, U., Reichart, B., et al. (2007). Shedding of the endothelial glycocalyx in patients undergoing major vascular surgery with global and regional ischemia. Circulation 116, 1896-1906.

Reinisch, A., Hofmann, N.A., Obenauf, A.C., Kashofer, K., Rohde, E., Schallmoser, K., Flicker, K., Lanzer, G., Linkesch, W., Speicher, M.R., et al. (2009). Humanized large-scale expanded endothelial colony-forming cells function in vitro and in vivo. Blood 113, 6716-6725.

Renner, B., Klawitter, J., Goldberg, R., McCullough, J.W., Ferreira, V.P., Cooper, J.E., Christians, U., and Thurman, J.M. (2013). Cyclosporine Induces Endothelial Cell Release of Complement-Activating Microparticles. J Am Soc Nephrol 24, 1849-1862.

Ricklin, D., Hajishengallis, G., Yang, K., and Lambris, J.D. (2010). Complement: a key system for immune surveillance and homeostasis. Nat Immunol 11, 785-797.

Ricklin, D., and Lambris, J.D. (2013). Complement in immune and inflammatory disorders: pathophysiological mechanisms. J Immunol 190, 3831-3838.

Ricklin, D., Reis, E.S., and Lambris, J.D. (2016). Complement in disease: a defence system turning offensive. Nat Rev Nephrol 12, 383-401.

Riedl, M., Fakhouri, F., Le Quintrec, M., Noone, D.G., Jungraithmayr, T.C., Fremeaux-Bacchi, V., and Licht, C. (2014a). Spectrum of complement-mediated thrombotic microangiopathies: Pathogenetic insights identifying novel treatment approaches. Seminars in Thrombosis and Hemostasis 40, 444-464.

Riedl, M., Noone, D.G., Khan, M.A., Pluthero, F.G., Kahr, W.H.A., Palaniyar, N., and Licht, C. (2014b). Complement activation on vascular endothelial cells results in polymorphonuclear leukocyte adhesion. J Am Soc Nephrol 25, 441A (FR-PO306).

Riella, L.V., Djamali, A., and Pascual, J. (2017). Chronic allograft injury: Mechanisms and potential treatment targets. Transplant Rev (Orlando) 31, 1-9.

Rignault-Clerc, S., Bielmann, C., Delodder, F., Raffoul, W., Waeber, B., Liaudet, L., Berger, M.M., Feihl, F., and Rosenblatt-Velin, N. (2013). Functional late outgrowth endothelial progenitors isolated from peripheral blood of burned patients. Burns 39, 694-704. 
Rodrigues-Diez, R., Gonzalez-Guerrero, C., Ocana-Salceda, C., Rodrigues-Diez, R.R., Egido, J., Ortiz, A., Ruiz-Ortega, M., and Ramos, A.M. (2016). Calcineurin inhibitors cyclosporine A and tacrolimus induce vascular inflammation and endothelial activation through TLR4 signaling. Sci Rep 6, 27915.

Rodriguez de Cordoba, S., Esparza-Gordillo, J., Goicoechea de Jorge, E., Lopez-Trascasa, M., and Sanchez-Corral, P. (2004). The human complement factor H: functional roles, genetic variations and disease associations. Mol Immunol 41, 355-367.

Rodriguez de Cordoba, S., Hidalgo, M.S., Pinto, S., and Tortajada, A. (2014). Genetics of atypical hemolytic uremic syndrome (aHUS). Semin Thromb Hemost 40, 422-430.

Rodriguez, L., Wu, X., and Guan, J. (2005). Wound-healing assay. Methods Mol Biol 294, 2329.

Rosove, M.H. (2014). Thrombotic microangiopathies. Seminars in Arthritis and Rheumatism 43, 797-805.

Ross, G.D., Lambris, J.D., Cain, J.A., and Newman, S.L. (1982). Generation of three different fragments of bound C3 with purified factor I or serum. I. Requirements for factor H vs CR1 cofactor activity. J Immunol 129, 2051-2060.

Sacks, S.H., and Zhou, W. (2012). The role of complement in the early immune response to transplantation. Nature reviews Immunology 12, 431-442.

Said, T., Al-Otaibi, T., Al-Wahaib, S., Francis, I., Nair, M.P., Halim, M.A., El-Sayed, A., and Nampoory, M.R. (2010). Posttransplantation calcineurin inhibitor-induced hemolytic uremic syndrome: single-center experience. Transplant Proc 42, 814-816.

Saito, A., and Munakata, H. (2005). Factor $\mathrm{H}$ is a dermatan sulfate-binding protein: identification of a dermatan sulfate-mediated protease that cleaves factor H. J Biochem 137, 225-233.

Sarrazin, S., Lamanna, W.C., and Esko, J.D. (2011). Heparan sulfate proteoglycans. Cold Spring Harb Perspect Biol 3.

Sato, T.N., Tozawa, Y., Deutsch, U., Wolburg-Buchholz, K., Fujiwara, Y., Gendron-Maguire, M., Gridley, T., Wolburg, H., Risau, W., and Qin, Y. (1995). Distinct roles of the receptor tyrosine kinases Tie-1 and Tie-2 in blood vessel formation. Nature 376, 70-74.

Sawada, S., Suzuki, G., Kawase, Y., and Takaku, F. (1987). Novel immunosuppressive agent, FK506. In vitro effects on the cloned T cell activation. J Immunol 139, 1797-1803.

Scheiring, J., Rosales, A., and Zimmerhackl, L.B. (2010). Clinical practice: Today's understanding of the haemolytic uraemic syndrome. European Journal of Pediatrics 169, 7-13.

Schiff, J., Cole, E., and Cantarovich, M. (2007). Therapeutic monitoring of calcineurin inhibitors for the nephrologist. Clin J Am Soc Nephrol 2, 374-384. 
Schmidt, C.Q., Herbert, A.P., Hocking, H.G., Uhrin, D., and Barlow, P.N. (2008a). Translational mini-review series on complement factor $\mathrm{H}$ : structural and functional correlations for factor $\mathrm{H}$. Clin Exp Immunol 151, 14-24.

Schmidt, C.Q., Herbert, A.P., Kavanagh, D., Gandy, C., Fenton, C.J., Blaum, B.S., Lyon, M., Uhrin, D., and Barlow, P.N. (2008b). A New Map of Glycosaminoglycan and C3b Binding Sites on Factor H. The Journal of Immunology 181, 2610-2619.

Schraufstatter, I.U., Trieu, K., Sikora, L., Sriramarao, P., and DiScipio, R. (2002). Complement c3a and c5a induce different signal transduction cascades in endothelial cells. J Immunol 169, 2102-2110.

Schreiber, A., Xiao, H., Jennette, J.C., Schneider, W., Luft, F.C., and Kettritz, R. (2009). C5a receptor mediates neutrophil activation and ANCA-induced glomerulonephritis. J Am Soc Nephrol 20, 289-298.

Seino, J., Eveleigh, P., Warnaar, S., van Haarlem, L.J., van Es, L.A., and Daha, M.R. (1993). Activation of human complement by mouse and mouse/human chimeric monoclonal antibodies. Clin Exp Immunol 94, 291-296.

Shibasaki, F., Price, E.R., Milan, D., and McKeon, F. (1996). Role of kinases and the phosphatase calcineurin in the nuclear shuttling of transcription factor NF-AT4. Nature 382, 370373.

Shiraishi, S., and Stroud, R.M. (1975). Cleavage products of C4b produced by enzymes in human serum. Immunochemistry 12, 935-939.

Sinha, A., Gulati, A., Saini, S., Blanc, C., Gupta, A., Gurjar, B.S., Saini, H., Kotresh, S.T., Ali, U., Bhatia, D., et al. (2014). Prompt plasma exchanges and immunosuppressive treatment improves the outcomes of anti-factor $\mathrm{H}$ autoantibody-associated hemolytic uremic syndrome in children. Kidney Int 85, 1151-1160.

Skerka, C., Licht, C., Mengel, M., Uzonyi, B., Strobel, S., Zipfel, P.F., and Józsi, M. (2009). Autoimmune forms of thrombotic micorangiopathy and membranoproliferative glomerulonephritis: Indications for a disease spectrum and common pathogenic principles. Molecular Immunology 46, 2801-2807.

Snanoudj, R., Royal, V., Elie, C., Rabant, M., Girardin, C., Morelon, E., Kreis, H., Fournet, J.C., Noel, L.H., and Legendre, C. (2011). Specificity of histological markers of long-term CNI nephrotoxicity in kidney-transplant recipients under low-dose cyclosporine therapy. Am J Transplant 11, 2635-2646.

Sofat, R., Mangione, P.P., Gallimore, J.R., Hakobyan, S., Hughes, T.R., Shah, T., Goodship, T., D'Aiuto, F., Langenberg, C., Wareham, N., et al. (2013). Distribution and determinants of circulating complement factor $\mathrm{H}$ concentration determined by a high-throughput immunonephelometric assay. J Immunol Methods 390, 63-73.

Solez, K., Colvin, R.B., Racusen, L.C., Sis, B., Halloran, P.F., Birk, P.E., Campbell, P.M., Cascalho, M., Collins, A.B., Demetris, A.J., et al. (2007). Banff '05 Meeting Report: differential 
diagnosis of chronic allograft injury and elimination of chronic allograft nephropathy ('CAN'). Am J Transplant 7, 518-526.

Song, D., Wu, L.-H., Wang, F.-M., Yang, X.-W., Zhu, D., Chen, M., Yu, F., Liu, G., and Zhao, M.-H. (2013). The spectrum of renal thrombotic microangiopathy in lupus nephritis. Arthritis research \& therapy $15, \mathrm{R} 12$.

Song, Y.H., Cai, G.Y., Xiao, Y.F., Wang, Y.P., Yuan, B.S., Xia, Y.Y., Wang, S.Y., Chen, P., Liu, S.W., and Chen, X.M. (2017). Efficacy and safety of calcineurin inhibitor treatment for IgA nephropathy: a meta-analysis. BMC Nephrol 18, 61.

Starzl, T.E., Klintmalm, G.B.G., Weil III, R., Porter, K.A., Iwatsuki, S., Schroter, G.P.J., Fernandez-Bueno, C., and MacHugh, N. (1981). Cyclosporin A and steroid therapy in sixty-six caadaver kidney recipients. Surgery, gynecology \& obstetrics 153, 486-494.

Starzl, T.E., Weil, R., Iwatsuki, S., Klintmalm, G., Schröter, G.P., Koep, L.J., Iwaki, Y., Terasaki, P.I., and Porter, K.A. (1980). The use of cyclosporin A and prednisone in cadaver kidney transplantation. Surgery, gynecology \& obstetrics 151, 17-26.

Suehiro, J., Kanki, Y., Makihara, C., Schadler, K., Miura, M., Manabe, Y., Aburatani, H., Kodama, T., and Minami, T. (2014). Genome-wide approaches reveal functional vascular endothelial growth factor (VEGF)-inducible nuclear factor of activated T cells (NFAT) c1 binding to angiogenesis-related genes in the endothelium. J Biol Chem 289, 29044-29059.

Sutherland, D., Strand, M., Fryd, D., Ferguson, R., Simmons, R., Ascher, N., and Najarian, J. (1984). Comparison of azathioprine-antilymphocyte globulin versus cyclosporine in renal transplantation. Am J Kidney Dis 3, 456-461.

Symmers, W. (1952). Thrombotic microangiopathic haemolytic anaemia (thrombotic microangiopathy). British Medical Journal 2, 897-903.

Tan, K., Lessieur, E., Cutler, A., Nerone, P., Vasanji, A., Asosingh, K., Erzurum, S., and AnandApte, B. (2010). Impaired function of circulating CD34(+) CD45(-) cells in patients with proliferative diabetic retinopathy. Exp Eye Res 91, 229-237.

Teoh, C.W., Riedl, M., and Licht, C. (2016). The alternative pathway of complement and the thrombotic microangiopathies. Transfus Apher Sci 54, 220-231.

Timmermans, F., Plum, J., Yoder, M.C., Ingram, D.A., Vandekerckhove, B., and Case, J. (2009). Endothelial progenitor cells: identity defined? J Cell Mol Med 13, 87-102.

Toshner, M., Dunmore, B.J., McKinney, E.F., Southwood, M., Caruso, P., Upton, P.D., Waters, J.P., Ormiston, M.L., Skepper, J.N., Nash, G., et al. (2014). Transcript analysis reveals a specific HOX signature associated with positional identity of human endothelial cells. PLoS One 9, e91334.

Totina, A., Iorember, F., El-Dahr, S.S., and Yosypiv, I.V. (2013). Atypical hemolytic-uremic syndrome in a child presenting with malignant hypertension. Clinical pediatrics 52, 183-186. 
Triantafilou, K., Hughes, T.R., Triantafilou, M., and Morgan, B.P. (2013). The complement membrane attack complex triggers intracellular Ca2+ fluxes leading to NLRP3 inflammasome activation. J Cell Sci 126, 2903-2913.

Tsai, H.M. (2013). Untying the knot of thrombotic thrombocytopenic purpura and atypical hemolytic uremic syndrome. American Journal of Medicine 126, 200-209.

Tse, W.Y., Nash, G.B., Hewins, P., Savage, C.O., and Adu, D. (2005). ANCA-induced neutrophil F-actin polymerization: implications for microvascular inflammation. Kidney Int 67 , 130-139.

Tugwell, P., Bombardier, C., Gent, M., Bennett, K., Bensen, W., Carette, S., Chalmers, A., Esdaile, J., Klinkhoff, A., and Kraag, G. (1990). Low-dose cyclosporin versus placebo in patients with rheumatoid arthritis. Lancet 335, 1051-1055.

Tura, O., Skinner, E.M., Barclay, G.R., Samuel, K., Gallagher, R.C., Brittan, M., Hadoke, P.W., Newby, D.E., Turner, M.L., and Mills, N.L. (2013). Late outgrowth endothelial cells resemble mature endothelial cells and are not derived from bone marrow. Stem Cells 31, 338-348.

Van Buren, D., Burke, J., and Lewis, R. (1994). Renal function in patients receiving long-term cyclosporine therapy. J Am Soc Nephrol 4, S17-S22.

van der Meer, A.D., Vermeul, K., Poot, A.a., Feijen, J., and Vermes, I. (2010). A microfluidic wound-healing assay for quantifying endothelial cell migration. American journal of physiology Heart and circulatory physiology 298, H719-725.

Vincenti, F., Rostaing, L., Grinyo, J., Rice, K., Steinberg, S., Gaite, L., Moal, M.C., MondragonRamirez, G.A., Kothari, J., Polinsky, M.S., et al. (2016). Belatacept and Long-Term Outcomes in Kidney Transplantation. N Engl J Med 374, 333-343.

Wagner, S.J., and Myrup, A.C. (2005). Toward closed-system culture of blood origin endothelial cells. Transfusion 45, 1201-1207.

Wallemacq, P.E., and Reding, R. (1993). FK506 (tacrolimus), a novel immunosuppressant in organ transplantation: clinical, biomedical, and analytical aspects. Clin Chem 39, 2219-2228.

Wallis, R. (2007). Interactions between mannose-binding lectin and MASPs during complement activation by the lectin pathway. Immunobiology 212, 289-299.

Walport, M.J. (2001a). Complement (Part 1). N Engl J Med 344, 1058-1066.

Walport, M.J. (2001b). Complement (Part 2). N Engl J Med 344, 1140-1144.

Wang, J.W., Bouwens, E.A., Pintao, M.C., Voorberg, J., Safdar, H., Valentijn, K.M., de Boer, H.C., Mertens, K., Reitsma, P.H., and Eikenboom, J. (2013). Analysis of the storage and secretion of von Willebrand factor in blood outgrowth endothelial cells derived from patients with von Willebrand disease. Blood 121, 2762-2772. 
Warwicker, P., Goodship, J., and Goodship, T. (1998a). Factor H-US? Nephrol Dial Transplant 13, 1921-1923.

Warwicker, P., Goodship, T.H., Donne, R.L., Pirson, Y., Nicholls, A., Ward, R.M., Turnpenny, P., and Goodship, J.A. (1998b). Genetic studies into inherited and sporadic hemolytic uremic syndrome. Kidney Int 53, 836-844.

Weiler, J.M., Daha, M.R., Austen, K.F., and Fearon, D.T. (1976). Control of the amplification convertase of complement by the plasma protein beta1H. Proc Natl Acad Sci 73, 3268-3272.

Wekerle, T., Segev, D., Lechler, R., and Oberbauer, R. (2017). Strategies for long-term preservation of kidney graft function. Lancet 389, 2152-2162.

Whaley, K., and Ruddy, S. (1976). Modulation of C3b hemolytic activity by a plasma protein distinct from C3b inactivator. Science 193, 1011-1013.

Wolfe, R.A., Ashby, V.B., Milford, E.L., Ojo, A.O., Ettenger, R.E., Agodoa, L.Y.C., Held, P.J., and Port, F.K. (1999). Comparison of Mortality in all patients on dialysis, patients on dialysis awaiting transplantation, and recipients of a first cadaveric transplant. N Engl J Med 341, 17251730.

Würzner, R., Riedl, M., Rosales, A., and Orth-Höller, D. (2014). Treatment of Enterohemorrhagic Escherichia coli-Induced Hemolytic Uremic Syndrome (eHUS). Seminars in thrombosis and hemostasis $1,508-516$.

Yang, B., Xi, X., Aronowski, J., and Savitz, S.I. (2012a). Ischemic stroke may activate bone marrow mononuclear cells to enhance recovery after stroke. Stem Cells Dev 21, 3332-3340.

Yang, L., Guan, H., He, J., Zeng, L., Yuan, Z., Xu, M., Zhang, W., Wu, X., and Guan, J. (2012b). VEGF increases the proliferative capacity and eNOS/NO levels of endothelial progenitor cells through the calcineurin/NFAT signalling pathway. Cell Biol Int 36, 21-27.

Yocum, D.E., Klippel, J.H., Wilder, R.L., Gerber, N.L., Austin, H.A., 3rd, Wahl, S.M., Lesko, L., Minor, J.R., Preuss, H.G., Yarboro, C., et al. (1988). Cyclosporin A in severe, treatmentrefractory rheumatoid arthritis. A randomized study. Ann Intern Med 109, 863-869.

Yoon, C.H., Hur, J., Park, K.W., Kim, J.H., Lee, C.S., Oh, I.Y., Kim, T.Y., Cho, H.J., Kang, H.J., Chae, I.H., et al. (2005). Synergistic neovascularization by mixed transplantation of early endothelial progenitor cells and late outgrowth endothelial cells: the role of angiogenic cytokines and matrix metalloproteinases. Circulation 112, 1618-1627.

Zaferani, A., Vives, R.R., van der Pol, P., Navis, G.J., Daha, M.R., van Kooten, C., Lortat-Jacob, H., Seelen, M.A., and van den Born, J. (2012). Factor H and properdin recognize different epitopes on renal tubular epithelial heparan sulfate. J Biol Chem 287, 31471-31481.

Zarifian, A., Meleg-Smith, S., O'Donovan, R., Tesi, R.J., and Batuman, V. (1999). Cyclosporineassociated thrombotic microangiopathy in renal allografts. Kidney Int 55, 2457-2466. 
Zipfel, P.F., and Skerka, C. (2009). Complement regulators and inhibitory proteins. Nature reviews Immunology 9, 729-740. 
